
VNIVERSIDAD

DSALAMANCA 800 AÑOS

CAMPUS DE EXCELENCIA INTERNACIONAL OSALAMANCA
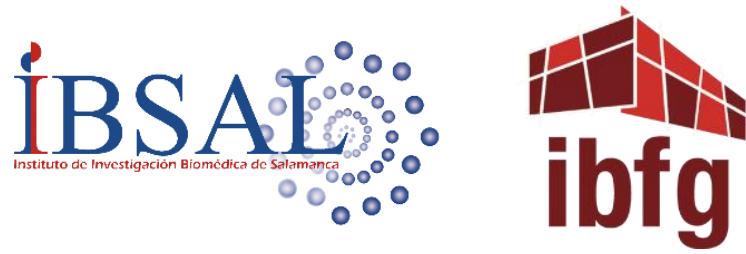

\section{EL POLIMORFISMO HUMANO ARG72PRO DE TP53 CONDICIONA LA SUSCEPTIBILIDAD NEURONAL AL $\beta$-AMILOIDE}

----- TESIS DOCTORAL ------

REBECA LAPRESA RUIZ DE GAUNA

SALAMANCA, 2016 
. 


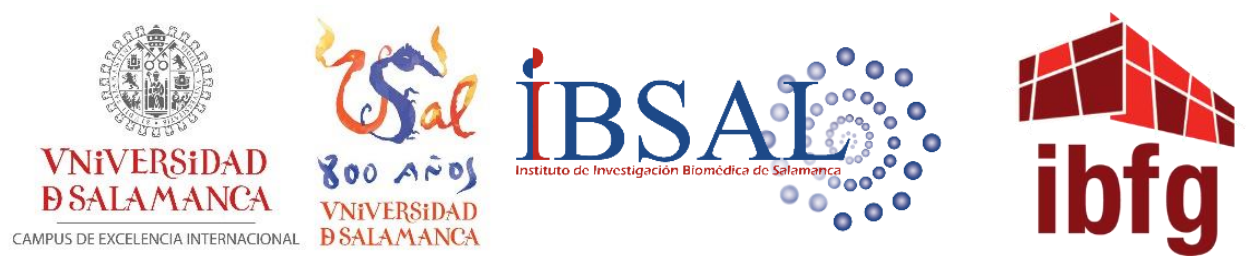

\section{EL POLIMORFISMO HUMANO ARG72PRO DE TP53 CONDICIONA LA SUSCEPTIBILIDAD NEURONAL AL $\beta$-AMILOIDE}

REBECA LAPRESA RUIZ DE GAUNA

DIRECTORES:

PROF. DR. JUAN PEDRO BOLAÑOS HERNÁNDEZ

DRA. ÁNGELES ALMEIDA PARRA 

D. Juan Pedro Bolaños Hernández, Catedrático de Bioquímica y Bilogía Molecular de la Universidad de Salamanca, y $D^{a}$ Angeles Almeida Parra, Doctora en Farmacia, Investigadora del Instituto de Investigación Biomédica de Salamanca del Hospital Universitario de Salamanca- Universidad de Salamanca y Profesora Asociada del Departamento de Bioquímica y Biología Molecular de la Universidad de Salamanca

CERTIFICAN:

Que el trabajo doctoral realizado bajo su dirección por $D^{a}$ Rebeca Lapresa Ruiz de Gauna, titulado "El polimorfismo humano Arg72Pro de Tp53 condiciona la susceptibilidad neuronal al $\beta$-amiloide", reúne las condiciones de originalidad requeridas para optar al grado de doctor por la Universidad de Salamanca y autoriza su presentación

Y para que así conste, firman la presente certificación en Salamanca, a 23 de septiembre de 2016.

VNIVERSITAS STVDII SALAMANIIN

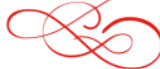



Este trabajo ha sido financiado con subvenciones concedidas por: el Ministerio de Educación, a través de una ayuda para la formación de profesorado universitario (FPU, AP2010-3655) y el Instituto de Salud Carlos III, a través de los proyectos FIS PI12/00685 y PI15/ 00473. 



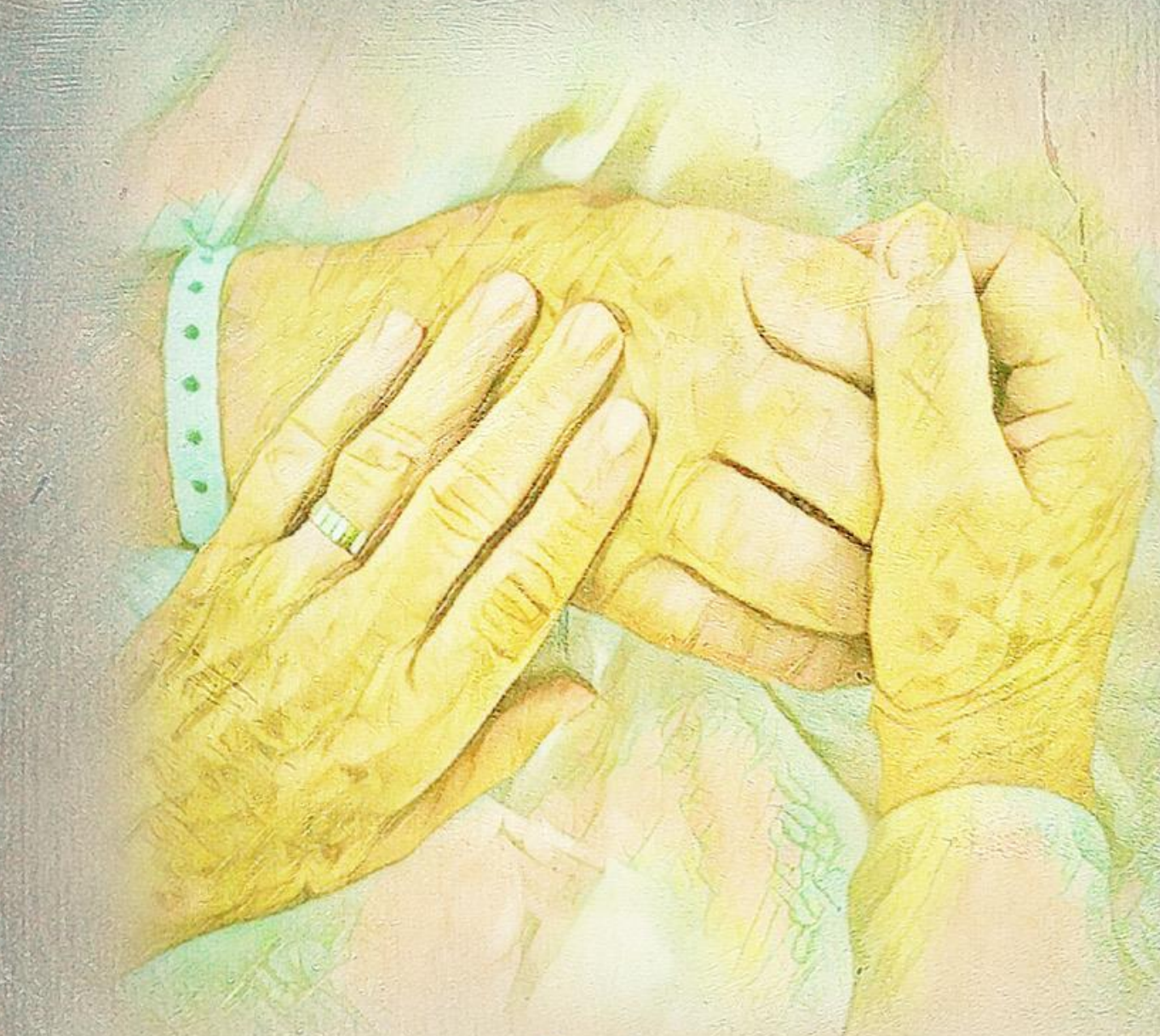

\section{a mi yayo}

'Cohro el río va a la hiar

y el rocio va a la flor

a hei vera tú venárás.

y nadie te querrá
como te quiero yo' 

Cuando me concedieron la beca parecía que los 4 años que tenía por delante iban a dar para mucho, $y$, sin embargo, se me han pasado volando. En esto cada uno de vosotros tenéis una parte de "culpa". Como dicen los Celtics, 'You'll never walk alone'. Por eso, quería agradeceros algunas cosas, pero como sabéis, me cuesta dejar por escrito mis emociones, así que seré breve.

Ángeles, muchas gracias por haberme dado esta oportunidad, por todo lo que me has enseñado, por encontrar el lado positivo a todos los resultados, por tu risa a través de la puerta... Gracias!

Juan Pedro, porque sin ti no hubiera sido posible, por tus aportaciones y consejos, gracias!

Emilio, gracias por tus charlas y consejos, por tener la puerta del despacho siempre abierta, y por medir los tiempos de otra manera.

A todos los compañeros del 2.8, por amenizar cada día, por la ayuda prestada, por sacarme una sonrisa, por los momentos de "viernes por la tarde" y por aguantar el "vórtice de entropía" que me rodea. También a todos los compañeros del 2.7, con quienes he compartido alguna estancia breve ;) A todos vosotros, por hacerme más fácil este camino, por las cañas, fiestas, disfraces, viajes, excursiones... gracias!

A las ex-vecinas del laboratorio de al lado, en especial a Cami, por tantos buenos ratos y locuras compartidas. Se os echa de menos!

Irene, por hacerme compañía, por el trabajo en cadena, por estar siempre disponible, por las tesis a medias y las sinapsis por el pasillo, pero sobre todo, por ser mi amiga, gracias! Chustin, gracias por estar siempre ahí (literalmente ;)), por tu ayuda, por tener una cerveza bien fría siempre que la necesito y por todas las que nos quedan por abrir.

A las noches de trivial y las sobredosis de lechugas (pochas), las comidas en la tabernita y el "porrón riojano", porque así se trabaja con otro espíritu $: ;$ 
A mi familia, porque sin vosotros no estaría aquí, por la oportunidad que me habéis brindado, por vuestra comprensión y por animarme siempre, muchas gracias!

A Andrés, mi "emotional support", por aguantarme, ayudarme, escucharme... por estar siempre ahí, porque como me dijiste un día "nuestra relación sin p53 ya no será lo mismo". Por hacerme la vida tan fácil....GRACIAS! También a mi Moki, por amenizar mis horas de escritura.

Esta andadura de 4 años no hubiera sido lo mismo sin vosotros, MUCHAS GRACIAS! 


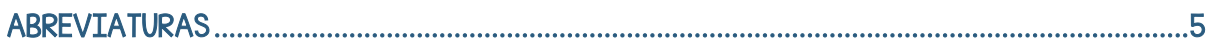

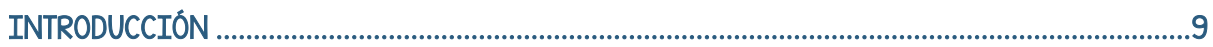

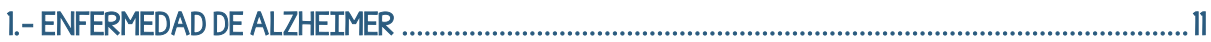

1.1.- CARACTERÍSTICAS GENERALES DE LA ENFERMEDAD DE ALZHEIMER ............................. 12

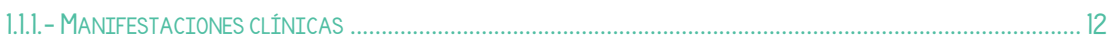

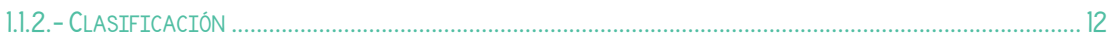

1.2.- FISIOPATOLOGİA DELA ENFERMEDAD DE ALZHEIMER ….................................................. 13

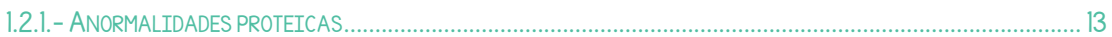

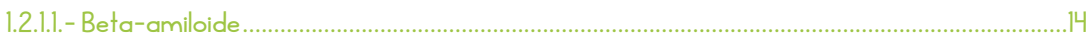

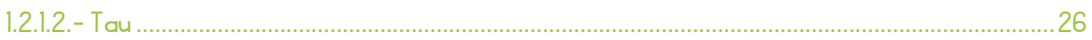

1.2.2.- DISFUNCIÓN MITOCONDRIAL EN LA ENFERMEDAD DE ALZHEIMER. ......................................................2

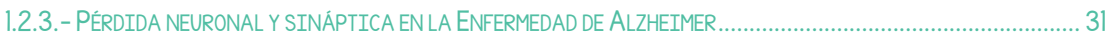

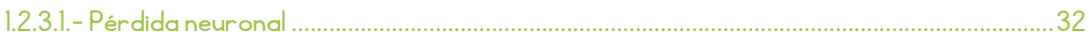

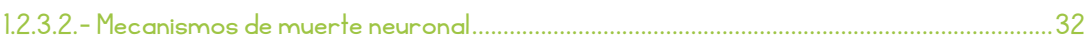

1.2.3.3.- Disfunción y pér dida sináptica.................................................................................35

1.3.- GENÉTICA EN LA ENFERMEDAD DE ALZHEIMER …........................................................... 37

1.3.1. - ENFERMEDAD DE ALZHEIMER FAMILIAR .................................................................................. 37

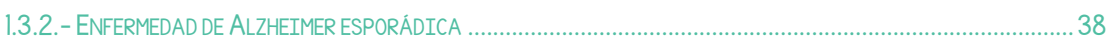

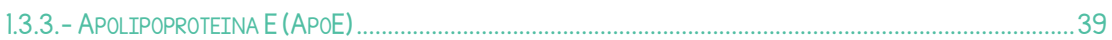

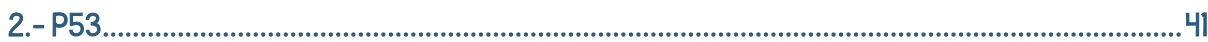

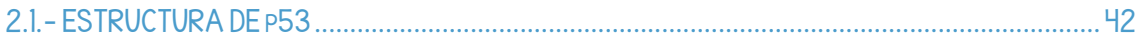

2.2.-ESTABILIZACIÓNDEP53 ............................................................................................. 43

2.2.1.- ESTABILIZACIÓN DE P53 EN LA ENFERMEDAD DE ALZHEIMER .......................................................

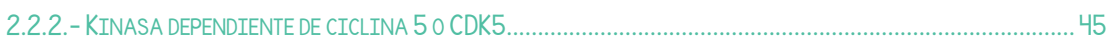

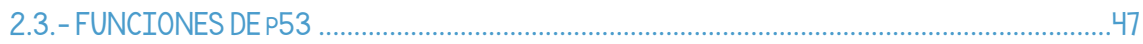

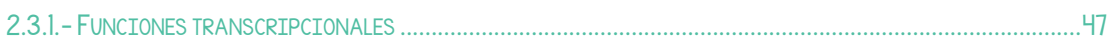

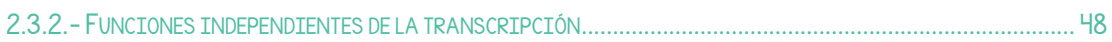

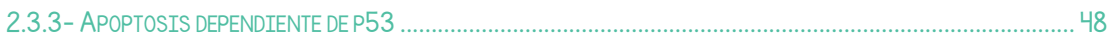

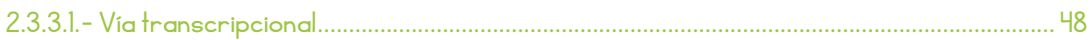

2.3.3.2.- Via no transcripcional ....................................................................................................... 49

2.3.3.3.- Apoptosis dependiente de p53 en la Enfermedad de Alzheimer ...................................50

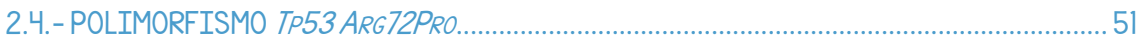

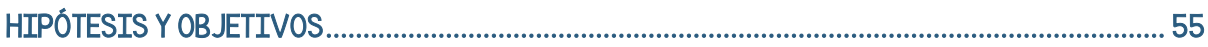

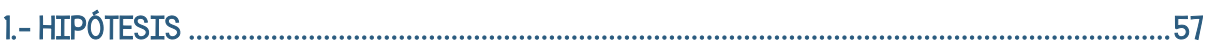

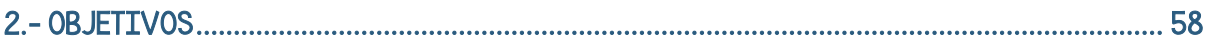

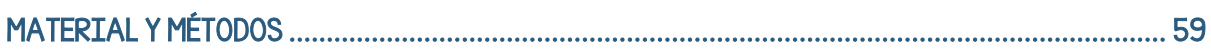

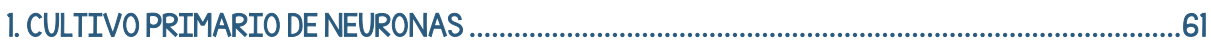


1.1. ESPECIES ENSAYADAS Y CONDICIONES DEL ANIMALARIO ............................................61

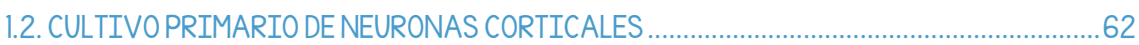

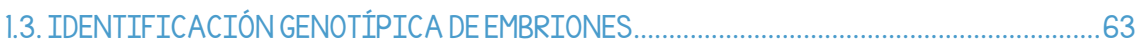

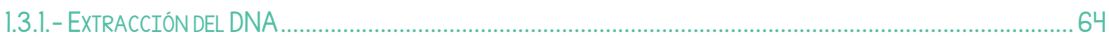

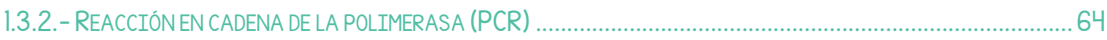

1.3.3.- ELECTROFORESIS EN GELES HORIZONTALES DE AGAROSA ................................................................. 65

2.- MODELO IN VITRODE NEUROTOXICIDAD POR B-AMILOIDE. .................................................... 66

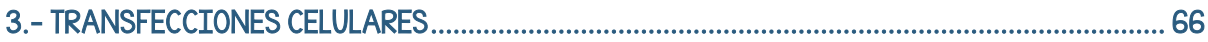

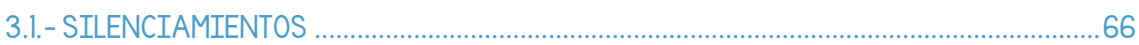

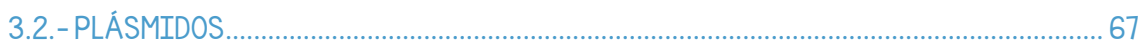

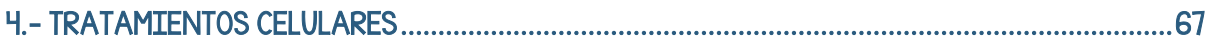

5.- DETERMINACIÓN DE LA APOPTOSIS NEURONAL POR CITOMETRÍA DE FLUJO .........................68

6.- DETERMINACIÓN DEL POTENCIAL DE MEMBRANA MITOCONDRIAL ( $\triangle \Psi M)$ COMO ÍNDICE DE

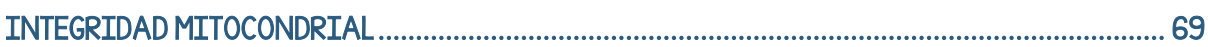

7.- DETERMINACIÓN DE LA EXPRESIÓN DE PROTEÍNAS MEDIANTE ANÁLISIS DE TRANSFERENCIA TIPO WESTERN ............................................................................................

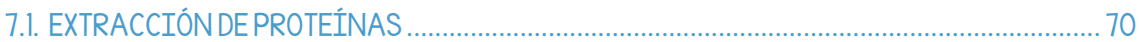

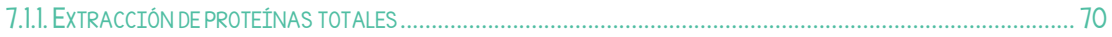

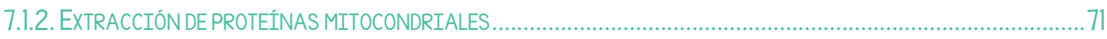

7.2. DETERMINACIÓN DE LA CONCENTRACIÓN DE PROTEÍNAS …......................................... 73

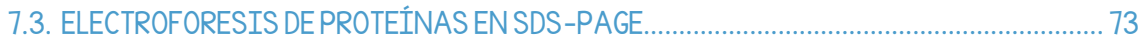

7.4. INMUNODETECCIÓN DE PROTEÍNAS POR WESTERNBLOT .............................................. 74

7.5. "STRIPPING" DE MEMBRANAS DE NITROCELULOSA .................................................... 75

8.- INMUNOCITOQUÍMICA Y MICROSCOPÍA DE FLUORESCENCIA ..............................................76

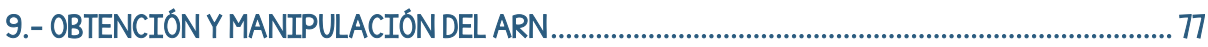

9.1. EXTRACCIÓNDERNA ........................................................................................................ 77

9.2. REACCIÓN EN CADENA DE LA POLIMERASA A TIEMPOREAL O CUANTITATIVA

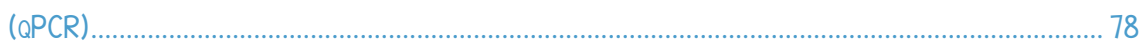

9.3. ELECTROFORESIS DE DNA EN GELES HORIZONTALES DE AGAROSA .........................80

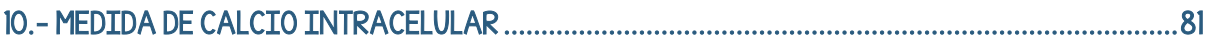

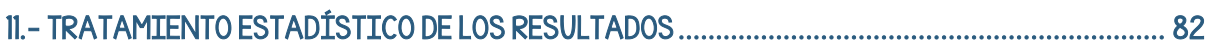

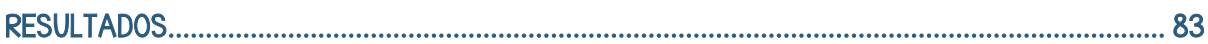

1.- ESTABLECIMIENTO DE UN MODELO IN VITRODE NEUROTOXICIDAD CAUSADA POR B-

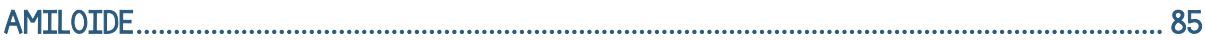

1.1.- EL BA25-35 INDUCE APOPTOSIS EN NEURONAS CORTICALES DE RATÓN EN CULTIVO PRIMARIO_.............85

1.2.- EL BA25-35 SE ACUMULA ENEL CITOSOL DE NEURONAS CORTICALES DE RATÓN EN CULTIVO PRIMARIO. 86 
1.3.- LOS OLIGÓMEROS DE BA25-35 INDUCEN DESPOLARIZACIÓN MITOCONDRIAL PREVIA A LA APOPTOSIS NEURONAL.

1.4.- LA ESTABILIZACIÓN FUNCIONAL DE P53 MEDIA LA NEUROTOXICIDAD PROVOCADA POR OLIGÓMEROS DE BA25-35.

2.- FUNCIÓN DE P53 EN LA NEUROTOXICIDAD ASOCIADA AL B-AMILOIDE. .91

2.1.- LA DISFUNCIÓN MITOCONDRIAL Y ACTIVACIÓN DE LA APOPTOSIS NEURONAL CAUSADA POR EL BA ESTÁ MEDIADA POR LA ESTABILIZACIÓN DE P53

2.1.1. - EL SILENCIAMIENTO DE P53 PREVIENE EL DAÑO NEURONAL CAUSADO POR EL B-AMILOIDE......................... 91

2.1.2.- LA ESTABILIZACIÓN P53 ES RESPONSABLE DE LA NEUROTOXICIDAD DEL B-AMILOIDE.............................92

2.2.- CDK5 MEDIA LA ESTABILIZACIÓN DE P53, LO CUAL DESENCADENA EL DAÑO MITOCONDRIAL Y LA MUERTE APOPTÓTICA.

3.- IMPLICACIÓN DEL POLIMORFISMO TP53 ARG72PROEN LA MUERTE NEURONAL ASOCIADA AL

B-AMILOIDE. .98

3.1.- LA VARIANTE POLIMÓRFICA ARg INCREMENTA LA SUSCEPTIBILIDAD DE LAS NEURONAS AL BA. 99

3.2.- El POLIMORFISMO ARg72PRODE TP53No AfECTA A LA RUTA dE ACTIVACIÓN DE CDK5 EN NEURONAS TRATADAS CONEL BA.

3.3.- LA ACTIVIDAD TRANSCRIPCIONAL DE P53 NO ES RESPONSABLE DE LA DIFERENTE SUSCEPTIBILIDAD QUE CONFIERE EL POLIMORFISMO ARG72PRODE TP53 A LAS NEURONAS FRENTE AL BA.

3.4LA VARIANTE POLIMÓRFICA ARG DE P53 SE TRANSLOCA A LA MITOCONDRIA, MIENTRAS QUE LA VARIANTE

PROSE SITÚA ENEL NÚCLEO.

4.- INFLUENCIA DE LOS DISTINTOS ALELOS DE LA APOLIPOPROTEÍNA E (APOE) SOBREEL POLIMORFISMO TP53 ARG72PRO. ..111

DISCUSIÓN .115

CONCLUSIONES 123

BIBLIOGRAFIA .127 


\section{ABREVIATURAS}

7-AAD: 7-amino-actinomicina D

$A B A D$ : $A \beta$-binding alcohol dehydrogenase

ADAM: alpha disintegrin and metalloproteinase

AICD: APP intracellular domain

AMPA: ácido-a-amino-3-(hidroxi-5-metil-4-isoxazolpropiónico)

ANOVA: análisis de la varianza

APAF1: apoptosis protease-activating factor-1

ApoE: apolipoproteína $\mathrm{E}$

APP: proteína precursora amiloide

ATP: adenosín trifosfato

BACE1: beta-site APP-cleaving enzyme 1

BACE2: beta-site APP-cleaving enzyme 2

Bad: $\mathrm{BCl}-2$ associated death promoter protein

Bak: $\mathrm{BCl}-2$ homologous antagonist killer

Bax: $\mathrm{BCl}-2$ associated $X$ protein

BCA: ácido bicinconínico

BCl-2: proteína de linfoma de células B-2

Bcl-xL: proteína de linfoma de células B-extra large

Bid: $\mathrm{BH} 3$ interacting-domain death agonist

BSA: albúmina sérica bovina

C83: CTF de 83 aminoácidos

C99: CTF de 99 residuos

CAMKII: proteína kinasa II dependiente de Ca2+- Calmodulina CCCP: cianuro 3-clorofenilhidrazona

Cok5: quinasa 5 dependiente de ciclina

Coks: quinasas dependientes de ciclina

cDNA: DNA codificante

CIP/KIP: proteínas inhibidoras de quinasas

Ct: ciclo umbral

CTD: dominio C-terminal 
CTE: cadena de transporte de electrones

CTF: fragmento C-terminal

CypD: ciclofilina D

DAPI: 4',6-diamidino-2-fenilindol

DBD: dominio de unión al DNA

DEPC: di-etil-piro-carbonato

DilC1: 1, 1', 3, 3, 3', 3' - hexametilindodicarburo-yoduro de cianina

DIV: días in vitro

DMSO: dimetilsulfóxido

DNA: ácido desoxirribonucleico

dNTPs: desoxirribonucleótidos trifosfato

dsDNA: DNA de doble cadena

EA: enfermedad de Alzheimer

EBSS: solución salina equilibrada de Earl

ECA: enzima conversora de angiotensina

ECE: enzima convertidora de endotelina

EDTA: ácido etildiaminotetraacético

EOAD: early-onset Alzheimer's disease

ET: endotelina vasoactiva

FAD: familial Alzheieme's disease

FCS: suero fetal de ternera

GAPDH: gliceraldehído 3-fosfato deshidrogenasa

GFP: proteína verde fluorescente

GSK-3: quinasa glucógeno sintasa 3

HEPES: ácido 4-(2-hidroxietil) piperazina-1-etano-sulfónico

IDE: enzima degradante de insulina

LOAD: late-onset Alzheimer's disease

LTP: depresión a largo plazo

LTP: long term potenciation

MAM: medio de aislamiento mitocondrial

Map-2: proteína asociada al microtúbulo-2

mGluR5: receptores metabotrópicos de glutamato

mRNA: ácido ribonucleico mensajero

mtDNA: DNA mitocondrial 
nAChR: receptor nicotínico de acetilcolina

NEP: neprilisina o encefalinasa

NFT: ovillos neurofibrilares

NLS: dominio de señalización de localización nuclear

NMDA: ácido N-metil-D-aspartato

OptiMEM: medio mínimo esencial optimizado

p3: péptido de $3 \mathrm{Kda}$

p75NTR: neurotrofina p75

pb: pares de bases

PBS: tampón fosfato salino

PCR: reacción en cadena de la polimerasa

PFA: paraformaldehído

PFTa: Pifithrin alpha

PHF: filamentos apareados helicoidales

PRD: dominio rico en prolina

PS: placas amiloideas o seniles

PSA: persulfato sódico de amonio

PSEN: presenilina

PTP: poro de transición de permeabilidad

qPCR: PCR cuantitativa o PCR a tiempo real

RIPA: tampón para ensayo de radioinmunoprecipitación

RNA: ácido ribonucleico

ROS: especies reactivas de oxígeno

$\mathrm{RT}$ : retrotranscriptasa

S.E.M.: error estándar de la media

SAD: sporadic Alzheimer's disease

SAPP $\alpha$ : soluble APP alpha fragment

SAPPB: soluble APP beta fragment

SDS: dodecil sulfato sódico

SDS-PAGE: electroforesis en gel de poliacrilamida con dodecil sulfato sódico

siRNA: small interfering RNA (RNA de interferencia)

SNC: sistema nervioso central

SNPs: single nucleotide polymorphisms

TAD: dominio de activación transcripcional 
TAE: tampón tris, ácido acético y EDTA

TBS: tampón tris salino

TEMED N,N,N,N'-tetrametilendiamina

TLCK: p-tosil-lisin-clorometil cetona hidrocloruro

TNFR: tumor necrosis factor receptor

TTBS: tampón tris salino con tween 20

u.a. Unidades arbitrarias

VAs: vacuolas autofágicas

VDAC: canal aniónico dependiente de voltaje

a7nAChR: subunidad alfa 7 del receptor nicotínico de acetilcolina

$\beta A$ : beta-amiloide

$\Delta \Psi \mathrm{m}$ : potencial de membrana mitocondrial 

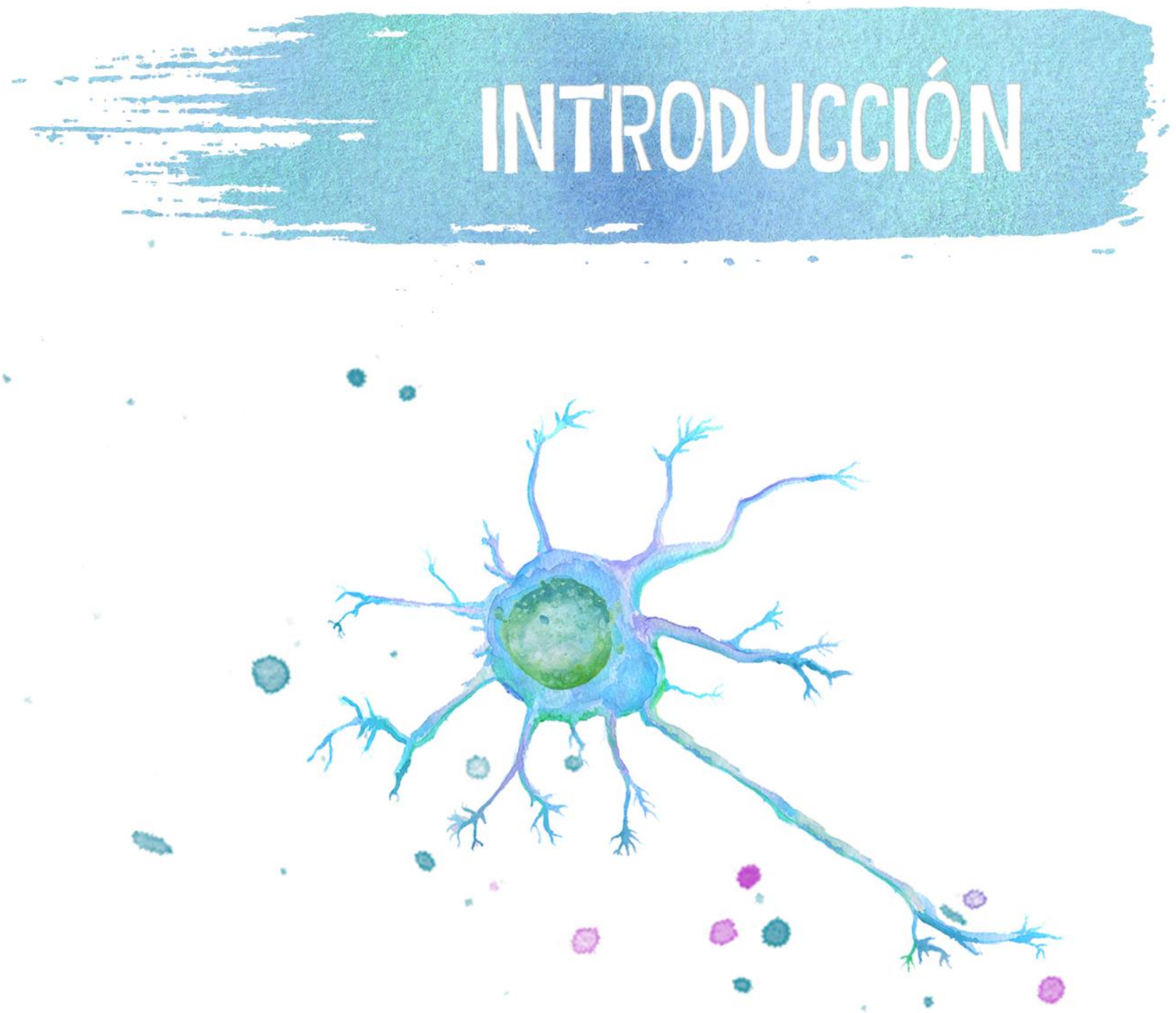



\section{1.- ENFERMEDAD DE ALZHEIMER}

La enfermedad de Alzheimer (EA) es el tipo de demencia más frecuente entre las personas mayores de 65 años. Fue descrita en 1907 por el neuropatólogo y psiquiatra alemán Aloïs Alzheimer (Stelzmann et al. 1995; Alzheimer 1907). La descripción se realizó en Auguste Deter, una paciente de 55 años que murió tras sufrir, durante cuatro años, una pérdida progresiva de memoria, desorientación espacio-temporal, alucinaciones, paranoia y trastornos de la conducta y del lenguaje. El análisis post-mortem del cerebro de la paciente reveló la presencia de depósitos extracelulares (placas) y marañas de fibras intracelulares (ovillos), que son lesiones histopatológicas que aún hoy en día se utilizan como los principales marcadores de diagnóstico de esta enfermedad.

La EA es un proceso neurodegenerativo progresivo e irreversible, caracterizado por un deterioro cognitivo, principalmente de la memoria y de habilidades intelectuales y de razonamiento, y por síntomas conductuales y neuropsiquiátricos (Khachaturian et al. 1985), que afectan a las actividades de la vida diaria (Dubois et al. 2010). Estas alteraciones son debidas a daños selectivos en las regiones cerebrales y circuitos neuronales implicados en estos procesos, tales como las áreas asociativas neocorticales, el hipocampo, la corteza entorrinal, la amígdala y el telencéfalo basal (Serrano-Pozo et al. 2011).

Entre los distintos tipos de demencias existentes, la demencia tipo Alzheimer es la de mayor incidencia y la más común entre las personas mayores de 60 años (Prince et al. 2013). La EA es el tercer problema de salud más grave en los países desarrollados, detrás de los accidentes cardiovasculares y el cáncer. Existen unos 50 millones de enfermos diagnosticados de Alzheimer en mundo, y se estima que esta cifra se triplique en el año 2050. El incremento de la población de edad avanzada hace que aumente progresivamente la incidencia del Alzheimer (Scheltens et al. 2016). 


\section{1.- CARACTERÍSTICAS GENERALES DE LA}

ENFERMEDAD DE ALZHEIMER

\subsection{1.- Manifestaciones clínicas}

Las manifestaciones clínicas de la EA se pueden clasificar en déficits cognitivos y síntomas neuropsiquiátricos.

Respecto a los déficits cognitivos, el principal síntoma que presentan los pacientes con EA es la pérdida de memoria episódica. Además de este cuadro amnésico, debido a que se trata de una demencia multidominio, los pacientes presentan también afasia, apraxia y agnosia (Rabins et al. 2007).

Entre los síntomas neuropsiquiátricos, el más frecuente que aparece en personas con la EA es la apatía. Además, también aparecen cuadros depresivos, de ansiedad, ideas delirantes y agresividad (Cummings et al. 1994; McKeith 2006).

\subsection{2.- Clasificación}

La EA se puede clasificar en distintos tipos según el aspecto al que se atienda. De esta manera, podemos clasificar la EA según:

- La edad de inicio (Tellechea et al. 2015):

- Temprana o de inicio precoz, EOAD learly onset Alzheimer's Disease): comienza antes de los 65 años, es de curso rápido y no supera el $1 \%$ de los casos.

- Tardía, LOAD (late-onset Alzheimer's Disease): aparece después de los 65 años, en su mayor parte es esporádica y de curso lento. Representa más del $98 \%$ de los casos.

- La implicación que tenga el factor genético (Cacace et al. 2016):

- Familiar, FAD (familial Alzheimer's Disease): causada por mutaciones en genes que se heredan de forma dominante, fundamentalmente mutaciones relacionadas con la proteína precursora amiloide o APP. Suele coincidir con la EA precoz.

- Esporádica, SAD (spporadic Alzheimer's Disease): aparece generalmente en los casos de EA tardía. Comienza pasados los 65 años y es el tipo más común. Aunque su causa es aún 
desconocida, se han descrito factores genéticos relacionados con el riesgo de padecer EA, siendo el mejor establecido hasta la fecha la presencia del alelo 4 de la apolipoproteína E (ApoE) (C.-C. Liv ef al. 2013).

Esta clasificación se muestra gráficamente en la Figura 1.

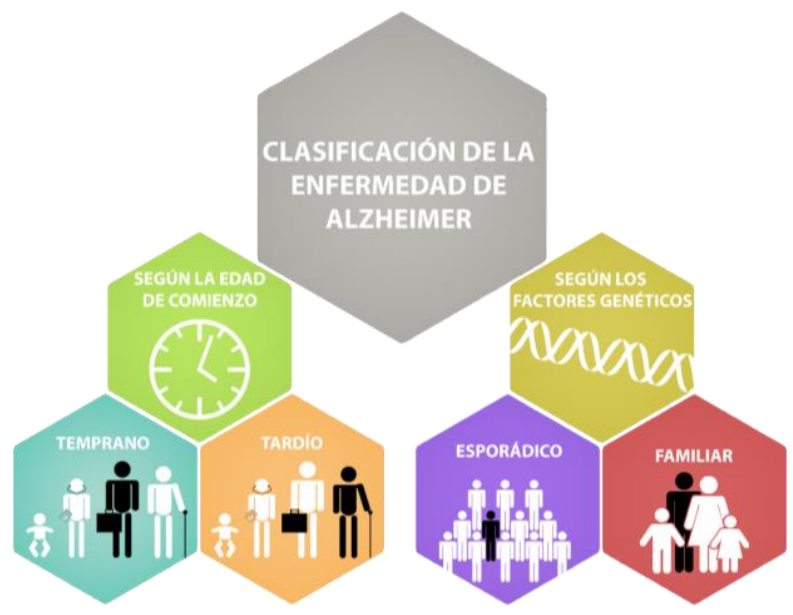

Figura 1. Clasificación de la Enfermedad de Alzheimer. La figura muestra las distintas formas de la EA en función de la edad de comienzo y de la influencia de los factores genéticos.

\section{2.- FISIOPATOLOGİA DE LA ENFERMEDAD DE ALZHEIMER}

La EA se caracteriza fundamentalmente por la presencia de cúmulos intra y extracelulares del péptido beta-amiloide (BA), por la presencia de ovillos neurofibrilares compuestos por la proteína Tau hiperfosforilada, por el daño mitocondrial y la pérdida neuronal y sináptica (Anand et al. 2014; Kumar et al. 2015).

\subsection{1.- Anormalidades proteicas}

Las dos proteínas típicamente alteradas en la EA son el BA y Tau (Querfurth \& Laferla 2010). 


\subsubsection{1.- Beta-amiloide}

Uno de los elementos clave de esta enfermedad son los depósitos de BA. Los péptidos B-amiloides constituyen el producto fisiológico de la proteína precursora amiloide (APP) mediante la escisión a través de las $\gamma$ y $B$ secretasas (Zetterberg et al. 2010).

\section{* Proteína Precursora Amiloide.}

La Proteína Precursora Amiloide o APP es una glicoproteína integral de membrana tipo I que posee un largo dominio extracelular $\mathrm{N}$-terminal globular, un dominio transmembrana y un dominio intracelular corto C-terminal. En humanos, el gen de la APP se localiza en el cromosoma 21 y consta de 18 exones (Zheng \& Koo 2006). El procesamiento alternativo del transcrito de la APP da lugar en humanos a 8 isoformas, de las cuales 3 son las más comunes: la forma de 695 aminoácidos, que se expresa fundamentalmente en el sistema nervioso central (SNC), y las de 751 y 770 aminoácidos, que se expresan de forma ubicua (Bayer et al. 1999; Zheng \& Koo 2006).

La función fisiológica de la APP no está aún bien establecida. Sin embargo, existen evidencias de que podría estar implicada en la inhibición del crecimiento de neuritas y del cono neuronal (Billnitzer et al. 2013), la migración de precursores neurales a la capa cortical durante el desarrollo (Young-Pearse et al. 2007) y en la potenciación a largo plazo (long term potenciation, LTP) (Weyer et al. 2011). Además, se ha descrito que la APP puede tener un papel neuroprotector como antioxidante, ya que es capaz de reducir el $\mathrm{Cu}^{2+} \mathrm{a} \mathrm{Cu}^{+}$ (Evin y Weidemann, 2002).

\section{* Procesamiento del APP y generación del ß-amiloide}

La APP se metaboliza por dos vías diferentes y mutuamente excluyentes: la vía secretora (o no amiloidogénica) y la vía amiloidogénica. Este procesamiento puede tener lugar en la membrana plasmática (Kinoshita et al. 2003), en la red Golgi (Xu et al. 1995), y retículo endoplásmico, endosomas, lisosomas y mitocondrias (Mizuguchi et al. 1992) (LaFerla et al. 2007).

\section{Vía no amiloidogénica:}

Es la ruta predominante de procesamiento de la APP y forma parte de la vía secretora normal de las células. Se denomina así porque la protelisis se 
produce dentro de la región amiloide, entre los aminoácidos 16 y 17, por lo que no genera BA. En esta ruta, la acción proteolítica de la $\alpha$-secretasa, que está anclada a la membrana, fragmenta la APP tras el residuo 687. Varios miembros de la familia ADAM (alpha disintegrin and metalloproteinase) de zinc metaloproteasas (ADAM9, ADAM10, ADAM17) (Kuhn et al. 2010) y la aspartil proteasa BACE2 (Beta-Site APP-Cleaving Enzyme 2) poseen actividad $\alpha$ secretasa (Allinson et al. 2003). Este corte libera SAPPa (soluble APP alpha fragment), un fragmento soluble que se libera dentro del lumen vesicular o al espacio extracelular. A este fragmento se le atribuyen propiedades neuroprotectoras, neurotróficas y sinaptogénicas (Mattson et al. 1993; Chasseigneaux \& Allinquant 2012; Stahl et al. 2014). Además, se genera un fragmento C-terminal o CTF de 83 aminoácidos (C83), que queda unido a la membrana. Posteriormente, el C83 es procesado por la $\gamma$-secretasa, que es un complejo enzimático del cual forman parte las presenilinas. Así, la $\gamma$-secretasa actúa dentro de la membrana contando en el residuo 711 ó 713, para dar lugar a los péptidos p3 (péptido de 3 KDa que puede encontrarse formando parte de las placas) y AICD (ㅅPP intraçellular domain), que es citosólico, y que parece tener una función en la regulación de la trascripción génica. Sin embargo, no todos los fragmentos CTFs son procesados, ya que algunos son degradados en endosomas tardíos o en lisosomas (Selkoe 2001; Selkoe 2008). Este procesamiento se esquematiza en la Figura 2.

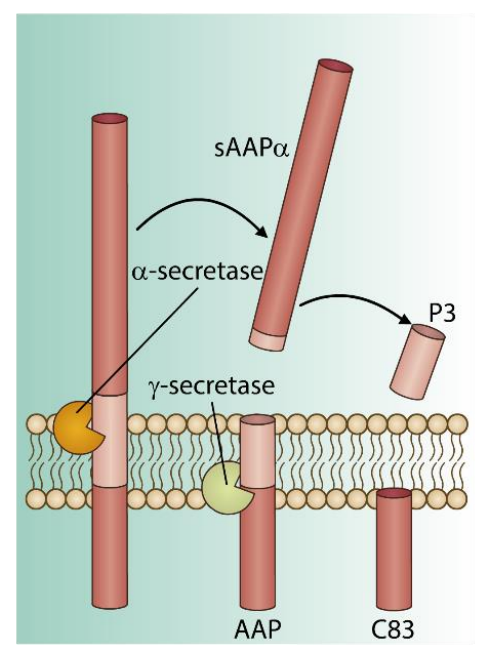

Figura 2. Procesamiento no amiloidogénico de la APP. EI primer corte enzimático está catalizado por la a-secretasa dentro de la región amiloide. Posteriormente, la acción proteolítica de la $\gamma$-secretasa da lugar a los péptidos p3 y C83. 


\section{Vía amiloidogénica:}

Es una ruta alternativa del procesamiento de la APP que da lugar a péptidos BA. Es una vía minoritaria en la mayoría de los tipos celulares, excepto en las neuronas. La producción de BA no es únicamente patológica, sino que se produce de forma normal y se detecta tanto en el plasma como en el fluido cerebroespinal de individuos sanos. Esta vía se inicia con la acción B-secretasa presente en la enzima BACE o BACE1 (Beta-Site APP-Cleaving Enzyme 1) que es una aspartil proteasa transmembrana tipo I. Esta enzima se encuentra presente principalmente en las células neuronales (Seubert et al. 1993; Cole \& Vassar 2007), específicamente en los compartimentos donde se produce el BA, como los endosomas y el aparato de Golgi, ya que requiere para su actividad un $\mathrm{pH}$ ácido como el que existe en el lumen de estos compartimentos. Tras cortar la APP en el residuo 671, la ß-secretasa libera el péptido SAPPB (soluble APP beta fragment) y el C99 (CTF de 99 residuos), que permanece unido a la membrana y que contiene la secuencia completa e intacta del BA. El C99 es sustrato de la $\gamma$-secretasa, gracias a la cual se libera el BA y el péptido AICD (Selkoe 2001; Selkoe 2008).

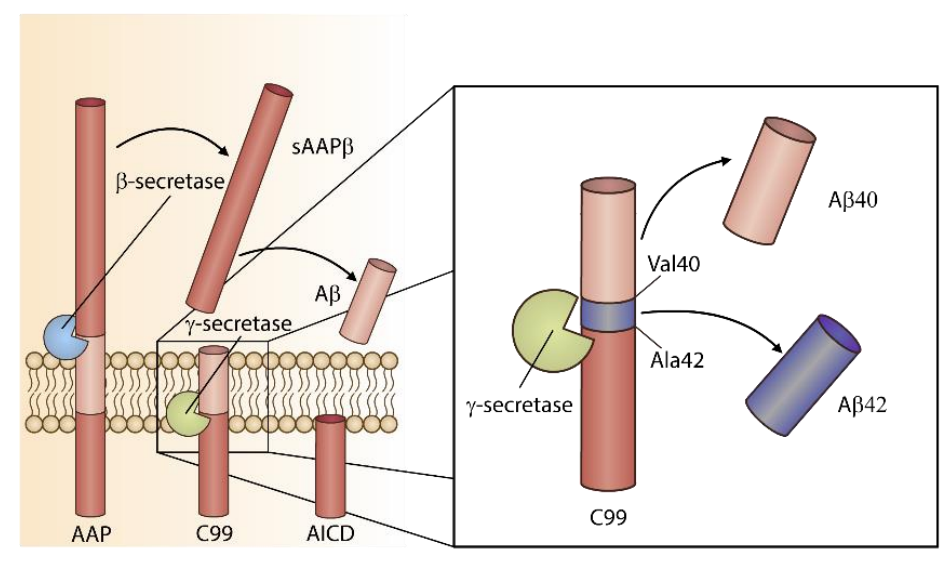

Figura 3. Procesamiento amiloidogénico de la APP. El primer corte enzimático es catalizado por la $\beta$-secretasa, lo que da lugar a los péptidos sAAP $\beta$ y C99. Posteriormente la acción proteolítica de la $\gamma$-secretasa da lugar al AICD y $\beta$ A. La longitud de los péptidos amiloides generados depende del sitio de corte de la $\gamma$-secretasa.

El sitio de procesamiento sobre el que actúa la $\gamma$-secretasa no tiene una secuencia específica. Por ello se generan péptidos amiloides de distinta longitud (Zhao et al. 2007) tal y como se esquematiza en la Figura 3. El péptido 
que se origina de forma mayoritaria termina en la Val40 ( $\beta A 40$ ) en el extremo Cterminal y es hidrosolube. Un pequeño porcentaje de los péptidos generados concluye en la Ala42, dando lugar al BA42, lo que hace que el péptido sea más rígido e hidrofóbico. Esto le confiere tendencia a agregarse y formar fibrillas, lo que lo hace más tóxico, especialmente para las neuronas (Yan \& Wang 2006).

Estudios posteriores han arrojado luz a cómo las presenilinas (familia de proteínas transmembrana que constituyen la subunidad catalítica de la enzima $\gamma$-secretasa) median la proteólisis intermembrana. En primer lugar, un corte inicial de la APP cerca de la interfase transmembrana-citosol por una endopeptidasa (corte $\varepsilon$ ) es seguido por múltiples cortes llevados a cabo por carboxipeptidasas, las cuales eliminan 3 ó 4 aminoácidos de forma secuencial del extremo C-terminal (cortes $\zeta$ y $\gamma$ ) (Haaspasalo \& Kovacs 2012; Sastre et al. 2001; Weidemann et al. 2002; Gu et al. 2001) tal y como se ilustra en la Figura 4:

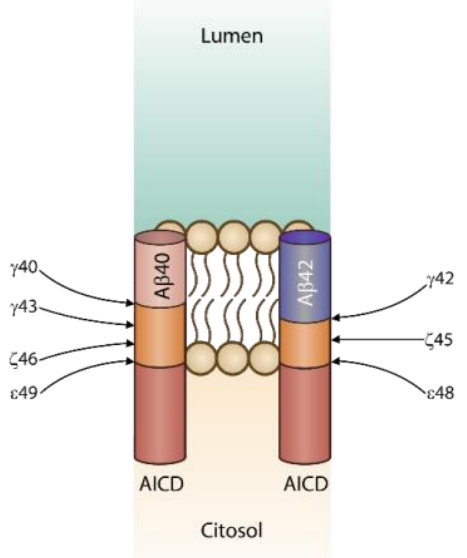

Figura 4. Procesamiento secuencial del AICD para dar lugar a péptidos $\beta A$. Modificado de (Selkoe \& Hardy 2016)

En condiciones fisiológicas, la APP se metaboliza mayoritariamente por la vía secretora y existe un equilibro entre la formación y eliminación de BA en el cerebro (Haass et al. 2012; Saido \& Leissring 2012).

\section{Vía alternativa de procesamiento de la APP:}

Recientemente, se ha identificado una ruta alternativa de procesamiento de la APP (Willem et al. 2015). Ésta vía consiste en un corte inicial de la APP por la $\eta$-secretasa en los aminoácidos 504-505, de manera que el péptido CTF- $\eta$ formado es posteriormente procesado por ADAM 10 ( $\alpha$-secretasa)

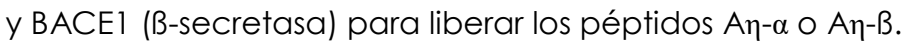


De forma similar a la producción de BA, la vía de procesamiento proteolítico alternativo de la APP ocurre en condiciones fisiológicas, pero podría estar alterada durante la patogénesis de la EA. La acumulación de n-secretasa (Sekine-Aizawa et al. 2001) y de CTF-n en neuritas distróficas y en la vecindad de placas neuríticas parece apoyar su potencial contribución a la patogénesis de la EA.

\section{* Degradación del B-amiloide}

Para la degradación metabólica de los péptidos de Aß existen distintos tipos de proteasas capaces de degradar las formas monoméricas, oligoméricas y/o fibrilares.

La neprilisina o encefalinasa (NEP) es una zinc-metaloproteasa capaz de hidrolizar péptidos circulantes. Es una endopeptidasa que se encuentra anclada en la membrana de la superficie celular y es capaz de eliminar el Bamiloide insoluble asociado a la membrana en forma tanto monomérica como oligomérica. La NEP es la enzima limitante de la degradación del BA in vivo (Iwata et al. 2000). Los animales que carecen de esta enzima sufren acumulación del péptido BA42 en el cerebro (Iwata et al. 2001). Además, se sabe que los niveles de NEP disminuyen durante el envejecimiento (Farris et al. 2007). Dicha disminución genera un aumento de BA, lo que puede provocar la inactivación oxidativa de la enzima, creando un círculo vicioso que conlleva una alta acumulación de amiloide en el cerebro (Hama \& Saido 2005).

La enzima degradante de insulina (IDE) es una tiol metaloproteasa que reconoce sustratos con estructura en hoja B-plegada. Es capaz de degradar BA en su estado monomérico (Kurochkin \& Goto 1994). In vitro, la IDE puede degradar tanto la forma BA40 como BA42. Los péptidos formados tras la degradación no tienden a agregarse en forma de oligómeros, por lo que los productos de la degradación no son tóxicos (Chesneau et al. 2000).

La enzima convertidora de endotelina (ECE) es una metaloproteasa transmembrana que cataliza la conversión de pro-endotelina en endotelina vasoactiva (ET). La isoforma 1 de esta enzima participa activamente en la degradación del BA (Eckman et al. 2003). 
La enzima conversora de angiotensina (ECA) es una zincmetaloproteasa unida a la membrana capaz de inhibir la agregación, depósito y toxicidad del BA al procesarlo proteolíticamente. Esta enzima es capaz de degradar tanto el BA40 como el BA42 endógenos (Hemming \& Selkoe 2005).

Además de la degradación proteolítica, existen reacciones mediadas por células implicadas en la eliminación del BA. Así, la microglía es capaz de engullir el BA extracelular. Los astrocitos participan en su degradación a través de internalización del BA mediada por receptor y facilitando su transferencia desde el SNC hasta la circulación sanguínea (Querfurth \& Laferla 2010).

\section{* Tipos de depósitos extracelulares de ß-amiloide}

Las placas amiloideas o seniles (PS) son agregados proteicos extracelulares formados principalmente por el péptido BA, que se deposita tanto en el parénquima cerebral como en la pared de los vasos sanguíneos cerebrales. Además, en las placas aparecen otros componentes (Atwood et al. 2002). En la Figura 5 se muestra un dibujo original de A. Alzheimer.

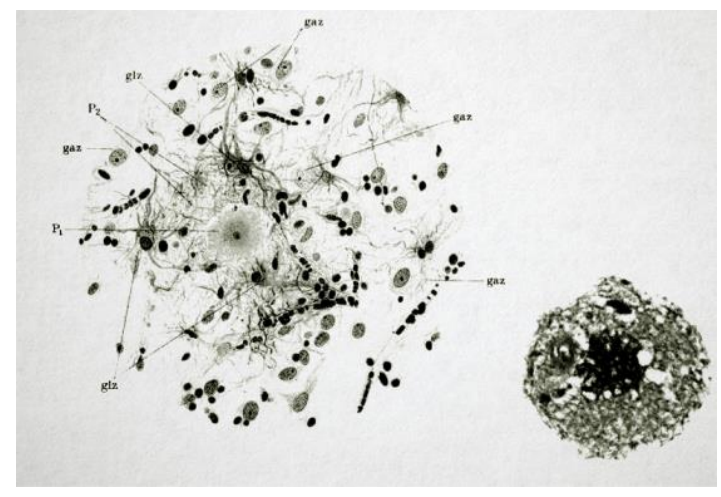

Figura 5. Dibujo original de Alois Alzheimer de las placas seniles. Alois Alzheimer realizó una serie de dibujos de las preparaciones histológicas procesadas con tinción de plata, en las que observó acumulaciones extracelulares, que hoy en día se conocen como placas seniles, formados fundamentalmente por $\beta$ A.

Los depósitos de $\beta$ A se dividen en placas neuríticas y placas difusas (Dickson 1997; Selkoe 2001; Armstrong 2006): 


\section{Placas difusas:}

Son depósitos extracelulares no fibrilares, también denominados placas preamiloides. Son placas difusas o amorfas sin núcleo compacto. Se relacionan con el parénquima cerebral y están compuestas fundamentalmente por BA42 (Dickson 1997).

\section{Placas neuríticas:}

Son depósitos extracelulares de aspecto filamentoso formados principalmente por fibrillas de BA42, además de BA40 (Perl 2010). Asociadas a estas placas aparecen neuritas distróficas inmunopositivas para Tau y células de la microglía, mientras que la astroglía se localiza en la periferia (Streit et al. 2009). El tiempo de formación de este tipo de placas es desconocido, ya que pueden formarse gradualmente durante un largo periodo de tiempo, incluso años. Su tamaño oscila entre 10 y $120 \mu \mathrm{m}$, mientras que la densidad es muy variable. Algunos autores las subdividen en placas primitivas, (esféricas y sin núcleo compacto) que aparecen en zonas cercanas a los axones y las sinapsis, y placas clásicas (con núcleo amiloide denso, redondo y compacto y un halo alrededor) que se asocian espacialmente a los vasos sanguíneos (Armstrong 2006; Armstrong 1998).

Los principales componentes que conforman los tres tipos de placas seniles se resumen a continuación en la Tabla 1.

Tipo de placa

PS Difusa

PS Neurítica

Primitiva

\section{Composición molecular}

APP truncada, $\beta A 42 / 43, A p o E$, a1-antiquimiotripsina, glicosaminoglicanos sulfatados, factores del complemento (C1q, C3, C4)

APP, $\beta A 42 / 43$, ubiquitina libre y conjugada, antígeno A68 PHF, Tau fosforilada, cromogranina A, s100b.

-Núcleo: $\beta A 42 / 43$, factores del complemento, inmunoglobulinas, a2-macroglobulina, ApoE, antitripsina -Halo: $\alpha$-sinucleína, cromogranina A, PHF.

Tabla 1. Tipos y composición de las placas seniles. Modificado de (Armstrong 2006). 


\section{* Acumulación intracelular de B-amiloide}

En los años 80 cuando se identificó por primera vez la existencia de BA en el interior celular, determinándose, además, que su presencia dentro de las neuronas no era dependiente de la edad y que este depósito solía estar ligado a los ovillos neurofibrilares. Estudios más recientes han determinado que la mayoría del BA intraneuronal corresponde fundamentalmente al BA42 (Gouras et al. 2000).

La acumulación intracelular de BA en neuronas y astrocitos parece tratarse de un acontecimiento temprano en la patogénesis de la EA. En este sentido, se han detectado acúmulos intracelulares de BA en las células piramidales del hipocampo y de la corteza entorrinal (D' Andrea et al. 2002), las regiones con afecciones patológicas más evidentes, tanto en pacientes con defectos cognitivos leves, propensos a la EA, como en modelos animales transgénicos de la EA (LaFerla et al. 2007). Esta acumulación de BA intracelular se da incluso en individuos sanos. El empeoramiento del déficit cognitivo y la formación de las PS conlleva un descenso en los niveles intraneuronales de BA (Gouras et al. 2000). Además, es posible encontrar BA en el interior de células microgliales, ya que forman parte del sistema regulador fagocítico que intenta controlar los depósitos extracelulares (Fu et al. 2014; Lai \& McLauring 2012; Lee \& Landreth 2010).

La acumulación intracelular de BA se produce por dos motivos, uno de ellos es que una vez sintetizado, no sea secretado y, el segundo, que tras ser secretado al exterior sea posteriormente recaptado hacia el interior celular (Bayer \& Wirths 2010; Oddo et al. 2006). Tal y como se ha resumido anteriormente en el presente documento, la APP puede estar en la red trans del Golgi, en el retículo endoplásmico, sistema endosomo-lisosomal y en la membrana mitocondrial además de en la plasmática, por lo que el BA puede formarse en dichos compartimentos celulares y quedarse en el interior celular. También cabe la posibilidad de que el BA secretado sea recaptado por la célula. En este sentido, se han identificado transportadores específicos, como la subunidad alfa 7 del receptor nicotínico de acetilcolina ( $\alpha 7 n A C h R)$, que posee alta afinidad por el BA y se internaliza tras su unión (Wang et al. 2000). El receptor de ApoE, denominado LDLR (receptor de lipoproteínas de baja densidad), también contribuye a la internalización del BA, así como los receptores NMDA. 
Parece existir un balance entre el amiloide intracelular y el extracelular, ya que la eliminación de BA extracelular con inmunoterapia reduce la cantidad de amiloide intracelular (Oddo et al. 2006). Diversos autores han demostrado que la aparición de amiloide intraneuronal precede a la formación de filamentos pareados helicolidales formados por la proteína Tau hiperfosforilada, debido a que el BA intracelular afecta a la función mitocondrial y de los proteosomas, aumentando los niveles de calcio intracelulares y provocando una disfunción sináptica, lo que facilita la hiperfosforilación de Tau (LaFerla et al. 2007).

\section{* Formas oligoméricas del ß-amiloide}

Hoy en día se piensa que las placas amiloides no son el principal agente causal de los problemas sinápticos o la pérdida neuronal, ya que no siempre el número de placas amiloides se correlaciona bien con la gravedad de la patología. Se ha descrito la existencia de formas tóxicas solubles de BA oligomérico capaces de generar estos daños (Bayer \& Wirths 2010). Estas formas son capaces de difundir por el parénquima cerebral, provocando pérdida sináptica y fallos cognitivos graves correlacionados con los niveles de BA soluble. Los grandes agregados insolubles amiloides parecen estar rodeados por un gran número de oligómeros más pequeños y difundibles.

Actualmente, se cree que las formas oligoméricas solubles, más pequeñas y difundibles serían las causantes de las daños más tempranos de la EA, incluso en momentos pre-sintomáticos (Haass \& Selkoe 2007). Existen multitud de tipos de amiloide oligomérico soluble. Los tipos de ensamblaje y sus principales características se resumen a continuación en la Tabla 2.

Hoy en día se conoce que los ADDLs (ligandos difundibles derivados del BA) y los oligómeros solubles de bajo número pueden inhibir el mantenimiento de la potenciación a largo plazo en el hipocampo e intervenir de forma rápida y reversible en la memoria. 


\begin{tabular}{|c|c|c|}
\hline $\begin{array}{l}\text { “Ensamblaje” } \\
\text { oligomérico }\end{array}$ & Características & Referencias \\
\hline Protofibrillas (PFs) & $\begin{array}{l}\text { Intermediarios de la fibrilización del } \\
\beta A ; \sim 150 \times 2 \mathrm{~nm} \text {; estructura de hoja } \beta \\
\text { plegada }\end{array}$ & $\begin{array}{l}\text { (Harper et al. } \\
\text { 1997; Walsh et al. } \\
\text { 1999) }\end{array}$ \\
\hline Estructuras anulares & $\begin{array}{l}\text { Estructuras tipo rosca con un } \\
\text { diámetro exterior de } 8-12 \mathrm{~nm} \text { y uno } \\
\text { interior de } 2-2,5 \mathrm{~nm}\end{array}$ & $\begin{array}{l}\text { (Bitan et al. 2003; } \\
\text { Lashuel et al. } \\
\text { 2002) }\end{array}$ \\
\hline $\begin{array}{c}\text { Ligandos difundibles } \\
\text { derivados del } \beta A \text { (ADDLs) }\end{array}$ & $\begin{array}{c}\text { Hexámeros, octámeros y } \\
\text { dodecámeros; sus niveles } \\
\text { correlacionan bien con el deterioro } \\
\text { cognitivo }\end{array}$ & $\begin{array}{l}\text { (Lambert et al. } \\
\text { 1998; Gong et al. } \\
\text { 2003) }\end{array}$ \\
\hline$\beta A^{*} 56$ & Aparente dodecámero & $\begin{array}{l}\text { (Lesné et al. } \\
\text { 2006) }\end{array}$ \\
\hline $\begin{array}{l}\text { Monómeros, dímeros y } \\
\text { trímeros solubles bA }\end{array}$ & $\begin{array}{l}\text { Producidos por células en cultivo; } \\
\text { alteran la estructura y función } \\
\text { sináptica }\end{array}$ & $\begin{array}{l}\text { (Walsh et al. } \\
\text { 2000; Walsh et al. } \\
\text { 2002) }\end{array}$ \\
\hline
\end{tabular}

Tabla 2. Características de los distintos estados de agregación del $\beta$ A. (Modificado de (Haass \& Selkoe 2007).

Además, los oligómeros solubles de BA pueden interferir en la señalización de receptores como NMDA (N-metil-D-aspartato) O AMPA (alphaamino-3-hidroxi-5-metilisoazol-4-propionato) en la membrana sináptica (De Felice et al. 2007), permitiendo el inicio de la respuesta LTP, pero no su permanencia, debido a que la presencia de BA provoca la internalización de los receptores NMDA mediante endocitosis (Haass \& Selkoe 2007). Los oligómeros pueden inducir cambios en la membrana neuronal y glial, lo que conlleva a la alteración de las vías de señalización, perturbación de la homeostasis del calcio, producción de especies reactivas de oxígeno, provocar cascadas inflamatorias y disfunciones mitocondriales (Rego \& Oliveira 2003; Mattson 2000).

\section{* Hipótesis de la cascada amiloide}

El descubrimiento del BA como principal componente de las placas seniles permitió formular la hipótesis de la cascada amiloide. Esta teoría propone que el depósito de BA es el evento inicial de la EA, provocando la formación de los ovillos neurofibrilares, la muerte celular $y$, finalmente, 
demencia (Beyreuther \& Masters 1991; Hardy \& Allsop 1991; Hardy \& Higgins 1992; Selkoe 1991).

En la última década, la hipótesis de la cascada del ßA se ha modificado de manera que se postula que cambios graduales en el estado estacionario del BA, debidos a cambios en su metabolismo, provocarían el inicio de la cascada amiloide, ya sea por sobreproducción de BA42, incrementando la proporción BA42/ßA40 o por falta de degradación del mismo. Este incremento favorecería la formación de oligómeros de BA42 que acabarían formando placas difusas. Ello provocaría la activación de la respuesta inflamatoria (astroglía y microglía) en el momento de la formación de las placas extracelulares, dando lugar a la pérdida de las espinas sinápticas y neuritas distróficas. Con el tiempo se genera estrés oxidativo y se ve afectada la homeostasis neuronal. Posteriormente, estos cambios neuronales provocarían daños en el transporte axonal y que la actividad fosfatasa de las quinasas estuviera alterada, provocando la hiperfosforilación de la proteína Tau y, consecuentemente, la formación de ovillos neurofibrilares. Esto a su vez, conllevaría alteraciones en la función sináptica, sutiles en un inicio, pero cada vez más graves y permanentes. Finalmente, la cascada terminaría con la muerte neuronal masiva y un estado de demencia progresivo (Selkoe \& Hardy 2016). Esta hipótesis se esquematiza en la Figura 6. 


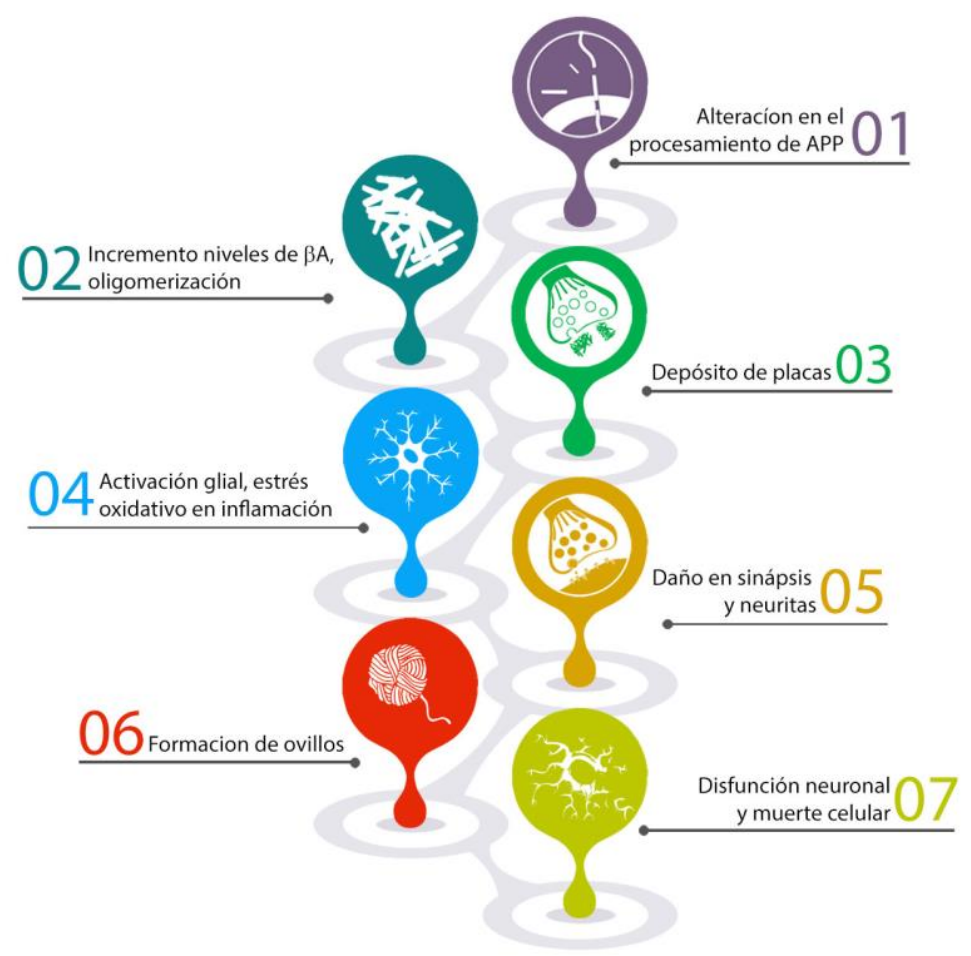

Figura 6. Eventos moleculares que constituyen la Hipótesis de la cascada amiloide. Modificado de (Selkoe \& Hardy 2016).

\section{* B-Amiloide 25-35}

Dentro de los fragmentos de BA estudiados, el undecapéptido BA25-35 representa el fragmento más corto de BA procesado in vivo por proteasas cerebrales (Kubo et al. 2002). Este péptido es el fragmento más corto capaz de formar grandes fibrillas con estructura de hoja- $\beta$ y que retiene toda la neurotoxicidad del BA completo (Stepanichev et al. 2006; Tickler et al. 2005; Mattson et al. 1997; Lau et al. 2003). Por ello se considera al BA25-35 como el dominio funcional del BA, responsable de sus propiedades neurotóxicas (Stepanichev et al. 2006; Stepanichev et al. 2003; Stepanichev MYu et al. 1998; Stepanichev et al. 2005; Limón et al. 2009)

Estructuralmente puede dividirse en dos dominios: uno hidrofílico, que contiene el sitio de plegamiento en $\beta$, y otro hidrofóbico, necesario para una agregación estable (Millucci et al. 2010). La estructura se muestra en la Figura 7. 
Estudios in vitro han mostrado que, a diferencia del péptido completo, el fragmento 25-35 no requiere de envejecimiento para llegar a ser tóxico (Pike et al. 1995), y forma fibras inmediatamente tras su disolución (Hensley et al. 1994).

In vivo, el BA25-35 se encuentra en neuronas del subículo y corteza entorrinal de cerebros de pacientes con EA.

El BA25-35 se acumula en cerebros de pacientes en forma racémica (de L a D-Ser ${ }^{26}$ ). Se ha sugerido una conversión in vivo de [D-Ser26] BA40 a fragmentos tóxicos como el [D-Ser26] BA25-35, lo que provoca una drástica pérdida neuronal en la capa CAl del hipocampo al potenciar la excitotoxicidad (Kubo et al. 2002; Kubo et al. 2003).

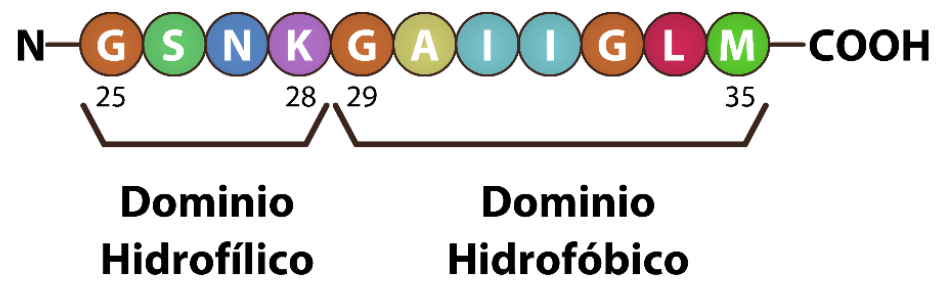

$\begin{array}{ll}\text { Sitio de } & \text { Necesario para la } \\ \text { plegamiento } & \text { agregación estable } \\ \text { en } \beta & \end{array}$

Figura 7. Estructura del péptido $\beta$ A25-35. Cadena de aminoácidos y dominios estructurales del péptido amiloide 25-35, que se considera el dominio funcional del $\beta$ A. Modificado de (Millucci et al. 2010).

\subsubsection{2.- Tau}

La proteína Tau es un fosfolipopéptido que se encuentra asociado a los microtúbulos del citoesqueleto, cuya función es estabilizar los microtúbulos y favorecer su oligomerización, por lo que es crítica para la supervivencia celular, ayudando a mantener la estructura interna de la célula. Cuando se produce una hiperfosforilación anómala de esta proteína, los microtúbulos del citoesqueleto se desorganizan y la proteína Tau al ser insoluble tiende a agregarse formando filamentos apareados helicoidales (PHF), los cuales forman finalmente los ovillos neurofibrilares (NFT o tangles) intracelulares característicos de la enfermedad de Alzheimer (Figura 8). La hiperfosforilación de Tau se produce en las neuronas con degeneración neurofibrilar y en las neuritas 
distróficas alrededor de los depósitos amiloides, dando lugar a placas neuríticas (Li et al. 2016). Tau tiene 79 resíduos de serina y treonina que son sensibles a la fosforilación por enzimas quinasas, como son principalmente la proteína quinasa dependiente de ciclina 5 (CDK5), la quinasa glucógeno sintasa 3 (GSK3), las proteín fosfatasas PP-1 y PP-2A y otras seríntreonin proteína-quinasas (Lee et al. 2001; labal \& Grundke-lqbal 2008). Debido a la presencia de NFTs intracelulares formados por la proteína Tau hiperfosforilada, la EA se considera una taupatía, término que agrupa distintas enfermedades con depósito anormal de Tau altamente fosforilada en neuronas y en células gliales. Además de la EA, existen otras taupatías como son la enfermedad de Pick, la parálisis supranuclear progresiva, la degeneración córtico-basal, la enfermedad de los granos argirófilos y otras taupatías ligadas a mutaciones en el gen de Tau, como la demencia fronto-temporal (Lee et al. 2001).

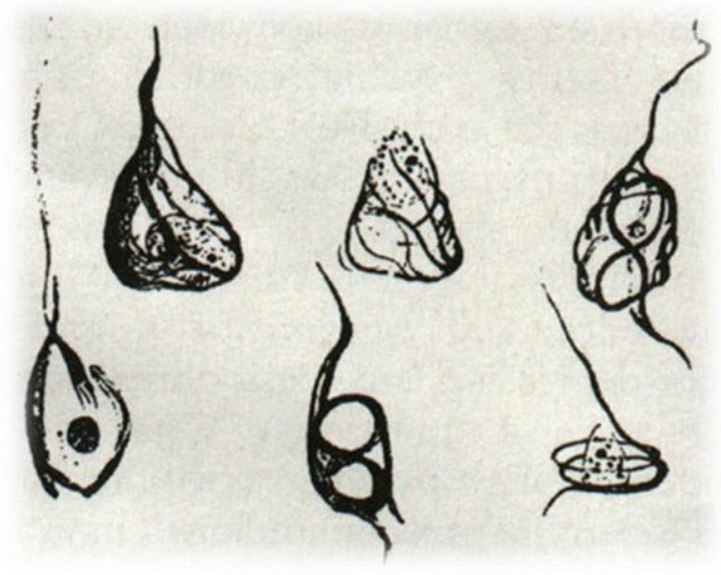

Figura 8. Dibujo original de Alois Alzheimer de los ovillos neurofibrilares. Alois Alzheimer realizó una serie de dibujos de las preparaciones histológicas procesadas con tinción de plata, en las que observó acumulaciones intraneuronales en forma de hilos o marañas, que actualmente se conocen como ovillos neurofibrilares formados por la proteína Tau hiperfosforilada.

Se sabe que la existencia de grandes cantidades de BA, así como el estrés oxidativo en las células o cambios en la transducción de señales, pueden provocar una desregulación en la actividad de las serín-treonin quinasas que fosforilan a Tau, provocando su hiperfosforilación y la generación de los ovillos neurofibrilares. Sin embargo, no todo el Tau hiperfosforilado forma PHF, ya que 
más de un $40 \%$ permanece en el citosol sin agregarse. La formación de ovillos provoca una degeneración del transporte axonal, lo que conlleva una pérdida sináptica, generación de neuritas distróficas y la muerte neuronal (labal \& Grundke-lqbal 2008).

El aumento en la expresión y fosforilación de Tau con la edad no afecta al inicio ni al progreso de la patología amiloidea, ya que el procesamiento y posterior acumulación de BA se produce de forma más temprana en el desarrollo de la enfermedad que la formación de NFTs (Nisbet et al. 2015; J Gotz et al. 2001; Lewis et al. 2001). Además, la existencia de mutaciones en Tau provoca neurodegeneración en ausencia de acumulación de BA, sugiriendo que la generación de NFTs no provoca un aumento en los niveles de BA, corroborando la hipótesis de la cascada amiloide, siendo el $\beta A$ el que favorece la formación de ovillos neurofibrilares (Oddo et al. 2007).

\subsection{2.- Disfunción milocondrial en la Enfermedad de Alzheimer.}

El BA es una potente "toxina" mitocondrial que afecta de forma especial al pool mitocondrial sináptico (Mungarro-Menchaca et al. 2002). Así, la exposición al BA inhibe enzimas clave mitocondriales tanto en el cerebro como en mitocondrias aisladas (Bolaños et al. 2009). Una de las más atacadas es la Citocromo C Oxidasa o complejo IV de la cadena de transporte de electrones (CTE). Se ha sugerido que la disfunción mitocondrial en la EA podría explicarse, al menos en parte, por la inhibición de la actividad enzimática de la Citocromo C Oxidasa por unión del BA1-42 a la subunidad 1 de dicha enzima (Hernandez-Zimbron et al. 2012). De esta manera, la cadena transportadora de electrones, la producción de ATP, el consumo de oxígeno y el potencial de membrana mitocondrial se ven afectados (Chen \& Yan 2007; Bolaños et al. 2009).

La disfunción mitocondrial es una característica prominente y temprana en la EA, de manera que casi la totalidad de las funciones mitocondriales se ven deterioradas en esta enfermedad (Schmitt et al. 2012), como se describe a continuación.

-Metabolismo energético reducido. La reducción del metabolismo energético en el cerebro enfermo es una de las anomalías mejor documentadas en la EA. 
De hecho, el bajo metabolismo glucolítico y su declive se consideran una herramienta útil para monitorizar cambios en la cognición y funcionalidad en la EA y $\mathrm{MCl}$, empleándose cada vez más para ayudar al diagnóstico y predecir el futuro deterioro cognitivo (Marcus et al. 2014; Bolaños 2016).

-Alteración de enzimas mitocondriales. Se ha demostrado que varias enzimas del metabolismo oxidativo, entre ellas el complejo $\alpha$-cetoglutarato deshidrogenasa, el complejo piruvato deshidrogenasa y la citocromo c oxidasa (Caspersen 2005), ven reducida su expresión y/o actividad en la EA (Querfurth \& Laferla 2010). Durante la fosforilación oxidativa, los transportadores de electrones liberan energía que conduce a la formación de ATP. Se ha descrito que el BA podría inhibir la respiración mitocondrial interaccionando con la subunidad $\alpha$ de la ATP-sintetasa, causando una disminución en los niveles de ATP (Schmidt et al. 2008). Esta alteración se ha correlacionado de forma significativa tanto con el estado clínico del paciente como con el número de placas seniles (Schmidt et al. 2008).

-Alteración en la homeostasis del $\mathrm{Ca}^{2+}$. Las mitocondrias son almacenes intracelulares de $\mathrm{Ca}^{2+}$ citosólico, que internalizan principalmente por uniporte y liberan mediante intercambiadores $\mathrm{Na}^{+} / \mathrm{Ca}^{2+} \circ \mathrm{H}^{+} / \mathrm{Ca}^{2+}$. Incrementos anormales de $\mathrm{Ca}^{2+}$ citosólico conllevan un rápido cúmulo del catión en la mitocondria, hecho especialmente importante en el SNC dada la función del $\mathrm{Ca}^{2+}$ en la neurotransmisión, plasticidad a corto y largo plazo y regulación de la transcripción génica (Berridge 1998; Xia \& Storm 2005; Lüscher \& Malenka 2012). Adicionalmente, la pérdida de la homeostasis del $\mathrm{Ca}^{2+}$ puede potenciar excitotoxicidad, un fenómeno íntimamente ligado a procesos neurodegenerativos. Las mitocondrias no funcionales contribuyen a la pérdida de homeostasis del $\mathrm{Ca}^{2+}$ intracelular. De hecho, se ha observado una mala gestión del catión en células periféricas de pacientes con EA. Además, existen evidencias indirectas que sugieren un elevado $\mathrm{Ca}^{2+}$ intracelular en cerebros de pacientes debido a que la quinasa dependiente de calmodulina y las calpaínas están elevadas en neuronas vulnerables de forma temprana en el proceso de la enfermedad (Green \& LaFerla 2008; Bojarski et al. 2008; Woods \& Padmanabhan 2012).

-DNA mitocondrial (mtDNA). Está descrito que la presencia de BA incrementa los niveles de radicales libres directa o indirectamente. El mtDNA, debido a su localización (en la principal fuente de ROS en la célula) y a su carencia de 
histonas e intrones, es especialmente sensible al efecto de las especies reactivas de oxígeno (ROS) generadas por el BA. Las mutaciones producidas al mismo por el daño oxidativo llevarán a la generación de proteínas de la cadena de transporte electrónico alteradas, lo que amplificará la producción de radicales libres y terminará por desencadenar la muerte celular (Bozner et al. 1997; Spuch et al. 2012). En presencia de BA, la ABAD (Aß-binding alcohol dehydrogenase, una enzima intracelular presente en la matriz mitocondrial) incrementa la fragmentación del mtDNA inducida por el BA (Lustbader et al. 2004).

-Potencial de membrana mitocondrial $\left(\Delta \Psi_{\mathrm{m}}\right)$. El $\Delta \Psi_{\mathrm{m}}$ puede verse reducido por múltiples mecanismos, incluyendo la deficiencia de sustratos oxidables por la mitocondria, un bloqueo en la respiración y por oxidación de proteínas de la CTE, como el Complejo I, que es el más sensible a la oxidación (Almeida \& Bolaños 2001; García et al. 2005). El Complejo I oxidado ROS altera tanto el flujo de protones como de electrones, lo que conduce a la despolarización de la mitocondria. Además, el BA interacciona de forma directa con la Ciclofilina D (CypD), un componente del Poro de Permeabilidad Transitoria mitocondrial (PTP) que se une a la Ciclosporina $\mathrm{A}$ y vuelve los canales más sensibles al $\mathrm{Ca}^{2+}$ (Casley et al. 2002; Du et al. 2008). Además, el BA intramitocondrial bloquea la entrada a la mitocondria de proteínas codificadas en el núcleo, de manera que el $\Delta \psi \mathrm{m}$ se ve reducido (Sirk et al. 2007).

-Vía apoptótica. El BA induce proteínas que se activan con estrés además de p53, las cuales se relacionan con la apoptosis. Además, la apertura del PTP conduce a la activación de caspasas (Y. Zhang et al. 2002). La mitocondria está posicionada en el centro de la vía intrínseca de la apoptosis, y muchos elementos de dicha vía están alterados o activados en el cerebro de la EA (Wang \& Youle 2009).

-Dinámica mitocondrial alterada. Las mitocondrias son orgánulos altamente dinámicos que experimentan continuamente eventos de fusión y fisión que regulan la morfología, distribución y número de mitocondrias. En neuronas tratadas con BA se han hallado incrementada la expresión de genes de fisión (Drpl y Fisl) y disminuidos los de fusión (Mfn1, Mfn2 y Opal). Estudios de microscopía electrónica en neuronas tratadas con BA se ha evidenciado un aumento de la fragmentación mitocondrial asociada a una fisión excesiva. A su vez, estos cambios dan lugar a modificaciones en la morfología mitocondrial, 
encontrándose mitocondrias más grandes y redondeadas en la EA (Wang et al. 2008).

Estas alteraciones en la función mitocondrial se esquematizan a continuación en la Figura 9.

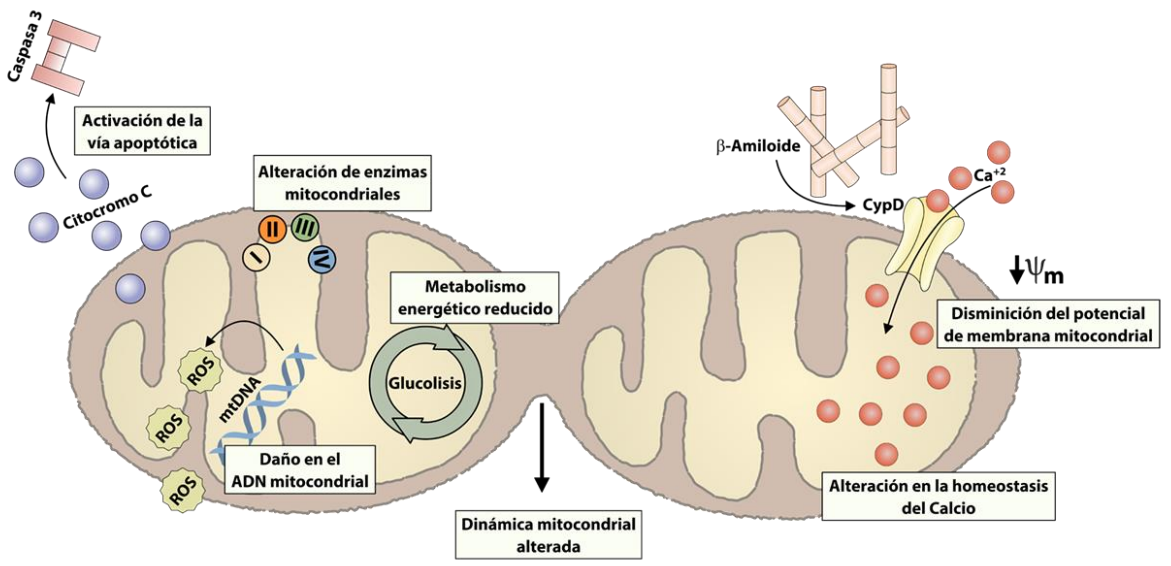

Figura 9. Eventos principales que conducen a la disfunción mitocondrial en la EA. El $\beta A$ induce la reducción del metabolismo energético y altera proteínas mitocondriales, de manera que se produce un exceso de ROS que daña el mtDNA. A su vez se ve reducido el potencial de membrana, lo que favorece la pérdida de capacidad tamponadora de calcio, así como la salida del citocromo c y la activación de la apoptosis intrínseca. Asimismo, la dinámica mitocondrial se encuentra alterada, de manera que se favorece el proceso de fusión mitocondrial.

\subsection{3.- Pérdida neuronal y sináptica en la Enfermedad de Alzheimer}

La pérdida neuronal y sináptica en la corteza cerebral y en el hipocampo es la causa principal del declive cognitivo en la EA, tal y como demuestran varios estudios en humanos (Masliah et al. 1989; Masliah et al. 1991; Terry et al. 1991; Serrano-Pozo et al. 2011) y en modelos animales (Shankar \& Walsh 2009). 


\subsubsection{1.- Pér dida neuronal}

Se ha descrito que algunas áreas del cerebro son especialmente vulnerables a los procesos neurodegenerativos de la EA, de manera que podrían manifestar disfunción neuronal desde las primeras etapas de la enfermedad. Así, la pérdida neuronal es especialmente prominente en el hipocampo, fundamentalmente en la región CAl y en la corteza cerebral, pérdida que va aumentando conforme la enfermedad progresa (Brun \& Englund 1981).

La pérdida neuronal se manifiesta primeramente en el lóbulo temporal medial (Scahill et al. 2002). La corteza entorrinal es la primera zona en afectarse, seguida del hipocampo, la amígdala y el parahipocampo (Lehericy et al. 1994; Chan et al. 2001; Dickerson et al. 2001; Killiany et al. 2002).

\subsubsection{2.- Mecanismos de muerte neuronal}

A pesar de que la pérdida neuronal es una característica de la EA, los mecanismos por los cuales ocurre no están del todo bien establecidos.

\section{Apoptosis en la Enfermedad de Alzheimer}

Se han observado incrementos en la muerte neuronal por apoptosis tanto en la forma esporádica como en la genética de la EA (Eckert, Marques, et al. 2003). La apoptosis es un tipo de muerte celular programada que está por la familia de proteínas BCl-2 (B-cell lymphoma 2 ) regulada por la activación de varias cisteinil-aspartato proteasa o caspasas. La apoptosis puede estar iniciada por el estrés oxidativo, daño en el DNA, desequilibrio en la homeostasis del $\mathrm{Ca}^{2+}$ o estrés del retículo endoplásmico (Culmsee y Landshamer, 2006). Las dos vías por las que puede iniciarse la apoptosis son (1) la intrínseca o mitocondrial y (2) la extrínseca o mediada por receptor.

1) La vía intrínseca o mitocondrial se inicia en la mitocondria. Está regulada por la familia de proteínas Bcl-2, dentro de la cual unos miembros son antiapoptóticos (BCl-2, BCl-XL (B-cell lymphoma-extra large)) y otros son proapoptóticos multidominio ( $\mathrm{Bax}$ ( $\mathrm{BCl}-2$ associated $X$ protein) y Bak (BCl-2 homologous antagonist killer)) O de tipo "BH3-only" (Bim (BCl-2-like protein 11), Bid (BH3 interacting-domain death agonist), Bad (BCl-2-associated death promoter protein)). Las proteínas BH3-only activan a las proapoptóticas multidominio, capaces de generar un poro en la membrana mitocondrial, 
mientras que las anti-apoptóticas inhiben la formación del poro. La formación del poro mitocodrial permite que el citocromo c retenido en el interior de la mitocondria se libere al citoplasma, donde formará complejo con la procaspasa-9, que se activará y junto con APAF1 (apoptosis proteaseactivating factor-1), forman el apoptosoma, que corta a la procaspasa-3, generando caspasa-3 activada, que es la caspasa efectora (Taylor et al. 2008; Almeida 2013).

Existen numerosas evidencias de la activación de la vía intrínseca o mitocondrial de la apoptosis en la EA. En este sentido, se ha demostrado la implicación de la familia Bcl-2 en la progresión de la apoptosis en la EA. Así, se ha observado una disminución en la proteína anti-apoptótica Bcl-2 en neuronas humanas (Paradis et al. 1996) a la par que un incremento en los niveles de proteínas pro-apoptóticas Bax y Bak en cerebros de pacientes con EA (Kitamura et al. 1998) y en neuronas humanas en cultivo (Paradis et al. 1996), aunque el mecanismo es aún desconocido. Este balance a favor de las proteínas pro-apoptóticas conlleva una pérdida del potencial de membrana mitocondrial y liberación de citocromo c al citosol (T. Liv et al. 2013). También existen evidencias de la activación de caspasa 9 (Sun et al. 2011 ) y caspasa 3 tanto en neuronas primarias expuestas a BA (Sun et al. 2011 ) como en cerebros de pacientes con EA (Louneva et al. 2008).

2) La vía extrínseca o de receptores de muerte se inicia con la unión a receptores de muerte de membrana (Fas y TNFR (tumor necrosis factor receptor) con sus ligandos. Se inicia una cascada intracelular de eventos en la que se activan las caspasas iniciadoras de la apoptosis, como la caspasa8 y 10 que, a su vez, activan a la caspasa-3, de naturaleza efectora, llevando a fin el proceso apoptótico (Taylor et al. 2008).

$\mathrm{Al}$ igual que en el caso anterior, también existen evidencias de la implicación de esta vía en la EA. Así, se ha observado una sobreexpresión de TNFR en células periféricas de pacientes de EA (Perry et al. 2001). Además, se ha detectado activación de la caspasa 8 en presencia de Fas en cerebros de pacientes con EA tanto en corteza como en hipocampo (Yew et al. 2004).

A continuación, en la Figura 10 se muestra la manera en la que los distintos elementos de ambas vías se ven afectados en la EA. 


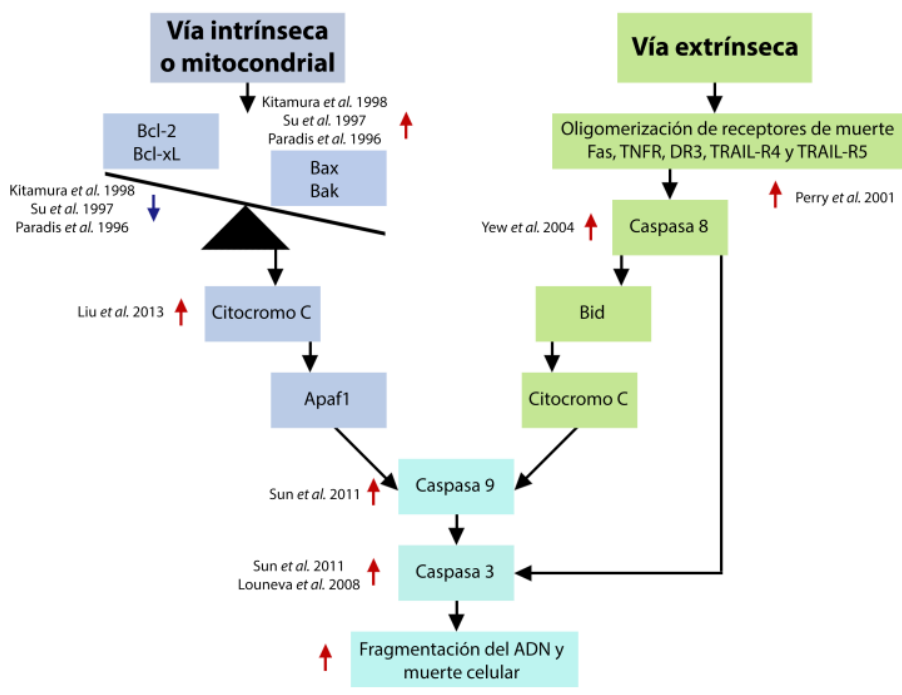

Figura 10. Afectación de los distintos elementos que conforman las vías intrínseca y extrínseca de la apoptosis en la EA.

Excitotoxicidad en la Enfermedad de Alzheimer

La excitotoxicidad es un fenómeno patológico que ocurre de forma particular en las neuronas por sobreestimulación de receptores NMDA y AMPA de glutamato. Esta excesiva estimulación conlleva la entrada masiva de $\mathrm{Ca}^{2+}$ en la neurona que activa una serie de enzimas, incluyendo las fosfolipasas, las endonucleasas, y proteasas tales como la calpaína, que, a su vez, activan distintas vías de señalización molecular implicadas en daño y muerte neuronal.

Se ha relacionado la acumulación de BA con incrementos en la sensibilidad de las neuronas a sufrir excitotoxicidad (Olney et al. 1998) además de con la excesiva estimulación de receptores NMDA (Miguel-Hidalgo et al. 2002). Adicionalmente, se ha sugerido que este fenómeno adquiere mayor importancia en etapas tardías de la enfermedad (Ikonomovic et al. 1999).

\section{Autofagia en la Enfermedad de Alzheimer}

El término autofagia se refiere a un proceso catabólico mediante el cual componentes celulares, orgánulos y proteínas mal plegadas son degradados en lisosomas para su reciclaje (Klionsky et al. 2011; Levine \& Kroemer 2008). La autofagia se inicia mediante la formación de vesículas con doble membrana, denominadas autofagosomas, que secuestran 
componentes celulares en un ambiente degradante. Los autofagosomas son transportados entonces a través de microtúbulos hacia la región perinuclear (que contiene la concentración más elevada de lisosomas), donde se fusionan con lisosomas para formar autolisosomas. En estas estructuras, los materiales capturados, así como la membrana interna, son degradados por encimas lisosomales (Levine \& Kroemer 2008). En estudios de microscopía electrónica en pacientes con EA se ha observado, en neuritas distróficas asociadas a placas amiloides, la acumulación de vacuolas autofágicas (VAs). Este descubrimiento supuso la primera evidencia de la participación de la autofagia en la patogénesis de la EA (Nixon et al. 2005). Al contrario que en cerebros sanos, en los que la presencia de VAs apenas es detectable, la abundancia de VAs en pacientes y en modelos animales de EA parece indicar que una proteólisis lisosomal autofágica alterada podría ser la causa de la acumulación patológica de proteínas en la EA (Liang \& Jia 2014).

\subsubsection{3.- Disfunción y pér dida sináptica}

Son muchos los estudios que sugieren que las sinapsis y las dendritas, las especializaciones a través de las cuales las neuronas reciben y envían señales, son particularmente vulnerables a la EA. La plasticidad sináptica es la capacidad de las sinapsis para reforzar o debilitar el contacto entre dos neuronas como respuesta al incremento o disminución de la actividad de las mismas, proporcionando la base para los distintos tipos de memoria y aprendizaje. Los tipos de plasticidad sináptica son la potenciación (LTP) y la depresión (LTD) a largo plazo. Actualmente se reconoce que los efectos que se producen en la plasticidad sináptica son la base del declive cognitivo que se produce en la EA (Koffie et al. 2011).

Los oligómeros de BA se pueden embeberse en las membranas lipídicas (Canale et al. 2013; Yates et al. 2013) formando poros amiloides anulares y canales iónicos de membrana que inducen cambios aberrantes en el citoesqueleto de las espinas dendríticas (Lee et al. 2014; Arispe 2004; Lacor et al. 2007). Además, la localización de estos oligómeros en la sinapsis implica la activación de muchos receptores tales como los receptores de glutamato NMDA y AMPA, el receptor nicotínico de acetilcolina (nAChR) y el de la neurotrofina p75 (P75NTR), seguido de la agrupación aberrante de receptores metabotrópicos de glutamato (mGluR5). Todo ello conduce a la pérdida 
neuronal y el fallo de LTP (Walsh et al. 2002). En particular, la activación de receptores NMDA y AMPA por oligómeros solubles de BA desencadena la disfunción mitocondrial mediada por $\mathrm{Ca}^{2+}$ y la disminución de niveles de la proteína quinasa II (CaMKII) dependiente de $\mathrm{Ca}^{2+} /$ Calmodulina en las sinapsis. Estos eventos de acompañan de una pérdida dramática de proteínas sinápticas como son la PSD-95, dinamina-1 y sinaptofisina (Sivanesan et al. 2013).

La pérdida de sinapsis y de espinas dendríticas observada en cultivos neuronales expuestos al BA y en cerebros de modelos transgénicos de EA es desproporcionada respecto a la pérdida neuronal, y es el hecho que mejor correlaciona con el declive cognitivo en pacientes con EA (Palop et al. 2006; DeKosky \& Scheff 1990; Lue et al. 1999; Bayer \& Wirths 2010). En estos modelos la degeneración va precedida por fallos en la actividad sináptica y por actividad aberrante en las red (Palop \& Mucke 2010; Marchetti \& Marie 2011), sugiriendo que esta disfunción sináptica es una manifestación temprana de la EA y que contribuye a su progresión.

Los principales eventos responsables de la disfunción sináptica en la EA se esquematizan a continuación en la Figura 11.

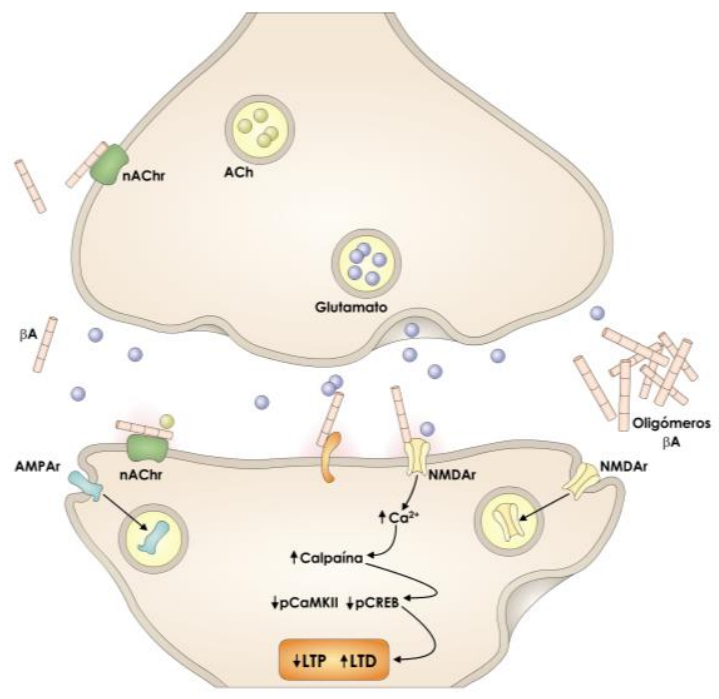

Figura 11. Eventos principales que conducen a la disfunción sináptica en la

EA. Las moléculas de $\beta$ A pueden actuar sobre las membranas neuronales tanto provocando malformaciones en las mismas, como actuando sobre receptores de membrana, lo que lleva a la pérdida de sinapsis y espinas dendríticas con el consiguiente deterioro cognitivo en la EA. 


\section{3.- GENÉTICA EN LA ENFERMEDAD DE ALZHEIMER}

La susceptibilidad conferida por múltiples genes y por las posibles interacciones entre ellos influye en el riesgo de padecer EA. De este modo, debido a la fuerte base genética de la EA, algunos autores la han definido como una enfermedad genética. Tal es así que estudios demuestran que la genética juega un papel importante en hasta el $80 \%$ de los casos de EA (Gatz et al. 2006; Tanzi 2012; Lambert et al. 2013; Bettens et al. 2013). Así, detrás de la edad avanzada, la historia familiar es el segundo gran factor de riesgo para la EA. La EA se considera una enfermedad genética dicotómica que presenta dos formas: la forma temprana o familiar de la enfermedad (Early Onset-Familial Alzheimer's Disease, EO-FAD) que se caracteriza por una herencia de tipo mendeliana, y la forma tardía o esporádica (Late Onset AD, LOAD), sin un patrón de herencia definido (Tanzi 2012; Bettens et al. 2013).

\subsection{1.- Enfermedad de Alzheimer familiar}

La EA familiar se diagnostica en familias con más de un miembro que sufre AD. Generalmente, los casos familiares son de comienzo temprano (antes de los 65 años), aunque se han descrito casos de comienzo tardío (Bekris et al. 2010). La forma familiar se debe, en su mayoría, a mutaciones raras y altamente penetrantes en uno de estos tres genes principales: APP, PSEN1 y PSEN2 (Presenilina 1 y 2 respectivamente) (Cacace et al. 2016).

La mayoría de mutaciones en el gen de la APP se localizan en los exones 16 y 17, bien en la zona de corte de la $\alpha$-secretasa, en la zona central de la región amiloide o en la zona de corte de la $\gamma$-secretasa (Weggen \& Beher 2012). Estas mutaciones dan cuenta únicamente del $9 \%$ de los casos familiares de EA (AD mutation database; http://www.molgen.ua.ac.be/ADMutations/).

La mayoría de casos familiares de EA está causada por mutaciones en los genes PSEN1 y PSEN2, los cuales poseen una estructura muy similar $y$ codifican proteínas con alta homología: la Presenilina 1 y la Presenilina 2. Ambas proteínas forman parte del complejo enzimático $\gamma$-secretasa, responsable del segundo corte de la APP (Rogaev et al. 1995; Sherrington et al. 1995; Levy-Lahad et al. 1995; Bekris et al. 2010). En la Tabla 3 se muestran las mutaciones en estos genes implicados en la etiopatogenia de la EA. 


\begin{tabular}{lccccc}
\hline Gen & Proteína & Cromosoma & Mutaciones & $\begin{array}{c}\text { Fenotipo } \\
\text { molecular }\end{array}$ & $\begin{array}{c}\text { Edad de } \\
\text { comienzo }\end{array}$ \\
\hline APP & $\begin{array}{c}\text { Proteína } \\
\text { precursoa } \\
\text { amiloide }\end{array}$ & $21 q 21$ & 24 & $\begin{array}{c}\text { Incrementa la } \\
\text { producción y } \\
\text { agregación } \\
\text { de } \beta \text { A y el } \\
\text { ratio } \beta \text { A42/40 }\end{array}$ & $39-67$ \\
\hline PSEN1 & Presenilina 1 & $14 q 24$ & 185 & $\begin{array}{c}\text { Incrementa el } \\
\text { ratio } \beta \text { A42/40 }\end{array}$ & $28-79$ \\
\hline PSEN2 & Presenilina 2 & $1 \mathrm{q} 31$ & 14 & $\begin{array}{c}\text { Incrementa el } \\
\text { ratio } \beta \text { A42/40 }\end{array}$ & $39-85$ \\
\hline
\end{tabular}

Tabla 3. Genes y sus mutaciones implicados en el desarrollo de Enfermedad de Alzheimer precoz. (Tanzi 2012)

\subsection{2.- Enfermedad de Alzheimer esporádica}

La forma tardía o esporádica de la EA es la más común, y se caracteriza por una edad de comienzo superior a los 65 años. En la forma esporádica se ha observado un complejo patrón de herencia en el cual los factores genéticos trabajan conjuntamente con factores ambientales para determinar el riesgo de sufrir EA.

Se sabe que polimorfismos génicos comunes tienen influencia sobre la susceptibilidad a padecer LOAD aproximadamente en el $50 \%$ de los casos. Sin embargo, hasta el momento la única variante génica considerada como un factor de riesgo establecido para $L O A D$ es el alelo 4 del gen de la apolipoproteina E, localizado en el cromosoma 19q13 (Strittmatter et al., 1990).

A partir del establecimiento del alelo 4 como factor genético de riesgo, se han analizado posibles asociaciones de cientos de genes con la EA. Durante los últimos años, la estrategia más común para encontrar nuevos genes candidatos para el riesgo de sufrir EA ha sido el estudio de asociación del genoma completo (GWAS). Así, se han identificado más de 20 loci de susceptibilidad. La relación entre dichos loci y la progresión de la demencia no se ha estudiado exhaustivamente, poniendo de manifiesto la necesidad de emplear otras estrategias para identificar más genes implicados en las manifestaciones patológicas de la EA (Wang et al. 2015). En la Tabla 4 se muestran los genes asociados a un aumento del riesgo de padecer EA y el mecanismo responsable de dicho riesgo. 


\begin{tabular}{|c|c|c|c|c|}
\hline Gen & SNP & Localización & $\begin{array}{c}\text { Incremento } \\
\text { del riesgo }\end{array}$ & $\begin{array}{c}\text { Fenotipo molecular } \\
\text { propuesto }\end{array}$ \\
\hline APOE & $\begin{array}{l}\text { rs429358 } \\
\text { rs7412 }\end{array}$ & $19 q 13$ & $400-1500$ & $\begin{array}{l}\text { Eliminación de } \beta A ; \\
\text { metabolism lipídico }\end{array}$ \\
\hline CD33 & rs3865444 & $19 q 13.3$ & 10 & Eliminación de $\beta A$ \\
\hline CLU & rs11136000 & $8 p 21.1$ & 10 & Eliminación de $\beta A$ \\
\hline CR1 & rs3818361 & $1 q 32$ & 15 & Eliminación de $\beta A$ \\
\hline PICALM & rs3851179 & $11 q 14$ & 15 & $\begin{array}{l}\text { Producción y } \\
\text { eliminación de } \beta A ; \\
\text { señalización celular }\end{array}$ \\
\hline BIN1 & rs744373 & $2 q 14$ & 15 & $\begin{array}{l}\text { Producción y } \\
\text { eliminación de } \beta A ; \\
\text { señalización celular }\end{array}$ \\
\hline ABCA7 & rs3764650 & $19 \mathrm{p} 13.3$ & 20 & $\begin{array}{l}\text { Metabolismo lipídico, } \\
\text { señalización celular }\end{array}$ \\
\hline CD2AP & rs9349407 & $6 p 12.3$ & 10 & Señalización celular \\
\hline EPHA1 & rs11767557 & $7 q 34$ & 10 & Señalización celular \\
\hline ADAM10 & rs2305421 & $15 q 21$ & 10 & Producción de $\beta A$ \\
\hline
\end{tabular}

Tabla 4. SNPs (single nucleotide polymorphisms) asociados con el riesgo de padecer EA esporádica y su mecanismo patogénico propuesto. Adaptado de (Tanzi 2012).

\subsection{3.- Apolipoproteina E (ApoE)}

La apolipoproteína E es una glucoproteína plasmática implicada en el transporte de colesterol y otros lípidos en los diferentes tejidos. Es la principal apolipoproteína que se encuentra en el tejido cerebral, fundamentalmente en las células de la glía, interviniendo en los procesos de crecimiento y regeneración del tejido nervioso durante su desarrollo y tras diferentes tipos de lesiones, así como en el metabolismo del BA cerebral (BU 2009). El gen humano APOE contiene varios SNPs distribuidos a lo largo del gen (Nickerson et al. 2000). Dos SNPs en el exón 4 (rs429358: de Timina a Citosina; rs7412: de Citosina a Timina) dan lugar a tres haplotipos APOE que codifican tres isoformas proteicas distintas: ApoE2, ApoE3 y ApoE4 que difieren en los aminoácidos de las posiciones 112 y 158. Estas diferencias alteran profundamente la estructura y 
función de la ApoE (Mahley et al 2006). En la Tabla 5 se muestra la frecuencia alélica poblacional de las distintas variantes polimórficas.

\begin{tabular}{cccccc}
\hline Alelo APOE & rs429358 & $\begin{array}{c}\text { aminoácido } \\
\mathbf{1 1 2}\end{array}$ & rs7412 & $\begin{array}{c}\text { aminoácido } \\
\mathbf{1 5 8}\end{array}$ & $\begin{array}{c}\text { \% en la } \\
\text { población }\end{array}$ \\
\hline$\varepsilon 2$ & ICG & Cys & ICG & Cys & $5-10$ \\
$\varepsilon 3$ & ICG & Cys & CGC & Arg & $70-80$ \\
$\varepsilon 4$ & CGC & Arg & CGC & Arg & $10-15$ \\
\hline
\end{tabular}

Tabla 5. Polimorfismos de la ApoE que dan lugar a las distintas variantes y su frecuencia en la población. (Robert W Mahley \& Huang 2012)

En humanos existen tres genotipos homocigóticos (APOE2/2, E3/3 and E4/4) y tres heterocigotos (APOE3/2, E4/3 and E4/2). La frecuencia de los alelos en la población mundial es de 8,4\%, 77,9\% y 13,7\% para ApoE2, ApoE3 y ApoE4 respectivamente. Sin embargo, la frecuencia del alelo E4 incrementa dramáticamente ( 40\%) en pacientes con EA (Farrer et al. 1997). El alelo 4 no es ni necesario ni suficiente para provocar la enfermedad, pero actúa como un factor de riesgo genético que disminuye la edad de comienzo de la EA de manera dependiente de su concentración, tanto en la forma esporádica de la enfermedad como en la familiar de comienzo tardío (Corder et al. 1993; Saunders et al. 1993). Así, el alelo 4 tiene un importante efecto "dosis"dependiente en el riesgo y edad de comienzo de la EA de manera que según aumenta el número de alelos E4 de 0 a 2, el riesgo aumenta del 20 al 90\%, mientras que la edad de comienzo disminuye de los 84 a los 68 años (Corder et al. 1993; C.-C. Liu et al. 2013).

Para poner en conjunto los distintos genes cuyas mutaciones 0 polimorfismos están relacionados con la EA, en la Figura 12 se muestra de manera esquemática la contribución como factor causal o de riesgo de cada uno de los genes mencionados en la presente memoria. 


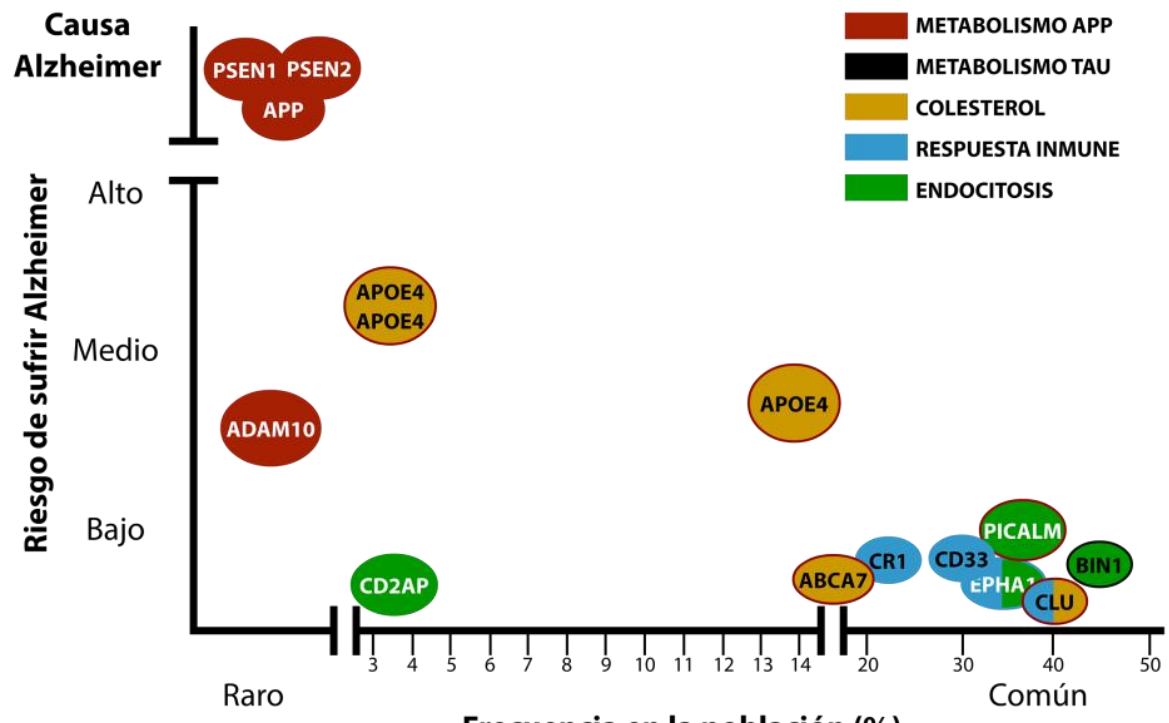

Frecuencia en la población (\%)

Figura 12. Genes que contribuyen al riesgo de desarrollar EA. El esquema muestra genes cuyas variantes influyen en el riesgo de padecer EA. Los distintos genes se han clasificado en función de (1) la contribución al riesgo, (2) la frecuencia poblacional y (3) el mecanismo por el cual modifican el riesgo. Modificado de (Scheltens et al. 2016).

\section{2.- $p 53$}

La proteína supresora tumoral p53, producto del gen Tp53, se descubrió en 1979 como una proteína de 53 kD unido al antígeno T SV40 grande en tumores y células transformadas, por lo que se postuló como un oncogen (Lane and Crawford, 1979, Linzer and Levine, 1979).

Esta proteína, también conocida como "guardián del genoma" desempeña importantes y diversas funciones celulares, como son el control del ciclo celular, senescencia y apoptosis, entre otras. Es por ello que sus niveles intracelulares están sujetos a una estrecha regulación. Así, en condiciones fisiológicas, la proteína p53 se encuentra en niveles muy bajos, con una vida media breve ( 5-20 minutos), debido fundamentalmente a la degradación vía proteasoma tras su poliubiquitinación por la E3-ubiquitina ligasa MDM2. No obstante, en condiciones de estrés celular, p53 se estabiliza por modificaciones post-traduccionales, de manera que se incrementa su vida media y se acumula 
en el interior de la célula provocando, en muchos casos, la muerte celular (Lavin \& Gueven 2006).

\section{1.- ESTRUCTURA DE p53}

La proteína p53 es un factor de transcripción inducible por estrés, biológicamente activo en forma de homo-tetrámero, de manera que contiene 4 × 393 residuos de aminoácido (Chan et al. 2004). La proteína p53 se estructura de la siguiente forma:

-El Dominio de Activación Transcripcional o TAD (residuos del 1 al 62) de p53 se encuentra en el extremo N-terminal y es esencial para la actividad transcripcional de p53. El TAD conecta el reconocimiento de los genes diana con su expresión mediante unión directa a co-activadores y componentes de la maquinaria transcripcional. Este dominio puede a su vez subdividirse en TAD1 y TAD2. El TAD2 parece esencial para la activación transcripcional de varios genes pro-apoptóticos.

-A continuación se encuentra el Dominio Rico en Prolina o PRD (residuos 63-94) (Joerger \& Fersht 2010). Este dominio es esencial para la actividad proapoptótica y supresora del crecimiento mediada por p53 (Harms et al. 2005).

- Los residuos 94-292 forman el Dominio de unión al DNA o DBD, y confieren a la proteína p53 su capacidad de unión al DNA. El DBD es responsable del reconocimiento y unión de p53 a sus DNA dúplex diana de manera secuencia-específica.

-El Dominio de Señalización de Localización Nuclear o NLS (residuos 316324) regula la entrada de p53 al núcleo.

- Los residuos 325-355 están involucrados en la tetramerización de p53, la cual es esencial para su actividad in vivo (Chan et al. 2004).

-El Dominio C-terminal o CTD está formado por los residuos 356-393, lleva a cabo importantes funciones reguladoras y es responsable de la modulación a la baja de la unión a ADN del DBD (Harms et al. 2005; Joerger \& Fersht 2010).

Esta estructura se esquematiza en la figura 13. 


\begin{tabular}{|lc|c|c|c|c|c|c|c|c|c|}
\hline p53 & N & TAD & TAD & PP & Núcleo de unión a ADN & L & Tet & ++ & C \\
\hline
\end{tabular}

Figura 13. Organización estructural de la proteína p53. El esquema muestra los distintos dominios estructurales de la proteína p53.

La proteína p53 interacciona con un amplio panel de patrones proteicos. La mayoría de estas interacciones proteína-proteína se realizan a través del TAD, algunas lo hacen a través del CTD y sólo unas pocas mediante el dominio de unión a ADN (Joerger \& Fersht 2010). Además, las regiones $\mathrm{N}$ - y C-terminal de p53 contienen multitud de residuos de aminoácidos susceptibles de modificaciones post-traduccionales, las cuales modulan tanto la activación como la estabilización y la unión a sus dianas de p53 (Xu 2003; Feng et al. 2005).

\section{2.- ESTABILIZACIÓN DE p53}

Las modificaciones post-traduccionales de p53 juegan un papel fundamental en la estabilización y regulación de la proteína (Appella \& Anderson 2001).

Se han descrito más de 36 residuos de aminoácidos modificados en p53 (Kruse \& Gu 2009). Los tipos de modificación post-traduccional incluyen fosforilación, acetilación, metilación, ubiquitinación, nedilación y sumoilación (Appella \& Anderson 2001; Kruse \& Gu 2008; Kruse \& Gu 2009). La modificación más común es la fosforilación, la cual da cuenta de todas las modificaciones descritas en la región $\mathrm{N}$-terminal, así como de la mayoría de las observadas en el DBD y en la región C-terminal (Appella \& Anderson 2001; Bode \& Dong 2004; Lavin \& Gueven 2006; Gu \& Zhu 2012).

Las modificaciones implicadas en la estabilización de la proteína p53 incluyen fosforilaciones, acetilaciones y O-glicosilaciones (Gu \& Zhu 2012), esquematizadas a continuación en la Figura 14. 


p53 N N

Figura 14. Modificaciones post-traduccionales de p53 directamente implicadas en su estabilización. El esquema muestra las modificaciones post-traduccionales de p53 más importantes implicadas en su estabilización, como son la fosforilación (P), glicosilación (G) y acetilación (Ac).

De todas las modificaciones descritas en la proteína p53, la fosforilación en la Ser-15 (Ser-18 en el ratón) es la mejor caracterizada, y se lleva a cabo, fundamentalmente, por la kinasa ATM (Saito et al. 2002) y por CDK5 tanto de forma directa (Lee et al. 2007) como de forma indirecta a través la activación de ATM (Tian et al. 2009).

\subsection{1.- Estabilización de p53 en la Enfermedad de Alzheimer}

La activación de p53 requiere de la estabilización de la proteína mediante modificaciones post-traduccionales, las cuales interrumpen su interacción con MDM2 (Hooper et al. 2007).

Hasta el momento existen evidencias indirectas de que la estabilización de p53 puede estar mediando, al menos en parte, el daño cerebral que se produce en la EA.

Se ha observado una relación entre algunos productos del metabolismo de la APP y p53 en la EA. Así, se ha descrito que el péptido BA42 induce la muerte neuronal mediada por p53 a través de la estabilización de Bax (Y. Zhang et al. 2002). Además, el dominio intracelular de la APP, AICD, controla p53 a nivel transcripcional (Alves da Costa et al. 2006).

En varios estudios realizados en pacientes se ha visto un incremento de los niveles de p53 en individuos con EA comparado con individuos sanos (Hooper et al. 2007; Kitamura et al. 1997). En este sentido, un estudio in vitro señala que el péptido $\beta$ A42 activa directamente el promotor de p53 (Ohyagi 
et al. 2005). Adicionalmente, en estudios de asociación genética de pacientes con enfermedad de Alzheimer se han encontrado genes de susceptibilidad, citados en el apartado 1.3.2 del presente documento, que son dianas de p53: BIN1, PICALM y CR1 (Merlo et al. 2014).

Todos estos indicios parecen indicar que la estabilización de p53 y la regulación de sus dianas transcripcionales desempeñan un papel importante en los procesos de muerte neuronal en la EA.

\subsection{2.- Kinasa dependiente de ciclina 5 o CDK5}

La kinasa dependiente de ciclina 5 o CDK5 es una serina-treonina quinasa que se activa mediante unión a la subunidad reguladora p35. La actividad de CDK5 está determinada por la concentración disponible de p35 (Lee et al. 1996; Zhu et al. 2005), que está, a su vez, controlada por el balance entre su síntesis y su degradación, así como por fosforilación (Zhao et al. 2009; Hisanaga \& Endo 2010). CDK5-p35 se encuentra asociada a membrana plasmática por miristoilación de p35. Durante el fenómeno de excitotoxicidad, la activación de los receptores ionotrópicos de glutamato, fundamentalmente NMDA, promueve la entrada de $\mathrm{Ca}^{2+}$ al interior de la célula, lo que provoca la activación de calpaínas que rompen p35 y se genera p25. Ésta se une a Cak5 provocando la hiperactivación de la quinasa (Lee et al. 2000; Kusakawa et al. 2000; Nath et al. 2000; Maestre et al. 2008) tal y como muestra la Figura 15.

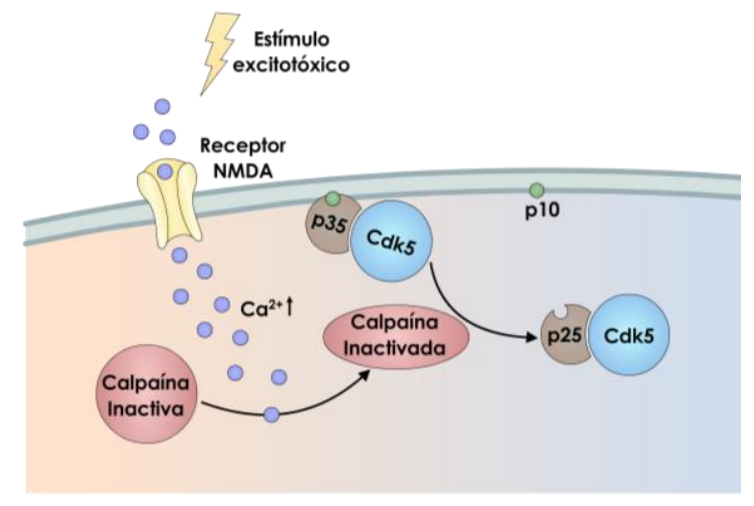

Figura 15. Vía de activación del complejo CDK5-p25. La entrada masiva de $\mathrm{Ca}^{2+}$ en el interior neuronal por sobreestimulación de receptores NMDA activa las calpaínas, y éstas, a su vez, generan $\mathrm{p} 25$ a partir de $\mathrm{p} 35$.

El complejo CDK5-p25. El activador de CDK5 truncado, p25, posee propiedades distintas a su precursor, p35. Así, la vida media de p25 es significativamente más larga que la de p35 (unas 3 veces superior) (Patrick et al. 1998), su unión a CDK5 es más fuerte que con p35 (Amin et al. 2002) y la 
ausencia de unión a la membrana por miristoilación permite actuar al complejo CDK5-p25 en localizaciones subcelulares diferentes, pasando de la periferia celular a regiones más peri-nucleares o al interior del núcleo, alterando así el patrón de sustratos a fosforilar (Kusakawa et al. 2000; Patrick et al. 1999; Asada et al. 2008). De este modo, el complejo CDK5-p25 es más estable y más activo que su precursor (Lopes \& Agostinho 2011; Maestre et al. 2008).

Mientras que p35 se relaciona con supervivencia neuronal, la hiperactivación de CDK5 por p25 tras la sobreestimulación de receptores NMDA, promueve muerte neuronal por apoptosis (Patrick et al. 1999; Maestre et al. 2008; Liu et al. 2015). Las diferentes funciones fisiológicas y patológicas asociadas a los complejos CDK5-p35 y CDK5-p25 se esquematizan a continuación en la Figura 16.

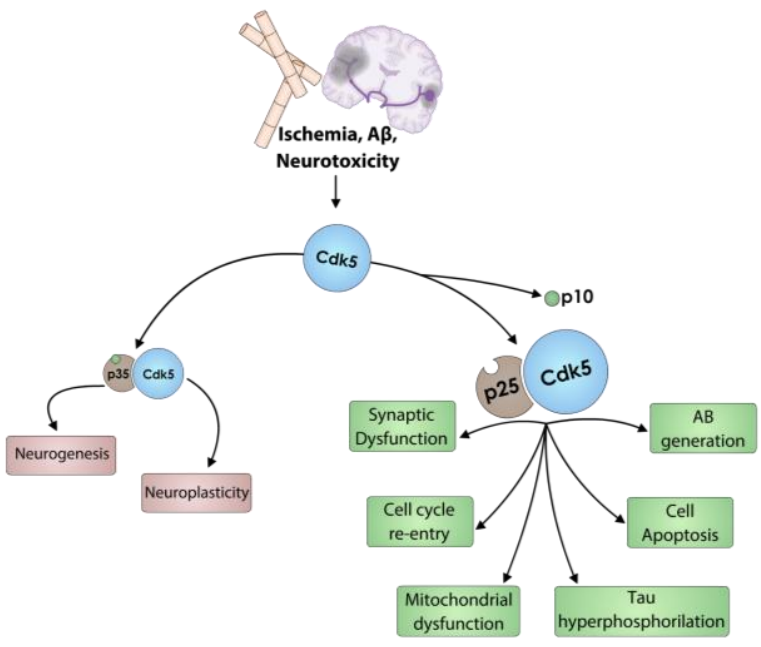

Figura 16. Papel diferencial de CDK5 en supervivencia o muerte neuronal en función de su unión a los activadores p35 o p25. CDK5 puede estar formando complejo tanto con p35 como con su forma truncada, p25. Mientras que el complejo CDK5-p35 está fundamentalmente implicado en neurogénesis y neuroplasticidad, los estímulos neurotóxicos, como la isquemia o el $\beta$ A, favorecen la conversión del dicho complejo en CDK5p25, el cual, fundamentalmente, desempeña acciones deletéreas para la neurona, como son favorecer la generación de $\beta$ A y la hiperfosforilación de Tau, la intervención en la disfunción mitocondrial y sináptica, la re-entrada en ciclo celular, llevando todo ello a la apoptosis neuronal. Modificado de (Liu et al. 2015).

Existen numerosas evidencias de la participación de CDK5 en los procesos fisiopatológicos propios de la EA. Así, fallos en la regulación de CDK5 afectan a varias vías de señalización intracelular en la EA, actuando como un 
enlace entre distintas vías neurotóxicas en la enfermedad (Liv et al. 2015; Lopes \& Agostinho 2011; Cruz \& Tsai 2004b; Lopes et al. 2010):

- Se ha relacionado la EA con una activación aberrante de CDK5 y sUs activadores p35 y p25 (Cruz \& Tsai 2004a; Patrick et al. 1999) y con un incremento en los niveles de la kinasa en cerebros de pacientes con EA (Lee et al. 1999; Crews et al. 2011).

- La forma truncada p25 puede generarse en presencia de BA (Lee et al. 2000).

- CDK5 induce la formación de BA mediante fosforilación de la APP (Liu et al. 2003; Zheng et al. 2005) y de la presenilina 1 (Lau et al. 2002), haciéndolas más propensas al metabolismo amiloidogénico.

- Numerosos estudios in vitro e in vivo muestran la relación de la activación de CDK5 por parte del BA con la fosforilación de Tau y la progresión de los ovillos neurofibrilares (Cruz et al. 2003; Maccioni et al. 2001).

- CDK5 media la reentrada en ciclo celular provocada por BA (Lopes et al. 2009).

\section{3.- FUNCIONES DE p53}

La multitud de funciones atribuidas a p53 pueden dividirse en trasncripcionales y no transcripcionales.

\subsection{1.- Funciones transcripcionales}

Como mejor se ha caracterizado a p53 es en relación a su función como factor de transcripción. Así, p53 se une de manera específica a secuencias del DNA y transactiva un gran número de genes con diversas funciones, entre las que destacan: parada de ciclo celular (p21, 14-3-3s, GADD45), apoptosis (Bax, PUMA, Noxa, Killer/DR5, Fas/CD95, Perp), autofagia (Dram1), antioxidante (Sestrina 1 y 2, GPX1) y metabolismo (TIGAR, SCO2) (Yu et al. 1999; Riley et al. 2008; Mirza et al. 2003; B. Wang et al. 2014). 


\subsection{2.- Funciones independientes de la transcripción}

Además de actuar como factor de transcripción, p53 posee funciones biológicas adicionales que desempeña de forma independiente de transcripción y en distintas localizaciones subcelulares.

- Así, en el núcleo, p53 interviene en procesos de transrepresión, replicación del DNA y recombinación homóloga (Gatz \& Wiesmüller 2006).

- Entre las acciones citoplasmáticas de p53 destacan la duplicación de centrosomas y la inhibición de la autofagia (Green \& Kroemer 2009).

- La función mitocondrial mejor caracterizada de p53 es la inducción de la apoptosis, que se detalla en el apartado 2.3.3.2 del presente documento. Además de inducir la apoptosis, p53 regula la necrosis y autofagia, y ejerce un papel de control de calidad mitocondrial mediante control de la mitofagia, preservación del ADN mitocondrial, regulación del metabolismo de la glucosa y la fosforilación oxidativa, manteniendo el estado redox y regulando la dinámica mitocondrial (D. B. Wang et al. 2014).

\subsection{3- Apoptosis dependiente de p53}

La demostración de que p53 promueve la apoptosis tiene importantes implicaciones en el SNC, en el que la muerte celular se observa tanto durante el desarrollo, como en respuesta al daño y en enfermedades neurodegenerativas, como son la EA y la Enfermedad de Huntington (Raff et al. 1993; Stefanis et al. 1997; Ghavami et al. 2014).

Una vez activado, p53 puede inducir su actividad apoptótica mediante distintas vías:

\subsubsection{1.- Via transcripcional}

Numerosos estudios han establecido que p53 promueve la apoptosis mediante transcripción, ya sea activando o reprimiendo la expresión de un panel de proteínas pro- y anti-apoptóticas, respectivamente (D. B. Wang et al. 2014):

En cuanto a la vía extrínseca, p53 activa transcripcionalmente Fas/Fas ligando y DR5/KILLER (Bieging \& Attardi 2012). 
En cuanto a la vía intrínseca o mitocondrial, p53 induce la expresión de PUMA, Noxa, Bid, Bad, Bax, p53AIP1y APAF1, entre otros (Riley et al. 2008; Mirza et al. 2003; Nakamura 2004). Además, reprime la expresión de BCl-2 (Miyashita T, Krajewski S, Krajewska M, Wang HG, Lin HK, Liebermann DA, Hoffman B 1994) y BCl-xL (Sugars et al. 2001) (D. B. Wang et al. 2014).

\subsubsection{2.- Via no transcripcional}

En la última década se ha evidenciado el papel de p53 como inductor de apoptosis de manera no transcripcional (Haupt et al. 1995), que incluye su acción directa en la mitocondria (Vaseva \& Moll 2009; Green \& Kroemer 2009) e interacciones proteína-proteína (Green \& Kroemer 2009; FernandezFernandez \& Sot 2011).

Varios estudios han descrito la presencia de p53 en fracciones mitocondriales tras sufrir un estrés (Sansome et al. 2001; Marchenko et al. 2000). Consecuentemente, la mera presencia de p53 en la membrana mitocondrial externa parece ser suficiente para desencadenar apoptosis en ausencia de una señal externa de estrés (Marchenko et al. 2000; Mihara et al. 2003; GomezSanchez et al. 2011).

En respuesta a estrés, un pool citoplasmático de p53 se transloca rápidamente a la membrana mitocondrial externa, donde se comporta como una proteína "BH3-only", la cual interacciona físicamente con miembros antiapoptóticos (BCl-xL, BCl-2) y/o pro-apoptóticos como PUMA (ㅁ53 upregulated modulator of apoptosis), Bax y Bak. Esta familia es un grupo de proteínas definido por la presencia de una región con similitud de secuencia, llamada dominio BH3, y por ello son llamadas proteínas "BH3-only". Esta actividad de p53 como proteína "BH3-only" sorprende en cierta medida ya que carece de dominio BH3. Estas interacciones de p53 con miembros de la familia Bcl-2 facilitan la permeabilización de la membrana mitocondrial externa mediada por Bax/Bak para dar lugar a la liberación del Citocromo c y la activación de la cascada de caspasas (Marchenko et al. 2000; Mihara et al. 2003; Arima et al. 2005; Gomez-Sanchez et al. 2011).

Existen dos tipos de proteínas BH3: activadoras y facilitadoras (Letai et al. 2002). Los activadores se unen de forma transitoria y activan directamente a Bax/Bak en la mitocondria, mientras que los facilitadores permiten la activación 
de Bax de manera indirecta al formar complejo con Bcl-2 y Bcl-xL. PUMA actúa y como activador (Chipuk et al. 2004) como facilitador (Kuwana et al. 2005) de p53.

PUMA parece ser el enlace entre las vías apoptóticas de p53 dependiente e independiente de transcripción (Vousden 2005), ya que una vez inducida su expresión por p53 tras un estrés, se transloca a la mitocondria, donde interacciona con BCl-xL permitiendo la liberación de p53 para activar a Bax (Zilfou \& Lowe 2009).

\subsubsection{3.- Apoptosis dependiente de p53 en la Enfermedad de Alzheimer}

Existen evidencias de que p53 desempeña un papel esencial en la muerte neuronall en muchos desórdenes neurológicos, obtenidas tanto de modelos in vitro como in vivo (Chang et al. 2012; Culmsee \& Mattson 2005). En este sentido, diversos estudios han implicado a p53 en la muerte neuronal tanto en enfermedades neurodegenerativas agudas como el ictus (Crumrine et al. 1994; Culmsee et al. 2001) y el traumatismo cerebral (Napieralski et al. 1999), como en enfermedades neurodegenerativas crónicas, como son la enfermedad de Parkinson (Duan et al. 2002) y la EA (De La Monte et al. 1997; Culmsee et al. 2001).

Tanto en modelos animales como en cerebros de pacientes con EA se han descrito evidencias de esta relación (Sajan et al. 2007). Se han observado aumentos en la inmunorreactividad de p53 en neuronas dañadas en cerebros de pacientes con EA (De La Monte et al. 1997). Además, se ha encontrado un patrón similar en cerebros de animales transgénicos que sobre-expresan BA1-42 (LaFerla et al. 1996). En este modelo de ratón transgénico, se han asociado niveles elevados de p53 en neuronas con expresión citoplasmática de BA y con eventos característicos de la apoptosis, como rotura de cadenas del DNA. Además, se han detectado elevados niveles de expresión de factores apoptóticos, incluída la proteína p53, en cerebros de pacientes con Síndrome de Down, los cuales comparten algunas de las alteraciones características de la EA (de la Monte 1999). Más aún, estudios en neuronas primarias humanas muestran que el BA42 intracelular es capaz de provocar apoptosis neuronal a través de p53 y Bax (Y. Zhang et al. 2002). La implicación de p53 en la muerte 
neuronal en la EA no se reduce sólo a las neuronas, ya que la inhibición de las vías de señalización dependientes de p53 en microglía es capaz de atenuar la neurotoxicidad inducida por el BA25-35.

Sin embargo, no todos los datos que relacionan p53 con la EA van en este sentido. Así, según Merlo et al., p53 parece tener un papel neuroprotector ante la muerte neuronal provocada por la presencia de agregados de Tau. Así, p53 prevendría la neurodegeneración mediante la regulación de genes sinápticos como BIN1 o el gen de la sinaptotagmina. La expresión de estos genes podría inducir una recuperación de la función sináptica, que es uno de los acontecimientos tempranos en la EA y que conduce a la pérdida de funciones cerebrales (Merlo et al. 2014). Además, en un modelo de toxicidad por BA en keratinocitos humanos en los que inactivan p53, Blasco et al. concluyen que la apoptosis en este tipo celular debida a la toxicidad por $\beta A$ es independiente de p53 (Blasko et al. 2000).

Pese a que la implicación de p53 en el Alzheimer parece estar establecida, el papel que esta molécula juega en la enfermedad es controvertido. Además, los mecanismos moleculares responsables de la estabilización, activación e inducción de la apoptosis por parte de p53 no se han esclarecido hasta el momento.

\section{4.- POLIMORFISM0 Tp53 Arg72Pro}

El polimorfismo Arg72Pro del gen Tp53 (rs1042522) se localiza en el codón 72 del exón 4 de dicho gen. Este SNP se debe a la sustitución de un único

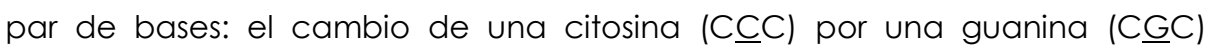
(Matlashewski et al. 1987).

Se han observado grandes diferencias de frecuencias alélicas en el codón 72 en función de la etnia. En el hemisferio norte, el alelo Pro 72 muestra un gradiente norte-sur (Sjalander et al. 1996), desde una frecuencia de 0,17 en suecos a 0,63 en los nigerianos (Beckman et al. 1994). En Europa Occidental, América del Norte, Central y Sur y Japón, el alelo más común es $\operatorname{Arg}^{72}$, con frecuencias que oscilan entre 0,60 y 0,83 (Pinto et al. 2008). Sin embargo, las frecuencias de Pro $^{72}$ más elevadas (superiores a 0,40 ) se han observado en 
afroamericanos (Jin 1995, Weston 1992) y en chinos (Peixoto Guimaraes-2001 Ngan 1999)(Pinto et al. 2008). Se ha sugerido que esta correlación linear entre el alelo Pro ${ }^{72}$ y la latitud se debe a una selección de este alelo en individuos de ambientes expuestos a mayor luz ultravioleta (Beckman et al. 1994).

La sustitución del par de bases en el codón 72 provoca el cambio de un aminoácido prolina por uno arginina (Matlashewski et al. 1987) en el Dominio Rico en Prolina (PRD) de la proteína p53, que tal y como se ha indicado en el apartado 2.1, es esencial para su actividad pro-apoptótica. Este cambio en la estructura primaria de la proteína dentro de la región PRD es responsable de las diferencias observadas en ambas variantes polimórficas (Thomas et al. 1999):

En cuanto a la actividad transcripcional, la variante Pro ${ }^{72}$ es más activa que la $\mathrm{Arg}^{72}$. Esta diferencia no sería debida a diferencias en la capacidad de unión específica al ADN sino a diferencias en la capacidad de unión a elementos de la maquinaria transcripcional (Thomas et al. 1999).

Se han reportado diferencias en cuanto a la actividad apoptótica de ambas variantes. Algunos autores no han observado diferencias en la capacidad apoptótica pero sí en la cinética de la misma, siendo más rápida la variante Arg $^{72}$ (Thomas et al. 1999). Otros estudios, sin embargo, sí encuentran diferencias en cuanto a la capacidad de inducir apoptosis. Un estudio muestra que la mayor capacidad apoptótica observada en la variante $\mathrm{Arg}^{72}$ se debe a una mayor localización mitocondrial asociada a un exporte nuclear más eficiente que en la variante Pro $^{72}$ (Dumont et al. 2003). Estudios más recientes muestran que la mayor eficiencia apoptótica tras daño isquémico asociada a la variante $\mathrm{Arg}^{72}$ se debe a la traslicación por parte de p53-Arg72 a la mitocondria, donde se une e inactiva a Bcl-xL. Así, el secuestro de BCl-XL da lugar a la salida de citocromo c al citosol, así como a la activación de la vía intrínseca de la apoptosis por activación de la caspasa 9 (Gomez-Sanchez et al. 2011 ).

Estas diferencias en cuanto a actividades biológicas observadas en ambas variantes de la proteína p53 tienen repercusiones a nivel clínico. Así, teniendo en cuenta la diferente capacidad apoptótica de ambas variantes, se ha estudiado la influencia del polimorfismo Arg72Pro ampliamente en cáncer y 
en enfermedades neurodegenerativas (Gomez-Sanchez et al. 2011; Lanara et al. 2013).

En este sentido, se ha establecido una relación entre el SNP Arg72Pro de Tp53 y el pronóstico funcional en pacientes que han sufrido un ictus (GomezSanchez et al. 2011). El estudio muestra que el genotipo Arg/Arg se relaciona con un peor estado funcional tras ictus, tanto isquémico como hemorrágico (Gomez-Sanchez et al. 2011).

En glaucoma primario de ángulo abierto, primera causa de neurodegeneración óptica, se ha descrito la importancia del polimorfismo Arg72Pro en cuanto al riesgo, de manera que los pacientes con mayor riesgo son los que portan el alelo Pro (Neamatzadeh et al. 2015).

Se han publicado numerosos estudios en pacientes sobre la influencia del polimorfismo Arg72Pro en relación al riesgo (Lanara et al. 2013), pronóstico (Cescon et al. 2009) y respuesta al tratamiento (Tecza et al. 2015) de una amplia variedad de tipos de cáncer. Así, se ha descrito que ser portador del alelo Pro ${ }^{72}$ incrementa el riesgo y susceptibilidad en cáncer de pulmón (Qiao \& Hu 2013) y mama (Gonçalves et al. 2014), entre otros (Whibley et al. 2009). 


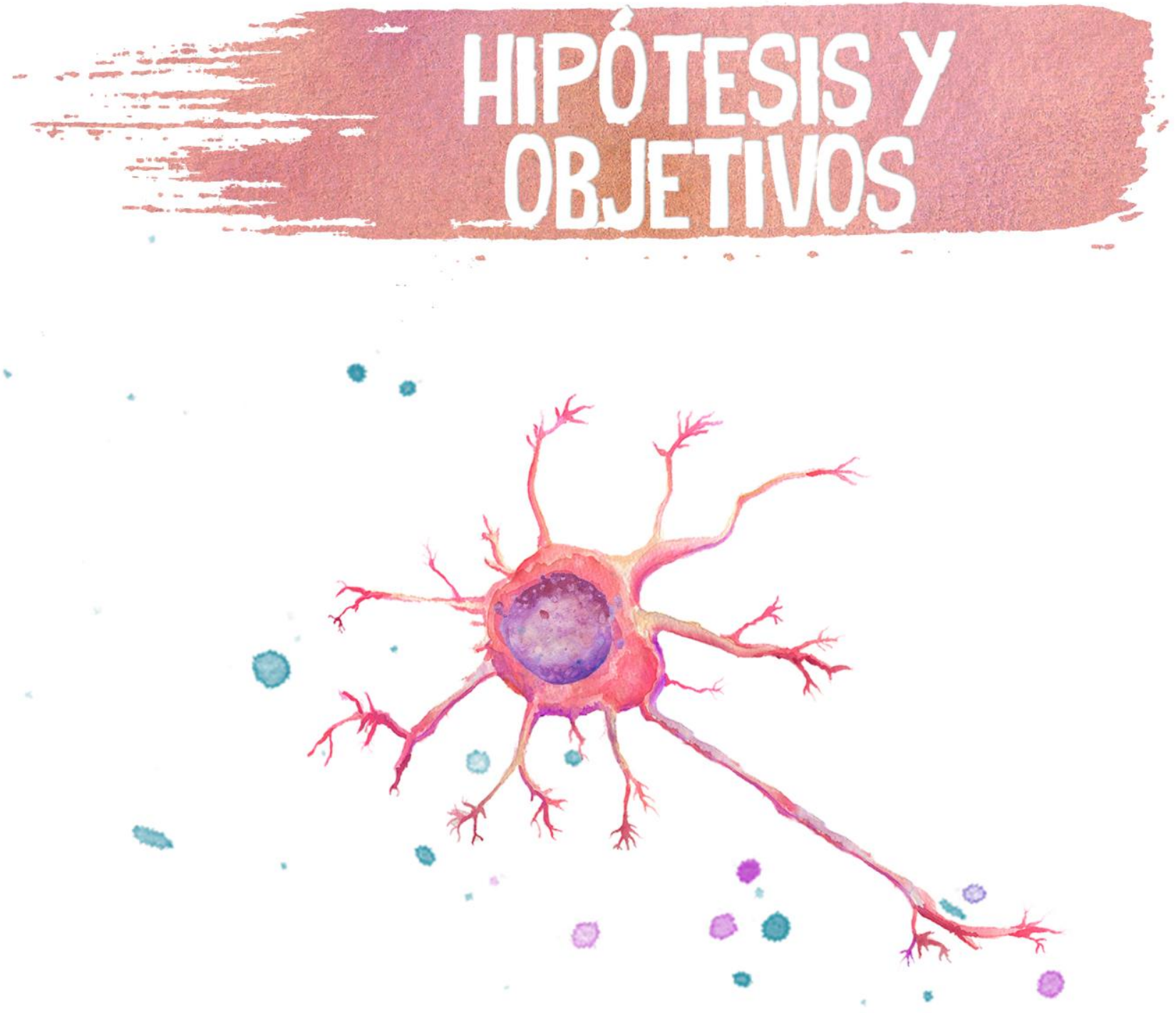



\section{1.- HIPÓTESIS}

La oligomerización de péptidos B-amiloide representa un evento central en la etiopatología de la enfermedad de Alzheimer. Así, oligómeros de BA desencadenan cascadas de señalización que implican, entre otros, la alteración de la homeostasis del calcio, producción de especies reactivas de oxígeno, procesos inflamatorios y disfunción mitocondrial, culminando todo ello en la apoptosis neuronal. Aunque está bien establecido el efecto neurotóxico del $B A$, se desconocen los mecanismos moleculares implicados en dicha neurotoxicidad, lo que explica, al menos en parte, la ausencia de un tratamiento específico y eficaz en esta grave enfermedad.

Se ha descrito la acumulación de la proteína p53 en áreas cerebrales dañadas de enfermos y modelos animales de EA, lo que le identifica como una posible diana molecular implicada en el proceso neurodegenerativo. Dado la potente actividad pro-apoptótica de p53, especialmente en neuronas, nosotros pensamos que la acumulación de p53 y proteínas relacionadas podría desempeñar una función esencial en la neurotoxicidad del BA. Además, el estudio de los mecanismos moleculares implicados en la cascada neurotóxica del BA nos permitirá identificar nuevas dianas moleculares con el objetivo de establecer nuevas vías de actuación terapéutica en la EA.

Hasta el momento, la variabilidad genética del polimorfismo del gen ApoE es el factor más importante asociado a la predisposición de la EA. Recientemente, hemos descrito que el SNP humano Arg72Pro de p53 regula la susceptibilidad de las neuronas a la apoptosis causada por la isquemia y, en consecuencia, determina el pronóstico funcional de pacientes de ictus. Aquí proponemos que el SNP podría tener un efecto más general, de manera que también estaría implicado en la susceptibilidad de las neuronas al BA, lo que podría condicionar la predisposición a sufrir la enfermedad. 


\section{2.- OBJETIVOS}

A la vista de los antecedentes e hipótesis, nos propusimos los siguientes objetivos:

1. Caracterizar la función de p53 en la vía de señalización responsable de la apoptosis neuronal causada por el B-amiloide

2. Investigar el efecto del polimorfismo humano Arg72Pro de Tp53 en la susceptibilidad de las neuronas al B-amiloide

3. Estudiar el impacto de las variantes polimórficas de ApoE sobre el efecto modulador del polimorfismo Arg72Pro de Tp53 en la neurotoxicidad del B-amiloide 

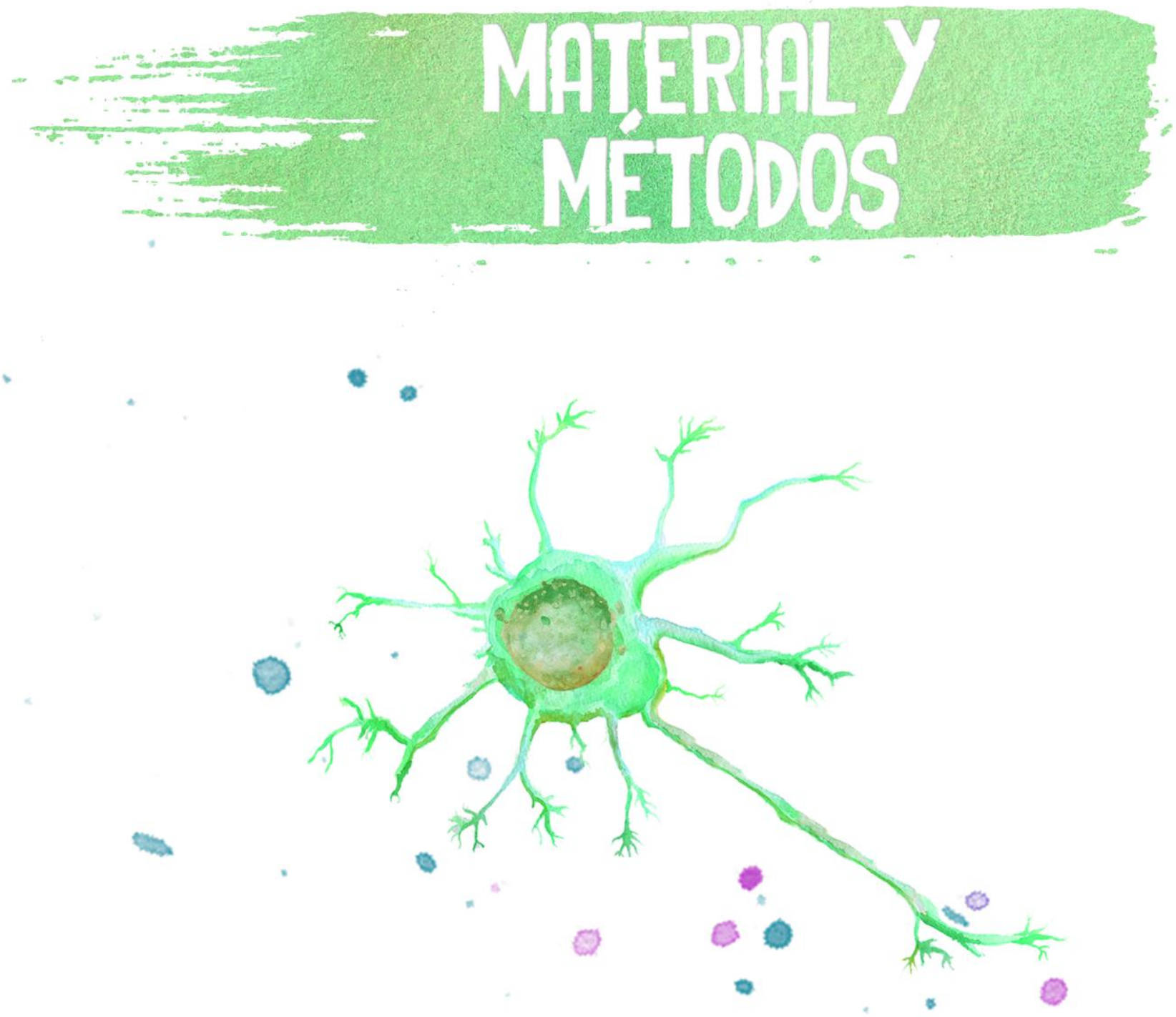



\section{CULTIVO PRIMARIO DE NEURONAS}

\subsection{ESPECIES ENSAYADAS Y CONDICIONES DEL ANIMALARIO}

Para la realización del cultivo primario de neuronas corticales, empleamos de ratón Mus musculus, L.1758 (Muridae, Roden, Mammalia) de la cepa C57 de 14,5 días de gestación, así como embriones Wild type y Knock-out para la proteína p53 (posterior genotipado en 1.3), criadas y suministradas por el Servicio de Experimentación Animal de la Universidad de Salamanca. También se utilizaron embriones de 14,5 días de gestación procedentes de ratones Knock-in para el polimorfismo humano de p53 Arg72Pro, que han sido cedidos por el Prof. G. David Jonhson (The University of Texas MD Anderson Cancer Center, Smithville, TX) y se encuentran ya en el animalario del Servicio de Experimentación Animal de la Universidad de Salamanca.

Los animales se criaron en jaulas y se mantuvo un ritmo de oscuridad de 12 horas, con la fase de oscuridad entre las 20:00 y las 8:00 horas del día siguiente. La humedad osciló entre el $45 \%$ y el $65 \%$ y la temperatura entre los $20^{\circ} \mathrm{C}$ y los $25^{\circ} \mathrm{C}$. Los animales se alimentaron ad libitum con una dieta sólida estándar ( $17 \%$ de proteínas, 3\% de lípidos, $58,7 \%$ de glúcidos, $4,3 \%$ de celulosa, $5 \%$ de minerales y $12 \%$ de humedad) y tuvieron en todo momento acceso libre al agua de bebida.

La edad gestacional de las hembras se controló limitándose a una noche el tiempo de cohabitación de las hembras vírgenes con los machos. A las 9:00 horas de la mañana siguiente se separaron aquellas que presentaban espermatozoides en el frotis vaginal, acompañados de células epiteliales de la vagina características del día fértil del estro. Bajo estas condiciones, el periodo de gestación se asume que es de 19,5 días para la ratona.

Todos los tratamientos con animales cumplen con la normativa vigente de la comisión europea del 18.06.2007 (2007/526/CE) y la legislación española (RD/1201/2005) sobre las líneas directrices relativas al alojamiento y cuidado de los animales utilizados para la experimentación y otros fines científicos. 


\subsection{CULTIVO PRIMARIO DE NEURONAS CORTICALES}

Para la realización del cultivo primario de neuronas corticales se emplearon embriones de 14,5 días para las ratonas. Todo el proceso se realizó en condiciones de esterilidad en una cabina de flujo laminar (TC48, Gelaire Flow Laboratories, Virginia, EEUU) y a temperatura ambiente (excepto la tripsinización que se realizó a $37^{\circ} \mathrm{C}$ ). Tras sacrificar las gestantes por dislocación cervical con previa anestesia con $\mathrm{CO}_{2}$ inhalado, se procedió a una rápida histerectomía para la obtención de los embriones. Con ayuda de tijeras, pinzas y papel impregnado en etanol al $70 \%$ se retiró el cráneo y se extrajo el cerebro (sin cerebelo ni bulbo). El tejido se disgregó en la solución de disgregación ( $\mathrm{NaCl}$ $116 \mathrm{mM}, \mathrm{KCl} 5,4 \mathrm{mM}, \mathrm{NaH}_{2} \mathrm{PO}_{4} 1,01 \mathrm{mM}, \mathrm{MgSO}_{4} 1,5 \mathrm{mM}, \mathrm{NaHCO}_{3} 26 \mathrm{mM}$, Dglucosa $4 \mathrm{mM}$, rojo fenol $10 \mathrm{mg} / \mathrm{l}$, albúmina fracción $\vee$ al 0,3\% p/v y DNAasa Tipo ( $20 \mu \mathrm{g} / \mathrm{ml} \mathrm{pH} \mathrm{7,1),} \mathrm{utilizando} \mathrm{un} \mathrm{bisturí} \mathrm{y} \mathrm{se} \mathrm{dejó} \mathrm{sedimentar} \mathrm{el} \mathrm{tejido} \mathrm{durante} 4$ minutos. Tras retirar el sobrenadante, el tejido disgregado se incubó durante 10 minutos a $37^{\circ} \mathrm{C}$ en la solución de tripsinización (solución de disgregación suplementada con tripsina al 0,025\% p/v), agitándola suavemente a intervalos de 4 minutos.

La tripsinización se detuvo añadiendo suero fetal de ternera (FCS; Roche, Roche Applied Science, Barcelona, España) a una concentración final del $10 \%(\mathrm{v} / \mathrm{v})$. A continuación, se centrifugó durante 5 minutos a $500 \times \mathrm{g}$. Seguidamente se aspiró el sobrenadante y el sedimento se resuspendió suavemente unas 9 veces en la solución de disgregación con una pipeta Pasteur de vidrio siliconada. Tras un periodo de sedimentación de 4 minutos, el sobrenadante que contenía las células disociadas se recogió cuidadosamente en un tubo de plástico tipo "Falcon" de 50 mL. Este proceso se repitió una vez más. La combinación de los sobrenadantes obtenidos se centrifugó durante 5 minutos a 500 x g. Las células se resuspendieron en el medio de cultivo específico para el crecimiento neuronal Neurobasal suplementado con B27 2\% y glutamina $2 \mathrm{mM}$ (Life Technologies, California, EEUU; antibiótico: penicilina G $100 \mathrm{U} / \mathrm{ml}$; estreptomicina $100 \mu \mathrm{g} / \mathrm{ml}$; anfotericina B $0.25 \mu \mathrm{g} / \mathrm{ml}$ ). Se realizó el conteo de las células viables, tras la tinción de la suspensión celular con azul de tripano (suspensión celular $10 \mu \mathrm{l}$; medio de cultivo $30 \mu \mathrm{l}$; azul de tripano $40 \mu \mathrm{l}$ ), empleando la cámara cuenta glóbulos de Neubaver (Zeiss, Oberkochen, Alemania) y el microscopio de contraste de fases. 
Las células se resuspendieron en medio de cultivo específico para el crecimiento neuronal (Neurobasal suplementado con B27 2\% y glutamina 2 mM; antibiótico: penicilina G $100 \mathrm{U} / \mathrm{ml}$; estreptomicina $100 \mu \mathrm{g} / \mathrm{ml}$; anfotericina B 0.25 $\mu \mathrm{g} / \mathrm{ml})$. Se realizó el conteo de las células viables, tras la tinción de la suspensión celular con azul de tripano (suspensión celular $10 \mu$ l; medio de cultivo $30 \mu \mathrm{l}$; azul de tripano $40 \mu \mathrm{l}$ ), empleando la cámara cuenta glóbulos y el microscopio de contraste de fases.

La densidad de siembra fue de $1,8 \cdot 10^{5}$ células $/ \mathrm{cm}^{2}$, sobre placas de cultivo de poliestireno (Nunc. Thermo Fisher Scientific, Roskiltd, Dinamarca) de 12, 24 y 96 pocillos, con una superficie de 4,2 y $0,32 \mathrm{~cm}^{2} /$ pocillo respectivamente, al igual que placas de 20,60 y $145 \mathrm{~cm}^{2}$, previamente tratadas con $10 \mu \mathrm{g} / \mathrm{ml}$ de poli-D-lisina (PDL) (Sigma Aldrich, Misuri, EEUU). Las células se mantuvieron en un incubador (Forma 310, Thermo Scientific, Barcelona, España) termostatizado a $37^{\circ} \mathrm{C}$ en atmósfera húmeda al $5 \%$ de $\mathrm{CO}_{2}$. Al tercer día en cultivo el medio se reemplazó por medio fresco. Las células se utilizaron en el día 8-9. Estos cultivos de neuronas responden a la activación química de mensajeros intracelulares que sugieren la presencia de receptores sinápticos funcionales (Almeida et al. 2004).

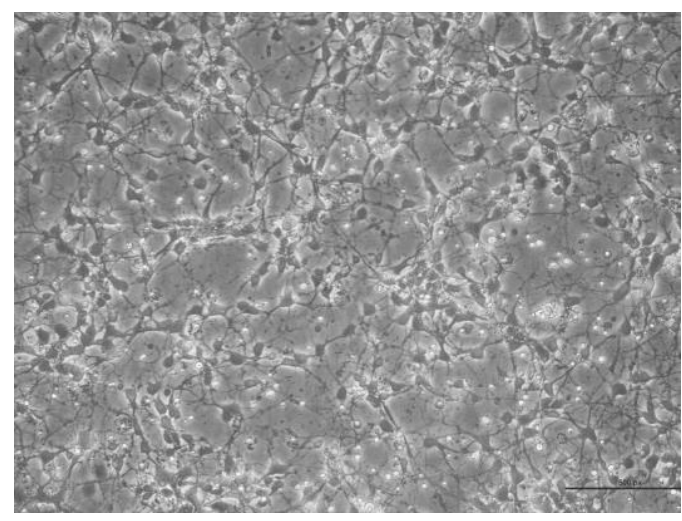

Figura 17. Neuronas corticales en cultivo primario. Microfotografías de contraste de fases de neuronas corticales primarias de ratón a 9 DIV.

\subsection{IDENTIFICACIÓN GENOTÍPICA DE EMBRIONES}

Para la identificación genotípica de los embriones de ratón se empleó la técnica de la reacción en cadena de la polimerasa (PCR) para amplificar 
secuencias específicas de los distintos alelos de p53, identificando así los individuos wild type (Wt), los heterocigotos y los Knock-out (Ko) de p53.

\subsection{1.- Extracción del DNA}

En primer lugar se extrae ADN genómico mediante digestión de un fragmento de la cola (2-4 mm) del embrión durante $40-60$ minutos a $55^{\circ} \mathrm{C}$ en agitación (1300 rpm) con proteinasa K (100 $\mu \mathrm{g} / \mathrm{ml}$, Sigma-Aldrich), en un medio tamponado a $\mathrm{pH}=8,5$ que contiene $\mathrm{KCl}(50 \mathrm{mM}), \mathrm{MgCl}_{2}(1,5 \mathrm{mM})$, Tris- $\mathrm{HCl}(10$ $m M)$, gelatina al 0,01\% (p/v), Nonidet P-40 al 0,45\% (v/v) y Tween-20 al 0,45\% $(\mathrm{v} / \mathrm{v})$. Terminada la reacción de digestión, se inactiva la proteinasa K con calor, a $95^{\circ} \mathrm{C}$ durante 15 minutos. Posteriormente se centrifugan las muestras a $7000 \mathrm{x}$ $g$ durante 15 segundos para separar los restos de tejido no digerido. En el sobrenadante resultante se mide la concentración de ADN en un espectrofotómetro UV-Vis Nanodrop 2000 (Thermo Scientific). En una alícuota de cada muestra se realiza la correspondiente dilución para lograr una concentración final igual en todas las muestras, y se analiza el genotipo de los animales mediante PCR.

\subsection{2.- Reacción en cadena de la polimerasa (PCR)}

La identificación genotípica de los animales se realizó mediante la amplificación de fragmentos específicos del gen de p53. Para cada reacción se preparó una mezcla de reacción compuesta por: 14,4 $\mu \mathrm{l}$ de agua libre de nucleasas, 2,5 $\mu$ l de Buffer EcoTaq (10X), $5 \mu$ de Betaína (5 M), 0,75 $\mu \mathrm{l} \mathrm{de} \mathrm{MgCl}_{2}$ (50 mM), 0,5 $\mu$ l de dNTPs (10 mM), 0,25 $\mu$ l de cada uno de los primers (Fw.p53, Rv.p53 y Fw.pPNT; $100 \mu$ M cada uno), 0,3 $\mu$ l de EcoTaq y 1,5 $\mu$ l de muestra.

Las secuencias de los primers empleadas para amplificar nuestros fragmentos específicos son las siguientes:

$\begin{array}{lc}\text { Fw.p53 } & \text { 5'-TGG TTT GTG CGT CT AGA GAC AGT 3' } \\ \text { Rv.p53 } & \text { 5'-AAG GAT AGG TCG GCG GTT CAT 3' } \\ \text { Fw.pPNT } & \text { 5'-CCA GCT CAT TCC TCC CAC TCA 3' } \\ \text { briones de p53. } & \end{array}$

El Fw.pPNT es un oligo que reconoce secuencias del vector que se utiliza para generar los individuos $\mathrm{KO}$ p53 y es necesario para poder amplificar el alelo KO durante la PCR. 
La PCR se realizó en el termociclador Eppendorf (Mastercicler®) ep, Eppendorf, Eppendorf Inc.; Enfield, EEUU), con temperatura de anillamiento de $58^{\circ} \mathrm{C}$ y 35 ciclos de amplificación, siguiendo el esquema:

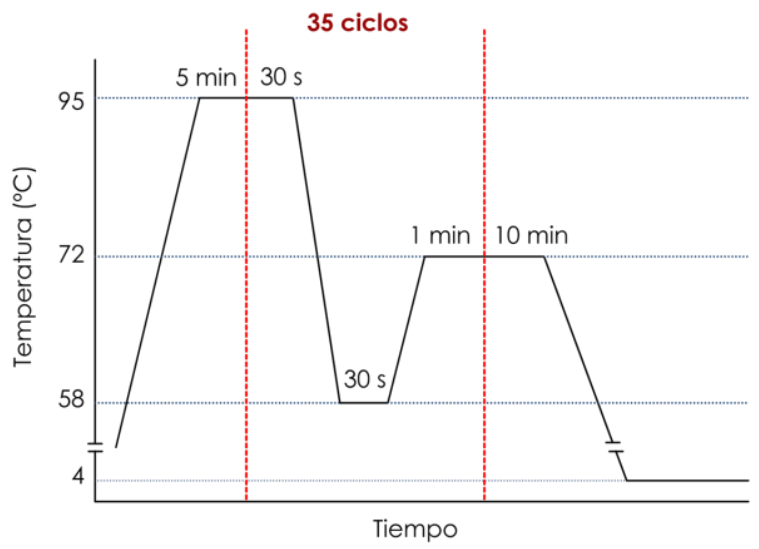

Figura 18. Esquema de PCR. El esquema muestra las temperaturas de los distintos pasos y los ciclos de amplificación empleados para identificar los individuos Wt y Ko de p53.

\subsection{3.- Electroforesis en geles horizontales de agarosa}

Los productos de la PCR se analizaron mediante electroforesis en gel de agarosa al 2\% (p/v) en tampón Tris-acetato-EDTA (ácido etilen-di-amino-tetraacético) (TAE/EDTA) al que se le añadieron $6 \mu \mathrm{l} / 100 \mathrm{ml}$ de Midori Green. Como marcador de peso molecular se utilizó el Plus DNA ladder 1Kb (Thermo Fischer Scientific).

La visualización de las distintas bandas de DNA amplificado se realizó mediante la utilización de un transiluminador (Gel Doc XR, Bio-Rad Laboratories, S.A.; Hercules, California, EEUU) y el software Quantity One (Bio-Rad Laboratories). 


\section{2.- MODELO IN VITRO DE NEUROTOXICIDAD POR ß- AMILOIDE.}

El modelo de neurotoxicidad in vitro consiste en el tratamiento de las neuronas con oligómeros del péptido B-Amiloide 25-35 (bioNova Científica S.L., Madrid, España). Recurrimos al empleo de oligómeros al ser consideradas las especies más neurotóxicas en la EA, así como al empleo del BA25-35 por ser el dominio activo del péptido completo, tal y como se recoge en el apartado 1.2.1.1 de la introducción del presente documento.

Para la obtención de oligómeros, primeramente se disolvieron los péptidos en agua ultrapura a una concentración de $1 \mathrm{mM}$. Los péptidos disueltos se incubaron durante 3 días a $37^{\circ} \mathrm{C}$ para permitir su agregación.

Así, a las neuronas en cultivo primario se les reemplazó el medio de cultivo por medio fresco con $10 \mu \mathrm{M}$ de BA25-35 oligomerizado 24 horas antes de la utilización de las mismas. A las células control se les reemplazó el medio por medio fresco en ausencia de BA. Como control adicional se emplearon células a las que se les reemplazó el medio por medio fresco con $10 \mu \mathrm{M}$ de BA35-25 (bioNova Científica S.L.) manipulado de la misma manera que el BA25-35, con la particularidad de que el BA35-25 actúa como control debido a que no posee capacidad de agregarse para formar oligómeros.

Para la realización de perfiles temporales, el medio se reemplazó por medio fresco con $10 \mu \mathrm{M}$ de BA25-35 a las 2, 4, 8, 16 y 24 horas antes de la recogida de muestras.

En los estudios inmunocitoquímicos se empleó el péptido BA25-35 biotililado (bioNova Científica S.L.).

\section{3.- TRANSFECCIONES CELULARES}

\section{1.- SILENCIAMIENTOS}

Para reducir la expresión de específica de ciertas proteínas se emplearon siRNAs (RNA pequeño de interferencia). Los siRNA se introdujeron en las células mediante transfección, empleando para ello el reactivo catiónico 
Lipofectamine RNAIMAXTM (Life Technologies) de acuerdo a las instrucciones del fabricante. Los silenciamientos proteicos se verificaron mediante transferencia tipo Western o mediante reacción en cadena de la polimerasa a tiempo real (RT-qPCR).

Las secuencias y las condiciones de los silenciamientos realizados quedan recogidas en la Tabla 7.

\begin{tabular}{|c|c|c|c|c|}
\hline SiRNA & Diana & Secuencia 5'-3' & Condiciones & Referencia \\
\hline siCdk5 & Cdk5 & AAGCCGUACCCGAUGUAUC & $\begin{array}{c}100 \mathrm{nM}, 3 \\
\text { días }\end{array}$ & $\begin{array}{l}\text { (Maestre et } \\
\text { al. 2008; } \\
\text { Zheng et al. } \\
\text { 2007) }\end{array}$ \\
\hline Sip53 & p53 & CCACUUGAUGGAGAGUAUUUU & $\begin{array}{c}100 \mathrm{nM}, 2 \\
\text { días }\end{array}$ & $\begin{array}{c}\text { (Hasegawa } \\
\& \\
\text { Yoshikawa } \\
\text { 2008) }\end{array}$ \\
\hline siluc & Luciferasa & CUGACGCGGAAUACUUCGAUU & $\begin{array}{c}\text { Como el } \\
\text { siRNA de } \\
\text { interés }\end{array}$ & $\begin{array}{l}\text { (Cuende et } \\
\text { al. 2008) }\end{array}$ \\
\hline
\end{tabular}

Tabla 7. siRNAs empleados para reducir la expresión de Cdk5 y p53. La tabla

recoge las secuencias y condiciones de transfección de cada uno de los siRNA empleados.

\section{2.- PLÁSMIDOS}

Para conseguir la expresión de específica de cada una de las variantes polimórficas del gen de la ApoE (E2, E3 y E4), se emplearon plásmidos cedidos por Andrew S. Plump (Rockefeller University, NY, EEUU), que contienen cada una de las variantes. Los plásmidos se introdujeron tanto en neuronas p53-Pro72 como en las p53-Arg ${ }^{72}$ mediante transfección, empleando para ello el reactivo catiónico Lipofectamine LTX Plus ReagentTM (Life Technologies) de acuerdo a las instrucciones del fabricante, 12 horas antes de la recolección de las mismas. A estos efectos, los plásmidos se utilizaron a una concentración final de 1,6 $\mu \mathrm{g} / \mathrm{ml}$.

\section{ㄴ.-- TRATAMIENTOS CELULARES}

Las neuronas en cultivo primario se trataron durante 24 horas con Pifitrina- $\alpha$ (PFT $\alpha$ ) (Sigma Aldrich) con la finalidad de inhibir la actividad transcripcional de p53. Para ello se reemplazó el medio de cultivo por medio 
fresco con PFTa 10 MM 24 horas antes de la utilización de las células. A las células control se les reemplazó el medio con medio fresco en ausencia de PFT $\alpha$.

Las neuronas en cultivo primario se trataron durante 24 horas con MK801 (Sigma Aldrich)) con la finalidad de inhibir de forma selectiva y no competitiva los receptores NMDA. Para ello se reemplazó el medio de cultivo por medio fresco con MK-801 $10 \mu \mathrm{M} 24$ horas antes de la utilización de las células. A las células control se les reemplazó el medio con medio fresco en ausencia de MK-801.

\section{5.- DETERMINACIÓN DE LA APOPTOSIS NEURONAL POR CITOMETRÍA DE FLUJO}

La muerte celular por apoptosis se determinó mediante citometría de flujo, tras teñir las células con anexina $\vee$ conjugada con DY634 (Immunostep, Salamanca, España) y 7-amino-actinomicina D (7-AAD) (Becton Dickinson Biosciences, Nueva Jersey, EEUU). El método se basa en la detección de la fosfatidilserina, un fosfolípido que en las células apoptóticas se transloca del interior al exterior de la membrana plasmática. La anexina $\vee$ es una proteína anticoagulante vascular que posee una gran afinidad por la fosfatidilserina. Por ello, unida a un fluorocromo adecuado, permite la identificación de las células apoptóticas tras su unión a dicho fosfolípido localizado en su superficie celular. Sin embargo, la anexina $\vee$ también es capaz de unirse a la fosfatidilserina en el interior de aquellas células que no tienen intacta su membrana plasmática (consideradas como necróticas). Por ello, junto con la anexina $\vee$ se utilizó un colorante que se une específicamente al DNA de las células necróticas, el 7AAD, para así poder identificar exclusivamente las células apoptóticas. De este modo, sólo aquéllas células inmunorreactivas para la anexina $\vee$, que mostraron ser negativas para el 7- AAD, se consideraron apoptóticas.

Las células se despegaron, se resuspendieron en Binding Buffer (BB: $10 \mathrm{mM}$ Hepes, $\left.140 \mathrm{mM} \mathrm{NaCl}, 2,5 \mathrm{mM} \mathrm{CaCl}_{2} ; \mathrm{pH}=7,4\right)$ y se incubaron con Anexina V-DY634 y 7-AAD durante 15 minutos a temperatura ambiente y en oscuridad. Tras la incubación se añadió más BB para dejar las células a una concentración de $\sim 10^{6} / \mathrm{ml}$. 
Las señales de la anexina $\vee$ y del 7-AAD se analizaron en los canales FL4 Y FL3, respectivamente, de un citómetro de flujo FACScalibur (BD Biosciences), equipado con un haz láser de argón de $15 \mathrm{~mW}$ sintonizado a $488 \mathrm{~nm}$, utilizando los programas CellQuest ${ }^{T M}$ para adquisición de eventos y Paint-A- Gate ${ }^{T M}$ PRO para el análisis de los mismos (BD Biosciences). Los resultados se expresaron como porcentaje de neuronas apoptóticas, correspondientes a las neuronas Anexina+/7AAD-. En determinados experimentos, las determinaciones se realizaron previa selección de poblaciones celulares identificadas mediante marcaje fluorescente con GFP.
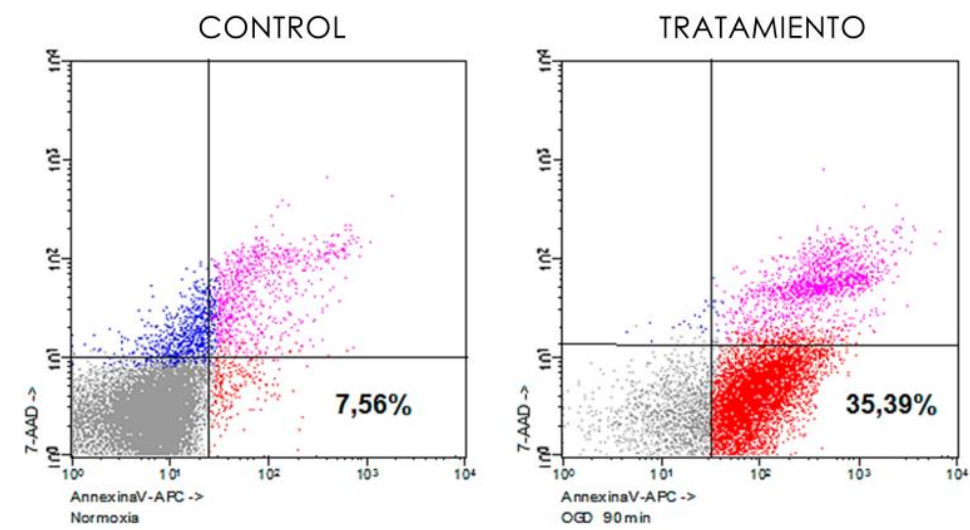

Figura 19. Registro de apoptosis medida por citometría de flujo. Registros de citometría de flujo en los que se observa la población de neuronas apoptóticas (rojo), considerándose como tales las Anexina+/7-AAD-.

\section{6.- DETERMINACIÓN DEL POTENCIAL DE MEMBRANA MITOCONDRIAL $(\triangle \Psi \mathrm{m})$ COMO ÍNDICE DE INTEGRIDAD MITOCONDRIAL}

La evaluación del potencial de membrana $(\Delta \psi \mathrm{m})$ se realizó por citometría de flujo, siguiendo las instrucciones del sistema comercial MitoProbeTM DilC 1 Assay Kit for Flow Citometry (Life Technologies). Esta sonda, dado su carácter catiónico, se acumula en las mitocondrias polarizadas, por lo que su pérdida es un índice de despolarización mitocondrial. 
Las células se despegaron, se resuspendieron en tampón fosfato salino (PBS: $\mathrm{NaCl} 136$ mM; KCl 2,7 mM; $\mathrm{Na}_{2} \mathrm{HPO}_{4} \cdot 2 \mathrm{H}_{2} \mathrm{O}$ 7,8 mM; $\mathrm{KH}_{2} \mathrm{PO}_{4}$ 1,7 mM; $\mathrm{pH}$ 7,4) con $50 \mathrm{nM}$ de la sonda, y se incubaron durante 30 minutos a $37^{\circ} \mathrm{C}$ en un baño con agitación suave y protegidas de la luz. Tras la incubación con la sonda, las células se centrifugaron a $700 \times g$ durante 3 minutos y los sedimentos se resuspendieron en tampón fosfato salino.

Los valores de $\Delta \Psi \mathrm{m}$ se expresaron como porcentajes. Se empleó el desacoplador mitocondrial carbonil cianuro 3-clorofenilhridrazona (CCCP) $10 \mu \mathrm{M}$ duranre 15 minutos para definir el $0 \%$ de $\Delta \psi \mathrm{m}$. La señal del fluorocromo se analizó en el canal FL4 del citómetro de flujo FACScalibur. Se utilizaron los programas CellQuest'TM para adquisición de eventos y Paint-A- Gate ${ }^{\mathrm{TM}}$ PRO para el análisis de los mismos. En determinados experimentos, las determinaciones se realizaron previa selección de poblaciones celulares identificadas mediante marcaje fluorescente con GFP.

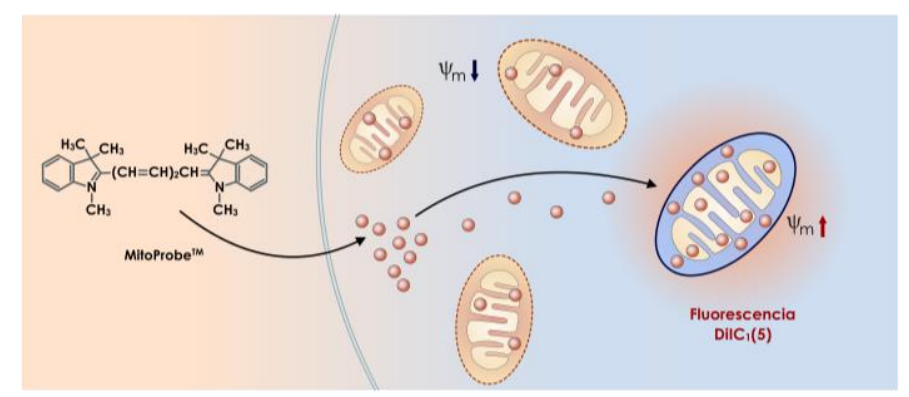

Figura 20. Sonda mitocondrial DilC 1 . Estructura de la sonda DilC $C_{1}$ apta para atravesar las membranas mitocondriales debido a su alta hidrofobicidad y carácter catiónico.

\section{7.- DETERMINACIÓN DE LA EXPRESIÓN DE PROTEÍNAS MEDIANTE ANÁLISIS DE TRANSFERENCIA TIPO WESTERN}

\subsection{EXTRACCIÓN DE PROTEÍNAS}

\subsubsection{Extracción de proteínas totales}

Para obtener extractos celulares de proteínas totales, las células se lavaron con PBS y se lisaron en tampón RIPA (dodecilsulfato sódico 1\%, EDTA 10 
mM, Triton Tx-100 1\% v/v, NaCl 150 mM, Na $\mathrm{PO}_{4} 10$ mM, pH 7,0), suplementado con inhibidores de fosfatasas $\left(\mathrm{Na}_{3} \mathrm{VO}_{4} 1 \mathrm{mM}\right.$, NaF $\left.50 \mathrm{mM}\right)$ y de proteasas (fluoruro de fenilmetilsulfonilo $100 \mu \mathrm{M}$, aprotinina $50 \mu \mathrm{g} / \mathrm{ml}$, leupeptina $50 \mu \mathrm{g} / \mathrm{ml}$, pepstatina $50 \mu \mathrm{g} / \mathrm{ml}$, anti-papaína $50 \mu \mathrm{g} / \mathrm{ml}$, amastatina $50 \mu \mathrm{g} / \mathrm{ml}$, bestatina 50 $\mu \mathrm{g} / \mathrm{ml}$, y el inhibidor de tripsina soybean) y se hirvieron durante 5 minutos. Los extractos se centrifugaron a 13,000 x g durante 10 minutos y el sobrenadante se trasladó a un nuevo tubo y se congelaron a $-80^{\circ} \mathrm{C}$.

\subsubsection{Extracción de proteínas miltocondriales}

Con objeto de aislar las fracciones mitocondrial y citosólica de las células tratadas, se utilizó un protocolo de fraccionamiento diferencial (Almeida \& Medina 1998), que se resume en la Figura 21. Para ello, se utilizaron $7-10 \cdot 10^{7}$ de células, previamente sembradas en placas de $145 \mathrm{~cm}^{2}$ (Nunc. Thermo Fisher Scientific). Una vez alcanzada la confluencia, y tras lavar con PBS a $4^{\circ} \mathrm{C}$, las células se desprendieron de la placa mediante raspado en medio de aislamiento mitocondrial (MAM), consistente en una disolución de sacarosa 320 $\mathrm{mM}$, EDTA dipotásico $1 \mathrm{mM}$, Tris- $\mathrm{HCl} 10 \mathrm{mM}$ y una batería de inhibidores de proteasas (AEBSF 2 mM, Aprotinina 0,3 $\mu$ M, Bestatina $130 \mu \mathrm{M}$, EDTA 1 mM, E-64 14 $\mu \mathrm{M}$, Leupeptina $1 \mu \mathrm{M})$, ajustada a $\mathrm{pH} 7,4$.

Tras centrifugar a 600 x g durante 5 min a $4^{\circ} \mathrm{C}$, el precipitado celular se resuspendió en $1 \mathrm{ml}$ de MAM y se sometió a un proceso de homogeneización con un pistilo de teflón, con objeto de lisar la membrana plasmática manteniendo intactas las mitocondrias. Tras 18-20 agitaciones a 600 rpm, se retiró una alícuota del homogenado celular $(\mathrm{H})$, y el resto se centrifugó a 1.300 $x \mathrm{~g}$ durante $10 \mathrm{~min}$ a $4^{\circ} \mathrm{C}$, conservando el sobrenadante (S1), que contiene la fracción mitocondrial.

El precipitado se resuspendió en $1 \mathrm{ml}$ de MAM, que se centrifugó a 1.300 $x \mathrm{~g}$ durante $10 \mathrm{~min}$ a $4^{\circ} \mathrm{C}$, conservando el nuevo sobrenadante (S2). Este protocolo se repitió hasta dos veces más con cada fracción (S1 y S2, hasta observar la desaparición de cualquier precipitado. En ese momento, S1 y S2 se sometieron a una nueva centrifugación, a $17.000 \times \mathrm{g}$ durante $10 \mathrm{~min}$ a $4^{\circ} \mathrm{C}$. El sobrenadante de S1 se conservó, constituyendo la fracción citosólica. Los precipitados de ambos tubos (S1+S2), que representan la fracción mitocondrial, se combinaron y resuspendieron en tampón RIPA para análisis de expresión 
proteica. La pureza de las fracciones mitocondrial y citosólica se comprobó mediante análisis de la actividad citrato sintasa y lactato deshidrogenasa, exclusivas de mitocondria y citosol, respectivamente. El grado de pureza de cada fracción fue de un 95-98\%.

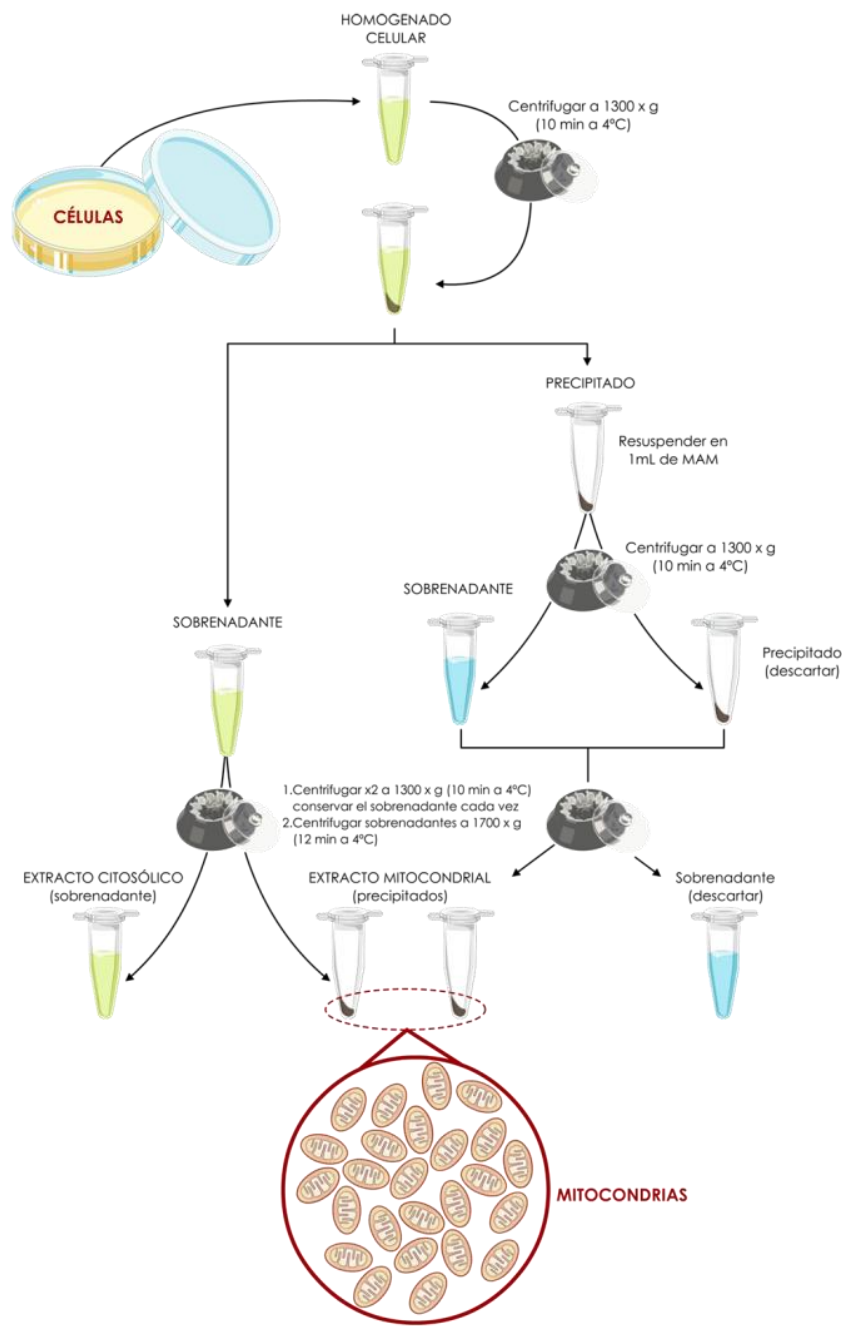

Figura 21. Fraccionamiento subcelular. La obtención de las fracciones mitocondrial y citosólica de células se realizó por un procedimiento de centrifugación diferencial. Para ello, se homogeneizaron las células con un pistilo de teflón, obteniendo un homogenado celular. Tras centrifugarlo a $1.300 \times \mathrm{g}\left(10 \mathrm{~min}\right.$ a $\left.4^{\circ} \mathrm{C}\right)$, se conservaron el sobrenadante (S1) y el sobrenadante que resultó de la resuspensión del pellet (S2). Después de 2 centrifugaciones de ambos sobrenadantes a la misma velocidad, el precipitado mitocondrial (P1+P2) se obtuvo al centrifugar S1 y S2 a 17.000 x g (12 min a $\left.4^{\circ} \mathrm{C}\right)$. 


\subsection{DETERMINACIÓN DE LA CONCENTRACIÓN DE PROTEINAS}

La concentración de proteínas de las muestras se midió mediante el ensayo del ácido bicinconínico (BCA; Pierce,Thermo Fisher Scientific, Illinois, EE.UU.). Este método se basa en la reducción del Cu2+ (azul) a Cu+ por parte de las proteínas de la muestra, el cual es capaz de reaccionar con el BCA originando una solución morada que se midió espectrofotométricamente en el lector de placas Varioskan Flash (Thermo Fischer, Vantaa, Finlandia) a $562 \mathrm{~nm}$. Se utilizó la albúmina sérica bovina (BSA) como estándar y todas las determinaciones se hicieron por triplicado.

\subsection{ELECTROFORESIS DE PROTEINAS EN SDS-PAGE}

La obtención de extractos proteicos totales se realizó después de lavar las células con PBS y lisarlas con tampón RIPA suplementado con los inhibidores de fosfatasas y proteasas (ver Sección 7.1.1.). Los extractos se recogieron en hielo e inmediatamente se hirvieron durante 5 minutos y se centrifugaron a 13,000 x g durante 10 minutos. La concentración de proteínas se determinó en el sobrenadante mediante el método colorimétrico del BCA.

Las proteínas $(10-100 \mu \mathrm{g})$ de los extractos obtenidos se separaron mediante electroforesis en gel de poliacrilamida SDS-PAGE (solución de acrilamida / bisacrilamida 29:1 o solución de acrilamida / bisacrilamida 29,2:0,8; BioRad Laboratories S.A.) al 8, 10, 12 ó 15\%, dependiendo del peso molecular de la proteína de interés. Para identificar dichos pesos moleculares, se utilizó un marcador de peso molecular (Page Ruler ${ }^{\mathrm{TM}}$ Plus Prestained Protein Ladder, Thermo Scientific). Las proteínas se separaron utilizando un sistema de electroforesis vertical (MiniProtean-3®, BioRad Laboratories, California, EE.UU.) y tampón de electroforesis (Tris $25 \mathrm{mM}$, glicina $200 \mathrm{mM}$ y SDS al 0,1\% p/v, pH 8,3).

Una vez finalizada la electroforesis, los geles se sometieron a electrotransferencia e inmunodetección mediante la técnica de Western Blot. 


\subsection{INMUNODETECCIÓNDE PROTEÍNAS POR WESTERN BLOT}

Las proteínas separadas en geles de SDS-PAGE se transfirieron electroforéticamente a membranas de nitrocelulosa (Hybond®), Amersham Biosciences, Nueva Jersey, EE.UU.) utilizando el sistema Mini-Transblot (Bio-Rad) y tampón de transferencia (Tris $25 \mathrm{mM}$, glicina $192 \mathrm{mM}$ y metanol al 20\% v/v, pH 8,3). A continuación, se bloquearon las membranas durante $1 \mathrm{~h}$ con leche (Sveltesse, Nestle) al 5\% (p/v) en TTBS (Tris 20 mM, NaCl 500 mM, Tween-20 al 0,1\% $\checkmark / \mathrm{v} ; \mathrm{pH} 7,5)$ a temperatura ambiente. Las membranas se incubaron a $4^{\circ} \mathrm{C}$ durante toda la noche en una solución de TTBS suplementado con BSA al $2 \%$ $(\mathrm{p} / \mathrm{v})$, que contenía el anticuerpo deseado (ver Tabla 8). Como control de carga, se utilizaron para extractos totales anti-GAPDH (Ambion, Austin, Texas, EEUU) y para extractos mitocondriales, anti-porina (voltage dependent anion channel, VDAC, Calbiochem, Darmstadt, Alemania). Al día siguiente, las membranas se lavaron 3 veces con TTBS y se incubaron con el anticuerpo secundario correspondiente, conjugado con la peroxidasa de rábano (HRP), en TTBS con leche al $2 \%$ durante una hora a temperatura ambiente. Tras lavar las membranas 3 veces con TTBS, y una con TBS (TTBS sin Tween-20), las membranas se incubaron, según la proteína a detectar, con los reactivos de quimioluminiscencia Super Signal West Dura (Pierce), Western Blotting Luminol Reagent (Santa Cruz Biotechnology, Texas, EE.UU.) e Immobilon Western Chemiluminiscent HRP Substrate (Merck Millipore; Darmstadt, Alemania), siguiendo las instrucciones de los fabricantes. Finalmente, las membranas se expusieron a una película de auto-radiografía (Fuji Medical X-Ray Film, Fujifilm) para detectar la señal. 


\begin{tabular}{ccccc}
\hline Anticuerpo & Especie & Dilución & Referencia & Casa comercial \\
\hline \multicolumn{4}{c}{ Anticuerpos Primarios } \\
P53 & Ratón & $1 / 250$ & 554157 & BD \\
PUMA & Conejo & $1 / 1000$ & Ab54288 & Abcam \\
Bax & Conejo & $1 / 500$ & Sc-493 & Santa Cruz \\
P21 & Ratón & $1 / 500$ & 556431 & BD \\
\hline Caspasa 3 activa & Conejo & $1 / 1000$ & 96615 & Cell Signalling \\
CDK5 & Conejo & $1 / 750$ & Sc-173 & Santa Cruz \\
\hline P35/p25 & Conejo & $1 / 500$ & Sc-820 & Santa Cruz \\
Citocromo c & Conejo & $1 / 250$ & Sc-7159 & Santa Cruz \\
VDAC & Conejo & $1 / 1000$ & PC548 & Calbiochem \\
GAPDH & Ratón & $1 / 10000$ & 4300 & Ambion \\
\hline
\end{tabular}

Anticuerpos Secundarios

\begin{tabular}{rrr}
$\mathbf{1} 1 / 10000$ & $170-6516$ & BioRad \\
$\mathbf{1} / \mathbf{1 0 0 0 0}$ & Sc-2030 & Santa Cruz \\
\hline
\end{tabular}

Tabla 8. Anticuerpos utilizados en esta memoria en estudios de expresión proteica por transferencia tipo western. En esta tabla se muestran los anticuerpos primarios y secundarios utilizados para los estudios de expresión proteica por transferencia de Western Blot (WB). Se especifican la especie, dilución empleada, la referencia y la casa comercial de cada anticuerpo.

\section{5. "STRIPPING" DE MEMBRANAS DE NITROCELULOSA}

En ocasiones, las membranas de nitrocelulosa de los Western Blot se reutilizaron y se incubaron de nuevo con un anticuerpo primario distinto al inicial. Para ello, fue necesario realizar stripping de las mismas, que consiste en incubar las membranas en un tampón para "stripping" (Restore Western Blot Stripping Buffer, Thermo Scientific) durante 15 minutos. Posteriormente, se lavaron 3 veces con TTBS a temperatura ambiente y se volvió a bloquear la membrana con leche al $5 \%(p / v)$. A partir de este momento, la incubación de los anticuerpos y el revelado se realizó de igual manera a la mencionada en la sección anterior. 


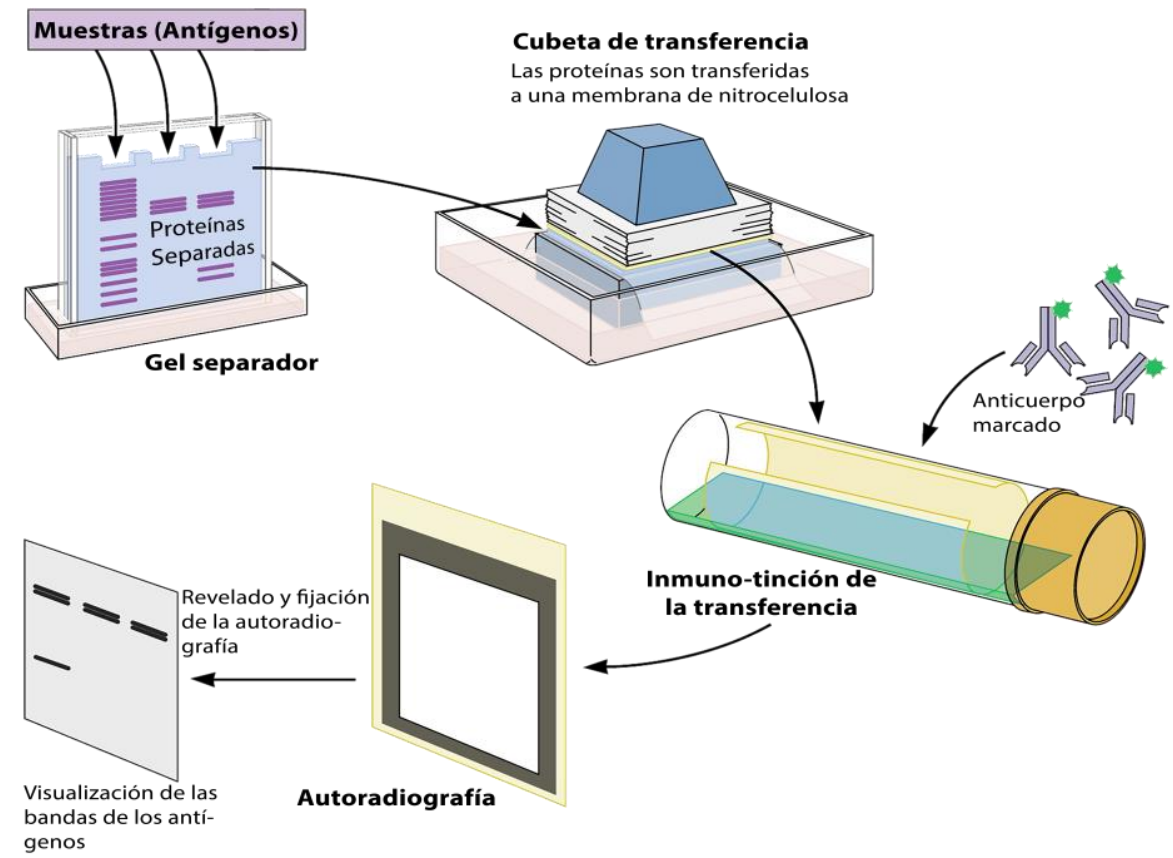

Figura 22. Esquema de la determinación de la expresión proteica mediante análisis de transferencia tipo western. El esquema muestra la electroforesis de proteínas en SDS-PAGE seguida de la transferencia a membranas de nitrocelulosa e inmunodetección.

\section{8.- INMUNOCITOQUÍMICA Y MICROSCOPÍA DE FLUORESCENCIA}

Para los ensayos de inmunocitoquímica las neuronas se cultivaron en cubreobjetos de cristal esterilizados al fuego y tratados con una solución de poliL-ornitina $15 \mu \mathrm{g} / \mathrm{ml}$ (Sigma-Aldrich) y fibronectina $1 \mu \mathrm{g} / \mathrm{ml}$ (Sigma-Aldrich).

A los 9 DIV las neuronas se lavaron con PBS, se fijaron con formaldehído al $4 \%(v / v)$ en PBS durante 30 minutos. Después se incubaron con glicina 0,1 M en PBS durante 20 minutos y se permeabilizaron con Triton X-100 al 0,25\% (v/v) en PBS durante 5 minutos. A continuación, se incubaron en la solución de bloqueo (Triton X-100 al $0.1 \%$ v/v y suero de cabra al $10 \%$ v/v en PBS) a temperatura ambiente durante 1 hora. Seguidamente, se incubaron con los anticuerpos anti-MAP2 1/500 (Sigma-Aldrich), anti-Caspasa 3 activa 1/300 (Cell Signalling) o anti-p53 1/100 (Becton Dickinson Biosciences) en suero de cabra al $5 \%$ en PBS durante toda la noche a $4^{\circ} \mathrm{C}$ en agitación suave. Al día siguiente, se 
lavaron 3 veces con PBS y se incubaron con los anticuerpos secundarios conjugados con los fluoróforos Cy3 o Cy5 a una dilución 1/500 (Jackson ImmunoResearch, EEUU) en suero de cabra al 5\% en PBS, durante 1 hora a temperatura ambiente, en oscuridad y en agitación suave. Posteriormente se lavaron 3 veces con PBS y se incubaron con los marcadores nucleares DAPI 30

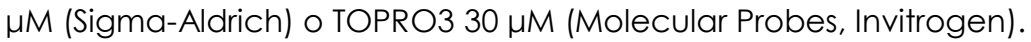

Los cubreobjetos se lavaron dos veces con PBS y una vez con agua estéril, tras lo cual se montaron sobre portaobjetos utilizando el reactivo SlowFade Antifadeld® (Invitrogen) para evitar la pérdida de fluorescencia. La visualización y adquisición de microfotografías confocales se llevó a cabo utilizando una magnificación de 63X en un microscopio Leika y de 100X en un confocal spinning disk Roper Scientific con microscopio Olympus IX81. Las imágenes se procesaron con el software ImageJ 1.49s.

\section{9.- OBTENCIÓN Y MANIPULACIÓN DEL ARN}

\subsection{EXTRACCIÓN DERNA}

La extracción de RNA se llevó a cabo con el kit comercial GenelutetM Mammalian Total RNA Kit (Sigma-Aldrich) según las instrucciones del fabricante.

Las neuronas a los 9 DIV se lisaron con una mezcla de $\beta$ mercaptoetanol:Lysis Solution en proporción 1:100 (v/v). Los lisados se filtraron con Genelute Filtration Column para eliminar los restos celulares y desechar el DNA, haciéndolos pasar por una columna con filtro y centrifugándolos a 16,000 $x$ g. Posteriormente, se añadió un volumen equivalente de etanol al $70 \%$ en agua DEPC (Di-etil-piro-carbonato) libre de RNasas y se vorteó hasta mezclar completamente. A continuación, se pasó la mezcla por Genelute Binding Column, donde se adherió el RNA. Se eliminó el filtrado y nos quedamos con la columna que se lavó una vez con Wash Solution 1.

Una vez separado el RNA, se trató la columna con $100 \mathrm{U}$ de DNAsa I (DNAse I, RNAse-free, Roche) durante 15 minutos a temperatura ambiente en un tampón compuesto por Tris- $\mathrm{HCl} 400$ mM, NaCl 100 mM, MgCl 60 mM y CaCl 10 mM; pH 7,9. Tras la incubación, para eliminar todos los restos de DNA y evitar la amplificación de DNA genómico, se lavaron las columnas tres veces, una con 
Wash Solution 1 y otra con Wash Solution 2 Concentrate/ethanol, lo que permitió un secado completo de la columna. Finalmente, el contenido de la columna se eluyó en un eppendorf nuevo con $50 \mu \mathrm{l}$ de Elution Solution mediante centrifugado a $16,000 \times g$ durante 1 minuto.

El RNA purificado quedó en el filtrado y se midió la concentración con un espectrofotómetro UV-Vis Nanodrop 2000 (Thermo Scientific). El ratio de absorbancia de 260 frente a $280 \mathrm{~nm}$ (A260 / A280), que determina la pureza del RNA, fue de 1,8 - 2 .

\subsection{REACCIÓN EN CADENA DE LA POLIMERASA A TIEMPO REAL O CUANTITATIVA (qPCR)}

Mediante esta técnica analizamos la expresión de múltiples genes (ver Tabla 9) que cuantificamos de forma relativa respecto a un control interno de expresión constante (housekeeping).

En la PCR a tiempo real los procesos de amplificación y detección se producen de manera simultánea, gracias a la emisión de fluorescencia por parte del SYBR Green (Applied Biosystems), fluorocromo que se intercala entre las hebras de DNA bicatenario, de modo que la fluorescencia es proporcional a la cantidad de producto de PCR amplificado (amplicón).

Antes de analizar la expresión de los diferentes genes, se puso a punto la concentración de cada oligonucleótido empleado como cebador (primer) y se calcularon las eficiencias de amplificación de los primers diseñados con los software Geneious (Biomatters Limited, Auckland, Nueva Zelanda) y Amplifix, (Universidad de Marsella, Marsella, Francia) utilizando diluciones seriadas de RNA. Se consideraron óptimas las eficiencias comprendidas entre el 85 y el $115 \%$. Las condiciones en las que se emplearon los distintos oligonucleótidos se resumen en la Tabla 9. Este paso es necesario para poder comparar la expresión de los diferentes genes mediante el Método Comparativo de $C_{\dagger}\left(\Delta \Delta C_{\dagger}\right)$. 


\begin{tabular}{|c|c|c|c|}
\hline Gen & Secuencia 5'-3' & Volumen & $\begin{array}{c}\text { Eficiencia } \\
(\%)\end{array}$ \\
\hline p53 & Comercial (BioRad) & $1 \mu \mathrm{l} /$ reacción & - \\
\hline Cdk5 & $\begin{array}{l}\text { F: AGCTACAACATCCTTGGTGA } \\
\text { R: ATGCGCTGCACAGGGTTACA }\end{array}$ & $\begin{array}{c}0,6 \mu \mathrm{l} \text { de una } \\
\text { solución } 10 \mu \mathrm{M}\end{array}$ & 95,7 \\
\hline Gapdh & $\begin{array}{l}\text { F: TCAGCAATGCCTCCTGCACCA } \\
\text { R: GCATGGACTGTGGTCATGAG }\end{array}$ & $\begin{array}{l}0,6 \mu \mathrm{l} \text { de una } \\
\text { solución } 10 \mu \mathrm{M}\end{array}$ & 108,2 \\
\hline
\end{tabular}

Tabla 9. Características y condiciones experimentales de los oligonucleótidos. En esta tabla se muestran tanto la secuencia como la concentración optimizada para la qPCR de cada uno de los primers empleados en esta memoria junto con el cálculo de las eficiencias para cada gen de estudio.

Para la cuantificación de expresión de los genes de estudio, se utilizó el kit comercial Power SYBR® Green RNA-to-C C TM 1-Step Kit (Applied Biosystems, California, EE.UU.), que permite acoplar la retrotranscripción y la amplificación en un único paso. Se partió de 100 ng de RNA y el volumen final por reacción fue de $20 \mu$. Todas las reacciones se hicieron por triplicado utilizando el termociclador Mastercycler ep Realplex (Eppendorf).

El perfil de cada reacción fue el siguiente: un ciclo de 30 minutos a $48^{\circ} \mathrm{C}$ (etapa de retrotranscripción), un ciclo de 10 minutos a $95^{\circ} \mathrm{C}$ (activación de la enzima DNA polimerasa), 40 ciclos de 15 segundos a $95^{\circ} \mathrm{C}$ (desnaturalización) y 1 minuto a $60^{\circ} \mathrm{C}$ (anillamiento y elongación).

El valor que se obtuvo por cada reacción fue el $C_{\dagger}$ (threshold cycle), es decir, ciclo en el que la fluorescencia emitida por el SYBR Green es detectable dentro de la fase lineal. Se obtiene así el Ct para cada uno de los genes de estudio y para el housekeeping (Gapdh). El incremento de $C_{+}\left(\Delta C_{\dagger}\right)$ es la diferencia entre el $C_{\dagger}$ de cada gen y el $C_{\dagger}$ de la Gapdh.

El Método Comparativo de C† relaciona el número de copias entre las distintas condiciones, que se obtiene al final de una reacción optimizada emplando la fórmula: 


$$
2^{-\Delta \Delta C_{\dagger}}
$$

2 - [( $C_{t}$ muestra $\left.-C_{f} G A P D H\right)-\left(C_{f}\right.$ calibrador $\left.\left.-C_{f} G A P D H\right)\right]$

Consideramos calibrador la condición sobre la que se compara la expresión y sobre la que se relativiza los resultados dándole el valor de 1. Niveles de expresión igual a 1 indican que la muestra problema presenta la misma expresión de un determinado gen que el control. Niveles $>1$ indican que hay un incremento de expresión con respecto al control, y niveles $<1$ indican que la expresión disminuye con respecto al control.

Los resultados se mostraron en unidades arbitrarias de expresión (fold o $n^{\circ}$ de veces de expresión) entre la muestra problema y un calibrador o control (cuantificación relativa).

\subsection{ELECTROFORESIS DE DNA EN GELES HORIZONTALES DEAGAROSA}

Esta técnica se utilizó tanto para separar los productos de PCR amplificados, como para separar los productos de la digestión realizada con enzimas de restricción y así poder distinguir diferentes fragmentos de DNA en función de su tamaño.

Antes de la electroforesis, se añadió a las muestras tampón de carga (azul de bromofenol al 0,25\%, xileno cianol al 0,25\% y ficol al 15\%). La electroforesis se realizó en geles de agarosa inmersos en una solución TAE IX (TAE 50X; Tris-acético 2 M, EDTA 0,05 M, acético glacial al 10\%, pH 8,0), a voltaje constante de $90 \mathrm{~V}$ durante 1 hora. Para calcular el tamaño de las bandas obtenidas, se incluyeron en los geles el marcador de peso molecular de $1 \mathrm{~Kb}$ Ladder Marker (Biotools, Madrid, España), que presenta un patrón de bandas que oscila de 0,25 a 10 Kb, o el marcador DNA Weight Marker XIII (50 pb ladder, Roche) cuyo patrón de bandas oscila de 50 a 2642 pb.

Para la realización de los geles se utilizó agarosa (Seakem® LE Agarose, Lonza, Basilea, Suiza) de baja electroendosmosis (menor número de grupos ácidos cargados a pH básico), para incrementar la movilidad electroforética del DNA, a una concentración variable 0.8 - 2\% en función del tamaño de la banda de interés.

A los geles se les añadió Midori Green DNA Stain (Nippon Genetics 
Europe $\mathrm{GmbH}$, Dueren, Alemania), que es una sonda fluorescente que se excita a $350 \mathrm{~nm}$ emitiendo luz verde a $540 \mathrm{~nm}$ cuando se intercala en la doble hebra del DNA. Para la visualización de las bandas se expuso el gel a un transiluminador de luz UV (Bio-Rad) y, para el posterior análisis de las imágenes, se utilizó el sistema digital Gel Doc (Bio-Rad).

\section{0.- MEDIDA DE CALCIO INTRACELULAR}

Para estimar los cambios en la concentración de $\mathrm{Ca}^{2+}$ libre intracelular ([ $\left.\left.\mathrm{Ca}^{2+}\right]_{c}\right)$ en cultivo primario de neuronas, se empleó la sonda fluorescente Fura2/AM (éster de Fura-2-acetoximetil; Life Technologies), un indicador fluorescente permeable a la membrana plasmática. Tras la unión del $\mathrm{Ca}^{2+}$ con Fura-2, el máximo de excitación de fluorescencia fluctúa de $380 \mathrm{~nm}$ (libre de $\mathrm{Ca}^{2+}$ ) a 340 $\mathrm{nm}$ (saturado de $\mathrm{Ca}^{2+}$ ), mientras que el máximo de emisión de fluorescencia se mantiene inalterado $a \sim 505 \mathrm{~nm}$ (ver Figura 23).

Las neuronas de 8-10 DIV sembradas en placas de 96 pocillos (Nunc) y se incubaron con Fura-2 (2 mM; disuelto en DMSO) durante 40 minutos en Neurobasal a $37^{\circ} \mathrm{C}$. Posteriormente, se lavaron y se incubaron con Standard Buffer ( $\mathrm{NaCl} 140 \mathrm{mM}, \mathrm{KCl} 2,5 \mathrm{mM}$, Tris- $\mathrm{HCl} 15 \mathrm{mM}$, D-glucosa $5 \mathrm{mM}, \mathrm{Na}_{2} \mathrm{HPO}_{4} 2 \mathrm{H}_{2} \mathrm{O}$ $1,2 \mathrm{mM}, \mathrm{MgSO}_{4} 1 \mathrm{mM}$ y $\mathrm{CaCl}_{2} 1 \mathrm{mM}, \mathrm{pH} \mathrm{7,4)}$ durante 30 minutos a $37^{\circ} \mathrm{C}$. Finalmente, el Standard Buffer se retiró y se reemplazó por Experimental Buffer ( $\mathrm{NaCl} 140 \mathrm{mM}, \mathrm{KCl} 2,5 \mathrm{mM}$, Tris- $\mathrm{HCl} 15 \mathrm{mM}$, D-glucosa 5 mM, Na2 $\mathrm{HPO}_{4} 2 \mathrm{H}_{2} \mathrm{O} 1$ $\mathrm{mM}$ y $\left.\mathrm{CaCl}_{2} 2 \mathrm{mM}, \mathrm{pH} 7,4\right)$, en presencia o en ausencia de MK-801 (10 $\left.\mu \mathrm{M}\right)$ (inhibidor de los receptores de glutamato NMDA).

Las emisiones de fluorescencia a $505 \mathrm{~nm}$, después de las excitaciones a 340 y $380 \mathrm{~nm}$, respectivamente, se registraron a intervalos de 1 segundo en un espectrofluorímetro Variokan Flash (Thermo Fischer) a $37^{\circ} \mathrm{C}$. Después de 10 segundos aproximadamente, se añadió NMDA (agonista de receptores glutamatérgicos de NMDA) a concentración excitotóxica (100 $\mu \mathrm{M})$ o $\beta$ A25-35 $(10 \mu \mathrm{M})$, en ambos casos junto con glicina $10 \mu \mathrm{M}$. Las emisiones se registraron durante 50 segundos más. 
Los cambios en la concentración de $\mathrm{Ca}^{2+}$ intracelular se estimaron calculando el ratio de la fluorescencia emitida a $505 \mathrm{~nm}$, obtenida después de la excitación a $340 \mathrm{~nm}$, dividida por la obtenida después de la excitación a 380 $\mathrm{nm}$ (F340 / F380). El ruido de fondo se determinó a partir de los valores obtenidos en las células carentes de Fura-2 (sólo en presencia del vehículo DMSO).

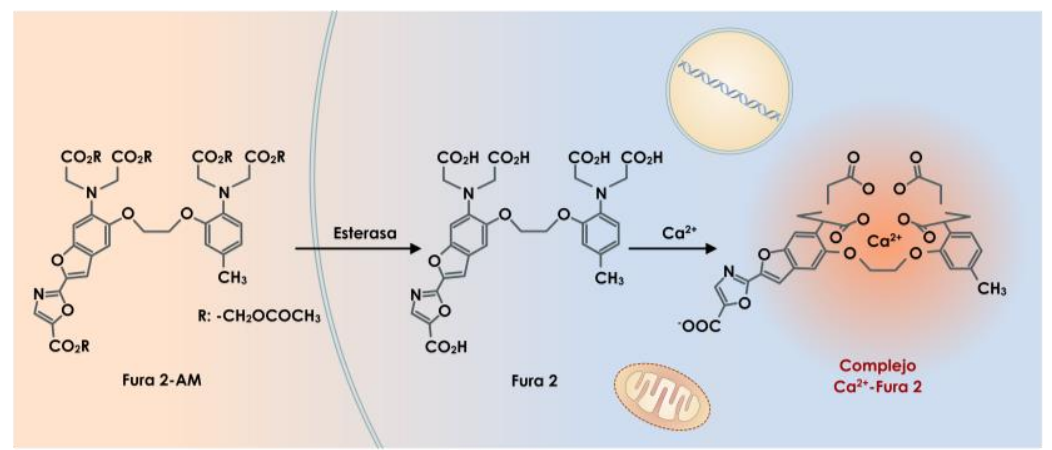

Figura 23. Detección de Ca ${ }^{2+}$ intracelular con la sonda Fura-2. La unión de $\mathrm{Ca}^{2+} \mathrm{a}$ la sonda produce cambios en la fluorescencia de excitación de la misma: de 380 nm, cuando la sonda estálibre de $\mathrm{Ca}^{2+}$, a $340 \mathrm{~nm}$ cuando la sonda está unida a $\mathrm{Ca}^{2+}$.

\section{1.- TRATAMIENTO ESTADÍSTICO DE LOS RESULTADOS}

Todas las determinaciones en células en cultivo fueron realizadas, al menos, por triplicado de un mínimo de tres cultivos. Los valores se expresaron como medias \pm S.E.M. (error estándar de la media) en, al menos, tres experimentos independientes. La significatividad se determinó mediante análisis de la varianza (ANOVA), seguido del test de Bonferroni (para comparaciones múltiples) o el test de la $t$ de Student (para comparaciones entre dos únicos grupos de valores). En todos los casos, un valor de $p<0,05$ se consideró estadísticamente significativo. El análisis estadístico se realizó con ayuda del software SPSS Statistics v23 (IBM, Nueva York, EEUU). 

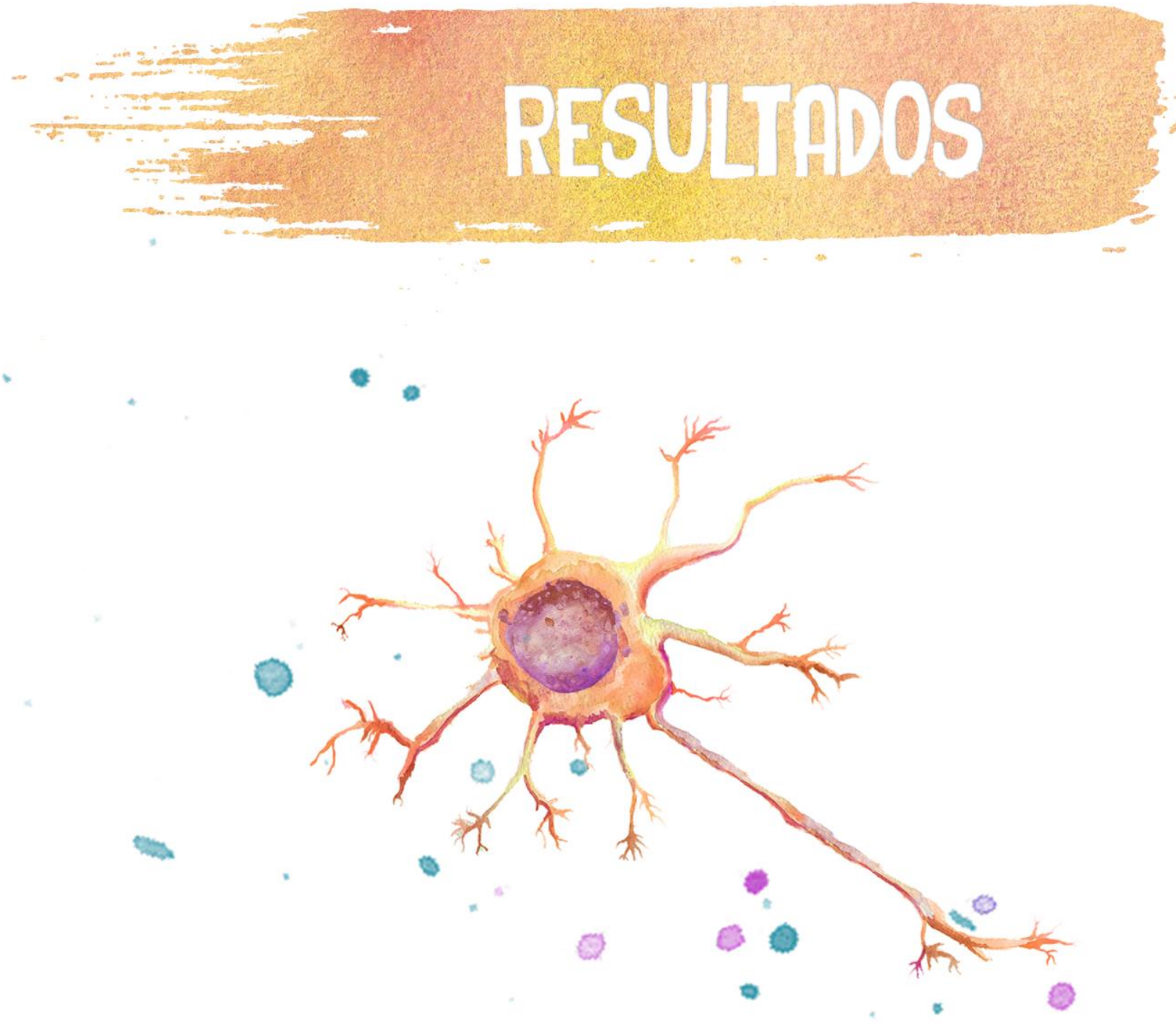



\section{1.- ESTABLECIMIENTO DE UN MODELO IN VITRO DE NEUROTOXICIDAD CAUSADA POR B-AMILOIDE}

Como hemos descrito en la Introducción, el BA es el principal componente de las placas amiloides presentes en los cerebros de pacientes que sufren la EA, lo que lo convierte en un elemento clave en el proceso neurodegenerativo asociado a esta enfermedad (Querfurth \& Laferla 2010; D'Andrea et al. 2002; LaFerla et al. 2007; Armstrong 2006). Aunque el efecto neurotóxico del BA está bien establecido, se desconocen los mecanismos moleculares implicados en dicha neurotoxicidad, lo que explica, al menos en parte, la ausencia de un tratamiento específico y eficaz en la EA (Kayed \& Lasagna-Reeves 2012; Mondragón-Rodríguez et al. 2012; Lansdall 2014; Yiannopoulou \& Papageorgiou 2013).

Para profundizar en los mecanismos moleculares responsables de la muerte neuronal causada por el BA, objetivo fundamental del presente trabajo, en primer lugar nos planteamos establecer un modelo de muerte neuronal in vitro mediada por BA, que nos permitiera estudiar el proceso.

\section{1.- El BA25-35 induce apoptosis en neuronas corticales de ratón en cultivo primario.}

El péptido BA25-35 constituye el fragmento más corto capaz de formar grandes fibrillas con estructura de hoja-B y que, por tanto, retiene la actividda neurotóxica del BA completo (Stepanichev et al. 2006; Tickler et al. 2005; Mattson et al. 1997; Lau et al. 2003). Es más, se ha considerado al BA25-35 como el dominio funcional del BA, responsable de sus propiedades neurotóxicas (Stepanichev et al. 2006; Stepanichev et al. 2003; Stepanichev MYu et al. 1998; Stepanichev et al. 2005; Limón et al. 2009). Por ello, decidimos incubar las neuronas en presencia de BA25-35, previamente oligomerizado, y determinamos la apoptosis neuronal por citometría de flujo. Como control empleamos el péptido BA35-25, sin actividad neurotóxica (Almeida et al. 2005), en las mismas condiciones. Como se muestra en la Figura 1, la incubación con BA25-35 durante 24 horas indujo la apoptosis neuronal desde una 
concentración de $10 \mu \mathrm{M}$, por lo que decidimos utilizar esta concentración en sucesivos experimentos.

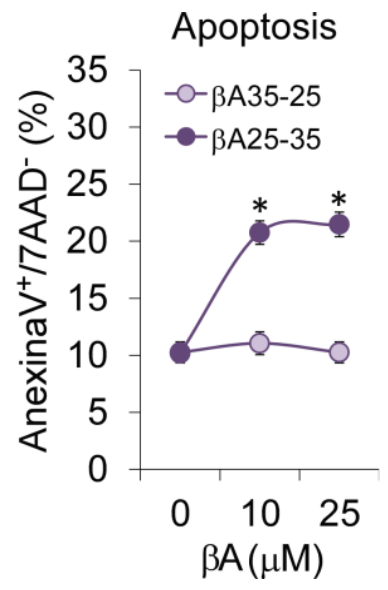

Figura 1. EI $\beta A$ induce apoptosis en neuronas corticales en cultivo primario. Las neuronas se incubaron en presencia de $\beta A 25-35$ (10 y $25 \mu \mathrm{M}$ ) durante 24 horas y la apoptosis neuronal se determinó mediante citometría de flujo. Como control se utilizaron neuronas incubadas con $\beta$ A35-25 (10 y $25 \mu \mathrm{M}, 24$ horas). Los datos son medias \pm S.E.M, ${ }^{*} p<0,05$ vs $\beta A 35-25$; (ANOVA post-hoc Bonferroni; $\mathrm{n}=3$ cultivos independientes).

\section{2.- El BA25-35 se acumula en el citosol de neuronas corticales de ratón en cultivo primario.}

Los oligómeros intracelulares de BA son las especies más neurotóxicas asociadas a la EA. Por ello, y una vez fijadas las condiciones de tratamiento con BA, nuestro siguiente paso fue estudiar si el BA25-35 era capaz de localizarse en el interior de las neuronas corticales en cultivo primario. Para ello, las neuronas se incubaron con oligómeros de BA25-35 biotinilado durante 8, 16 y 24 horas. Para identificar la posición del péptido en las neuronas, se realizaron análisis de inmunorreacción con el marcador específico neuronal MAP2 (MicrotubuleAssociated Protein 2; rojo) y con el marcador nuclear TOPRO3 (azul). Como se observa en la Figura 2, los oligómeros de BA25-35 biotinilado (verde) son capaces de penetrar en el interior neuronal, ya desde las 8 horas de tratamiento. Además, una vez en el interior, se acumulan en el citoplasma de manera dependiente del tiempo de tratamiento. 


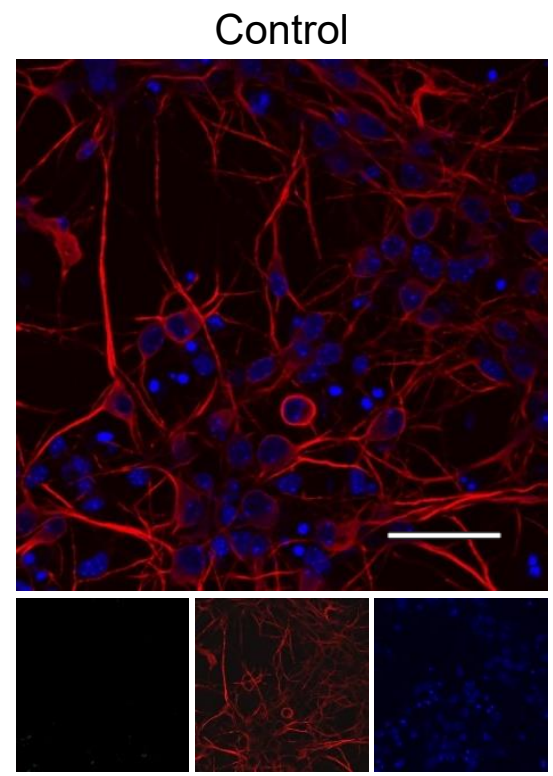

16h $\beta \mathrm{A}(25-35)$

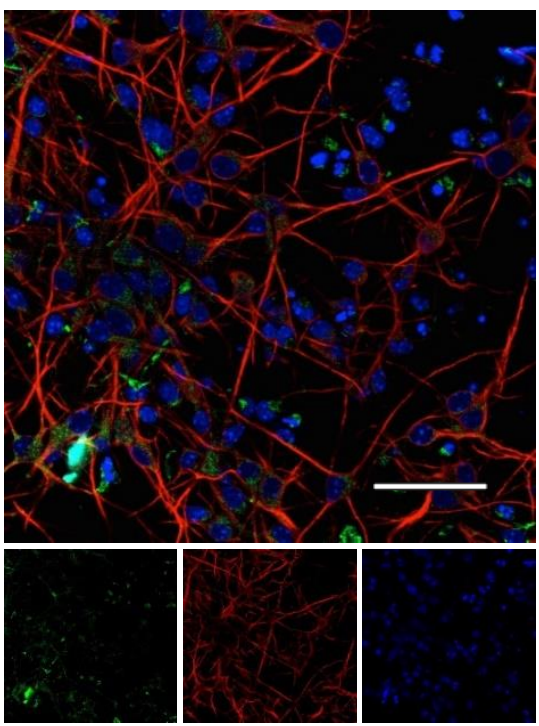

8h $\beta \mathrm{A}(25-35)$

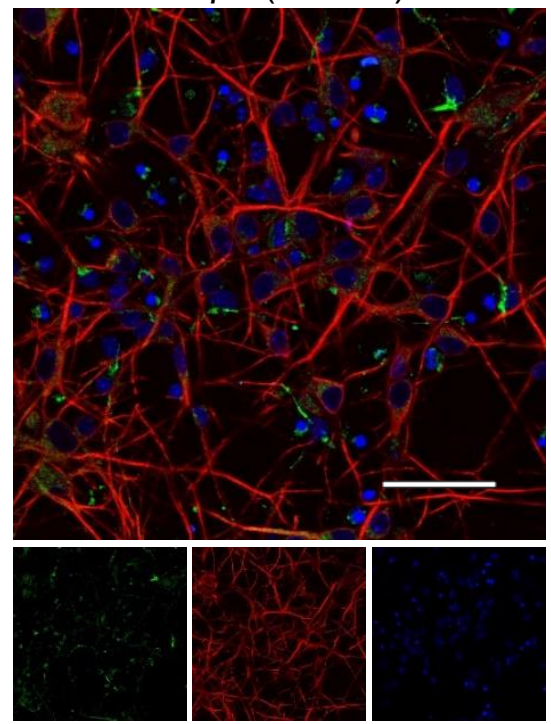

$24 \mathrm{~h} \beta \mathrm{A}(25-35)$

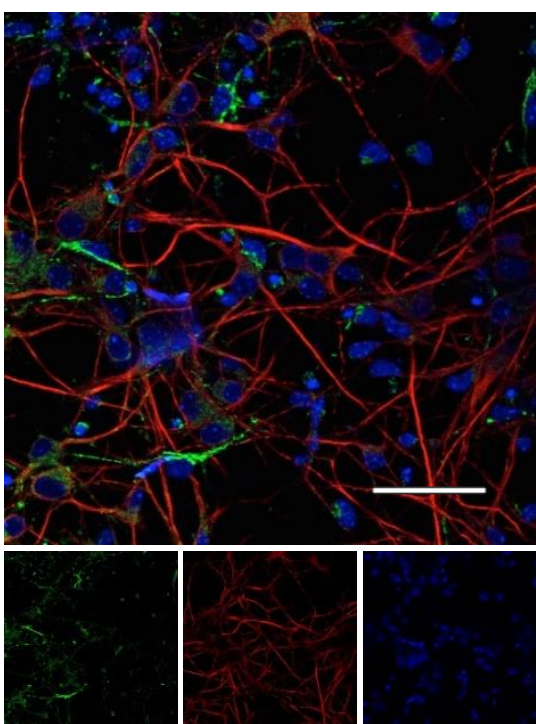

Figura 2. El $\beta$ A25-35 se internaliza en las neuronas y se acumula en el citosol. Las neuronas se trataron o no (Control) con oligómeros de $\beta A 25-35$ biotililado $(10 \mu \mathrm{M})$ a distintos tiempos $(8,16$ ó 24 horas). Se realizaron inmunocitoquímicas para determinar la localización del $\beta A 25-$ 35 (verde). Se utilizó MAP2 (rojo) como marcador neuronal y TOPRO3 (azul) como marcador nuclear. Barra $=50 \mu \mathrm{M}$. 


\section{3.- Los oligómeros de BA25-35 inducen despolarización mitocondrial previa a la apoptosis neuronal.}

La disfunción mitocondrial es un evento temprano en la EA, de manera que casi la totalidad de las funciones mitocondriales se ven afectadas (Schmitt et al. 2012; Bolaños et al. 2009; Chen \& Yan 2007). Resultados previos de nuestro grupo han puesto de manifiesto la importancia de la función mitocondrial en el balance entre la supervivencia y la muerte de las neuronas (García et al. 2005; Veas-Pérez de Tudela et al. 2015; Almeida \& Bolaños 2001). Por ello, decidimos investigar el posible efecto del BA sobre el potencial de membrana mitocondrial en neuronas. Como se observa en la Figura 3a, el BA25-35 provocó la despolarización mitocondrial desde las 8 horas de tratamiento, a juzgar por la disminución en el potencial de membrana mitocondrial. Además, y para estudiar la implicación de la disfunción mitocondrial sobre la neurotoxicidad del $B A$, decidimos determinar la apoptosis neuronal en las mismas condiciones experimentales. En la Figura $\mathbf{3 b}$ observamos que el BA25-35 indujo la apoptosis neuronal desde las 16 horas de tratamiento, es decir, posterior a la despolarización mitocondrial, lo que sugiere que el daño mitocondrial puede ser causa, y no consecuencia, del proceso apoptótico. Dado que el mantenimiento del potencial de membrana mitocondrial es esencial para la supervivencia neuronal (García et al. 2005; Veas-Pérez de Tudela et al. 2015; Almeida \& Bolaños 2001), nuestros resultados indican que la disfunción mitocondrial causada por el BA puede ser responsable de su neurotoxicidad. 
a

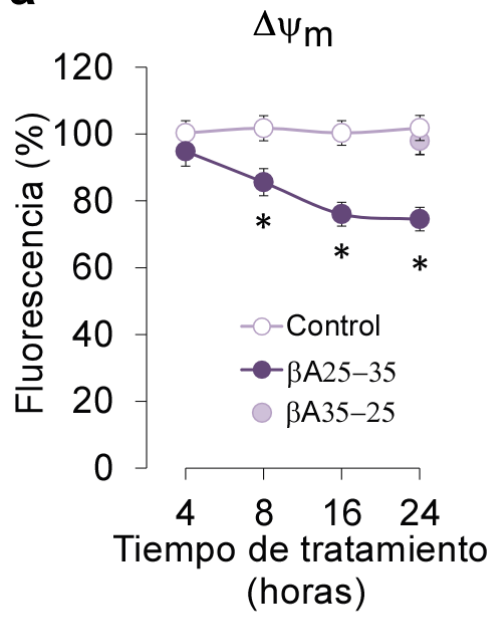

b

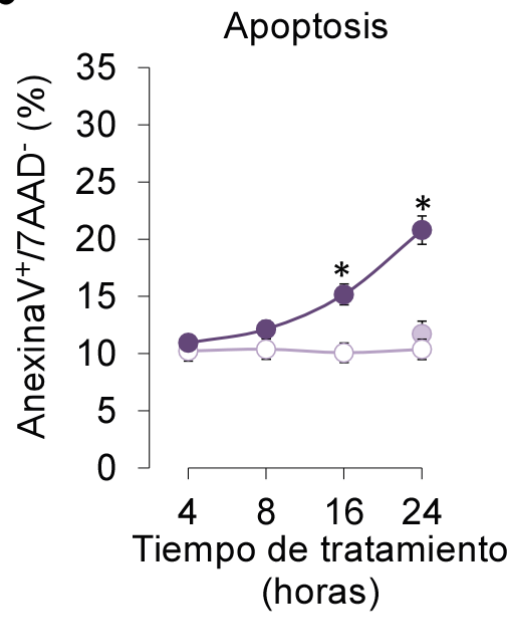

Figura 3. El $\beta A 25-35$ induce despolarización mitocondrial y muerte neuronal por apoptosis. Las neuronas se trataron o no (Control) con $10 \mu \mathrm{M}$ de $\beta A 25-35$ durante 4, 8, 16 y 24 horas. Como control adicional se emplearon neuronas tratadas con $10 \mu \mathrm{M}$ de $\beta$ A35-25 durante 24 horas. El potencial de membrana mitocondrial (a) y apoptosis (b) se analizaron mediante citometría de flujo, tal y como se describe en Material y Métodos. Los datos son medias \pm S.E.M, ${ }^{*} \mathrm{p}<0,05$ vs control; (ANOVA post-hoc Bonferroni; $\mathrm{n}=3$ cultivos independientes).

\section{4.- La estabilización funcional de p53 media la neurotoxicidad provocada por oligómeros de $\beta A 25-$ 35.}

Una vez establecido el modelo de neurotoxicidad del BA, decidimos investigar los mecanismos moleculares implicados en dicho efecto. Entre las dianas moleculares con actividad pro-apoptótica, especialmente en las neuronas, destaca p53. Así, la estabilización de p53 provoca la apoptosis neuronal mediante un mecanismo que implica, entre otros, la disfunción mitocondrial (Vaseva \& Moll 2009; Green \& Kroemer 2009; Gomez-Sanchez et al. 2011; Marchenko et al. 2000; Mihara et al. 2003). Se ha descrito la acumulación de p53 en áreas cerebrales dañadas de enfermos y modelos animales de EA. Por ello, decidimos estudiar la posible implicación de p53 en nuestro modelo experimental de neurotoxicidad. Mientras que los niveles de RNAm de p53 se mantuvieron constantes durante el tratamiento (Figura 4), 
observamos una acumulación de p53 desde las 4 horas de tratamiento con el BA, que se mantuvo incluso hasta las 24 horas (Figura 5). Es más, comprobamos que la estabilización de p53 era funcional, ya que se correspondía con un aumento en la expresión de su diana PUMA (ㅁ5늘 pregulated modulator of apoptosis) y de la caspasa 3 activa, ambos conocidos marcadores de la ruta apoptótica. Cabe destacar que la acumulación de p53 se observó con anterioridad a la disfunción mitocondrial (Figura 5) y la activación de la caspasa-3. Este hecho, junto con la acumulación de PUMA, que es una proteína que ejerce su acción apoptótica a través de la vía intrínseca o mitocondrial (Ren et al. 2010), sugieren que p53 podría estar implicada en el daño mitocondrial causado por el BA en las neuronas. Por tanto, nuestros resultados demuestran que el BA induce la estabilización de p53 en las neuronas, mediante un mecanismo post-traducional, lo que le convierte en una diana a tener en cuenta en la activación de la ruta de señalización que implica daño mitocondrial y la subsecuente apoptosis neuronal.

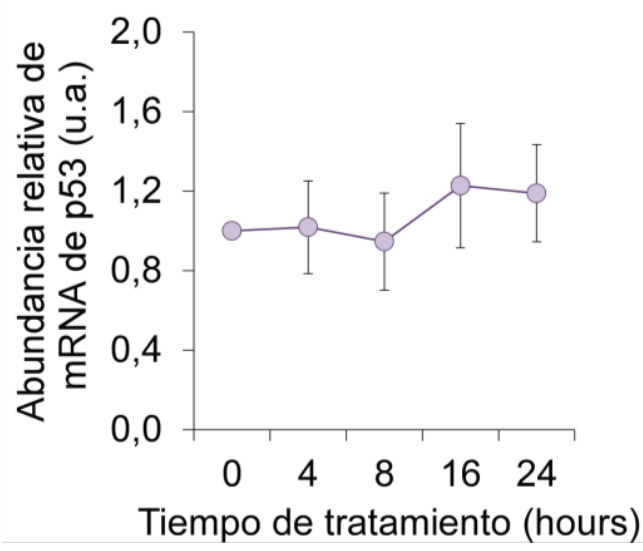

Figura 4. El ßA25-35 induce la estabilización de p53. La expresión del mRNA de $p 53$ se analizó mediante RT-qPCR en neuronas tratadas con ßA25-35 $10 \mu \mathrm{M}$ a distintos tiempos. Se empleó la Gapdh como housekeeping o gen de referencia para los análisis de RT-qPCR. Los datos son expresados como la media \pm S.E.M (ANOVA, post hoc Bonferroni; $\mathrm{n}=3$ experimentos independientes). 


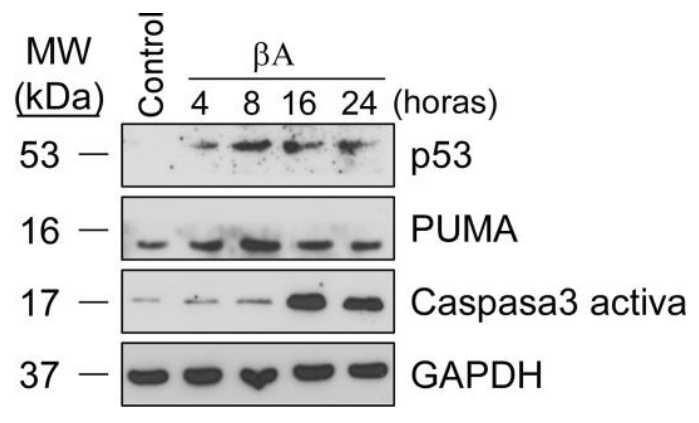

Figura 5. El $\beta$ A provoca la activación de la apoptosis tras la estabilización de p53. Las neuronas se trataron con $\beta A 25-3510 \mu \mathrm{M}$ durante 4, 8, 16 ó 24 horas. Se realizaron análisis de transferencia tipo Western de los niveles de expresión de p53, PUMA y Caspasa 3 activa. La expresión de GAPDH se utilizó como control de carga.

\section{2.- FUNCIÓN DE p53 EN LA NEUROTOXICIDAD ASOCIADA AL B-AMILOIDE.}

\section{1.- La disfunción mitocondrial y activación de la apoptosis neuronal causada por el BA está mediada por la estabilización de p53.}

Con objeto de demostrar la posible implicación de p53 en la neurotoxicidad del BA, recurrimos a dos estrategias experimentales encaminadas a reducir los niveles neuronales de p53, como son la transfección de las neuronas con siRNA contra p53 (sip53) y el uso de neuronas procedentes de ratones knockout (KO) de p53.

\subsection{1.- El silenciamiento de p53 previene el daño neuronal causado por el $\beta$-amiloide.}

Tras comprobar la eficacia del siRNA seleccionado para reducir la expresión de p53 (sip53) mediante la determinación de los niveles de p53 (Figura 6a), determinamos la apoptosis neuronal mediante citometría de flujo. Como se muestra en la Figura $\mathbf{6} \mathbf{b}$, el silenciamiento de p53 previno la muerte 
neuronal causada por el BA en las neuronas, lo que indica que la neurotoxicidad del péptido está causada por la estabilización de p53.

a

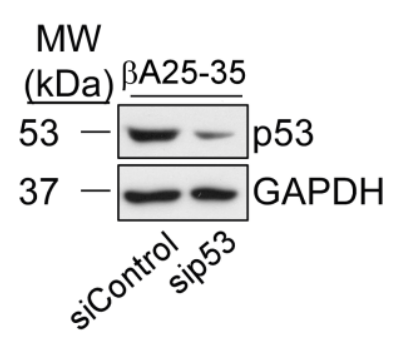

b

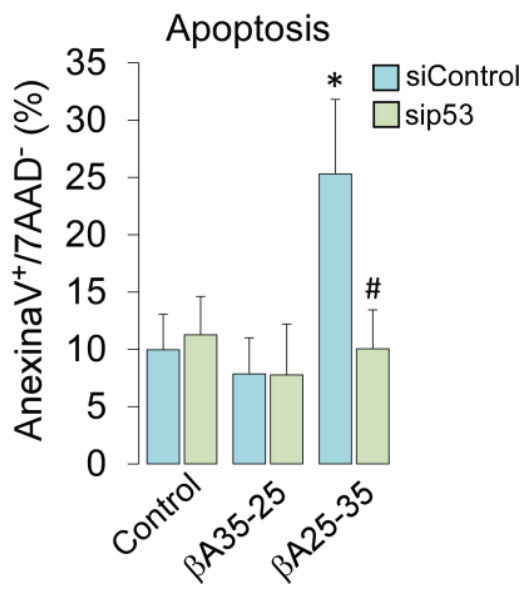

Figura 6. La reducción de los niveles de 553 previene la despolarización mitocondrial y la apoptosis neuronal causadas por el BA. Las neuronas se transfectaron con siRNA contra la luciferasa (siControl) o p53 (sip53). Tras 48 horas de la transfección, las neuronas se trataron o no (Control) con $10 \mu \mathrm{M}$ de $\beta \mathrm{A} 25-35$ durante 24 horas. (a) Se realizaron análisis de transferencia tipo Western de los niveles de expresión de p53. La expresión de GAPDH se utilizó como control de carga. (b) La apoptosis neuronal se analizó mediante citometría de flujo la apoptosis tal y como se describe en Material y Métodos. Los datos son medias \pm S.E.M, ${ }^{*} p<0,05$ vs control; (ANOVA; $n=3$ cultivos independientes).

\subsection{2.- La estabilización p53 es responsable de la neurotoxicidad del B-amiloide.}

Para confirmar la implicación del BA en la neurotoxicidad del BA, utilizamos cultivos de neuronas procedentes de ratones $\mathrm{KO}$ de $\mathrm{p} 53$ y se trataron con BA25-35 (10 $\mu \mathrm{M})$ durante 24 horas. Como se observa en la Figura 7, la ausencia de p53 previno la despolarización mitocondrial y la apoptosis causadas por el BA en las neuronas.

El análisis de la expresión de proteínas mediante Western confirmó que el BA25-35 estabiliza la proteína p53, así como de sus dianas moleculares como son p21, Bax y PUMA, y provocó la activación de la caspasa 3 activa (Figura 7c). Sin embargo, estos efectos no se observaron en las neuronas carentes de p53 (KOp53). 
a

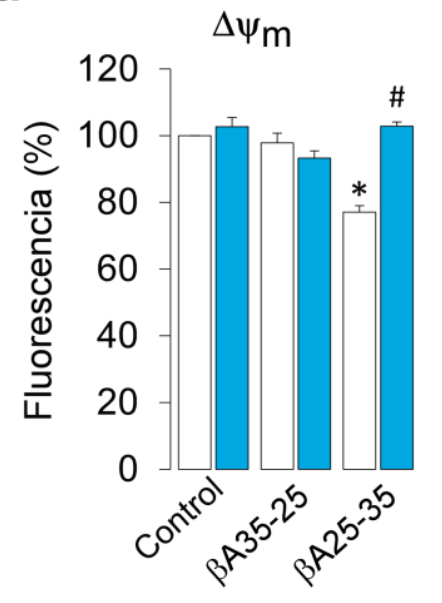

b

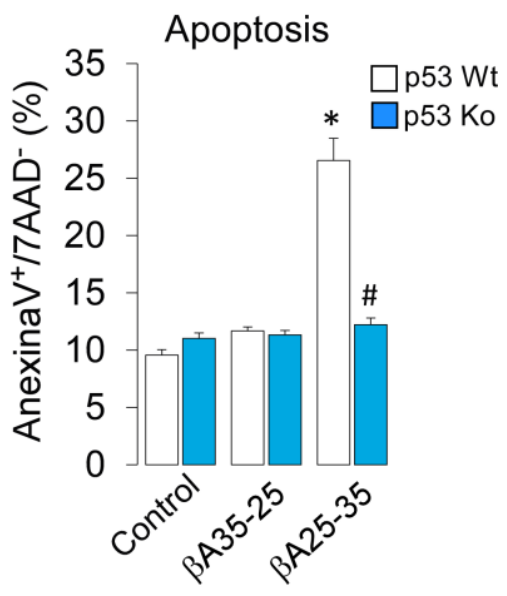

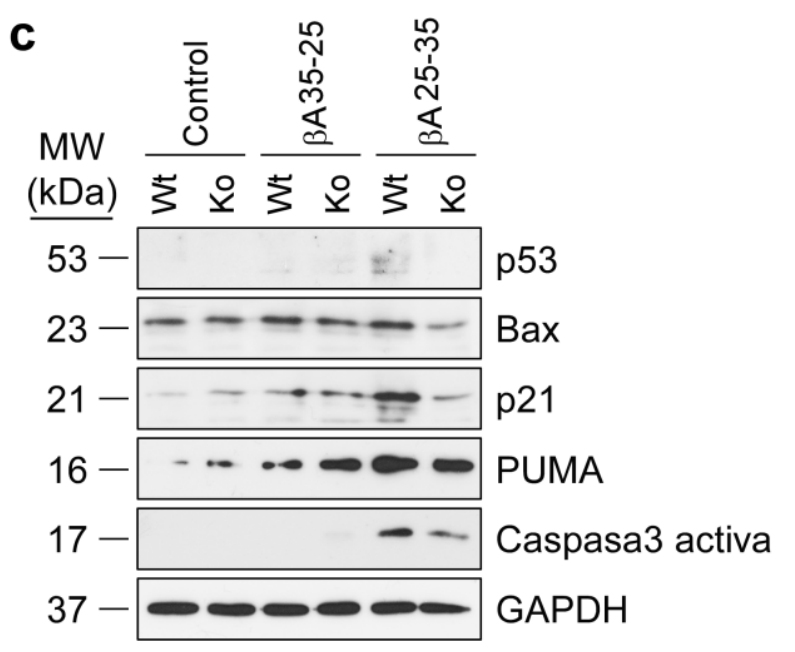

Figura 7. La ausencia de p53 previene la despolarización mitocondrial y la apoptosis neuronal causadas por el BA. Se realizaron cultivos de neuronas procedentes de ratones silvestres $(\mathrm{Wt})$ y knockout $(\mathrm{KO})$ de $\mathrm{p} 53$ y se trataron o no (Control) con $10 \mu \mathrm{M}$ de $\beta A 35-25$ o de $\beta A 25-35$ durante 24 horas. El potencial de membrana mitocondrial (a) y la apoptosis (b) se analizaron mediante citometría de flujo, tal y como se describe en Material y Métodos. (c) Se realizaron análisis de transferencia tipo Western de los niveles de expresión de p53, p21, Bax, PUMA y caspasa 3 activa. La expresión de GAPDH se utilizó como control de carga. Los datos son medias \pm S.E.M, ${ }^{*} p<0,05$ vs control, $\# p<0,05$ vs neuronas Wt tratadas con $\beta A 25-35$; (ANOVA post-hoc Bonferroni; $\mathrm{n}=3$ cultivos independientes). 
Por tanto, nuestros resultados demuestran que el BA induce la estabilización de p53 en las neuronas, lo que, mediante interacción con la mitocondria (Gomez-Sanchez et al. 2011) provoca la despolarización de la membrana mitocondria, lo que posteriormente desencadena la apoptosis en las neuronas, tal y como se ilustra en el esquema 1.

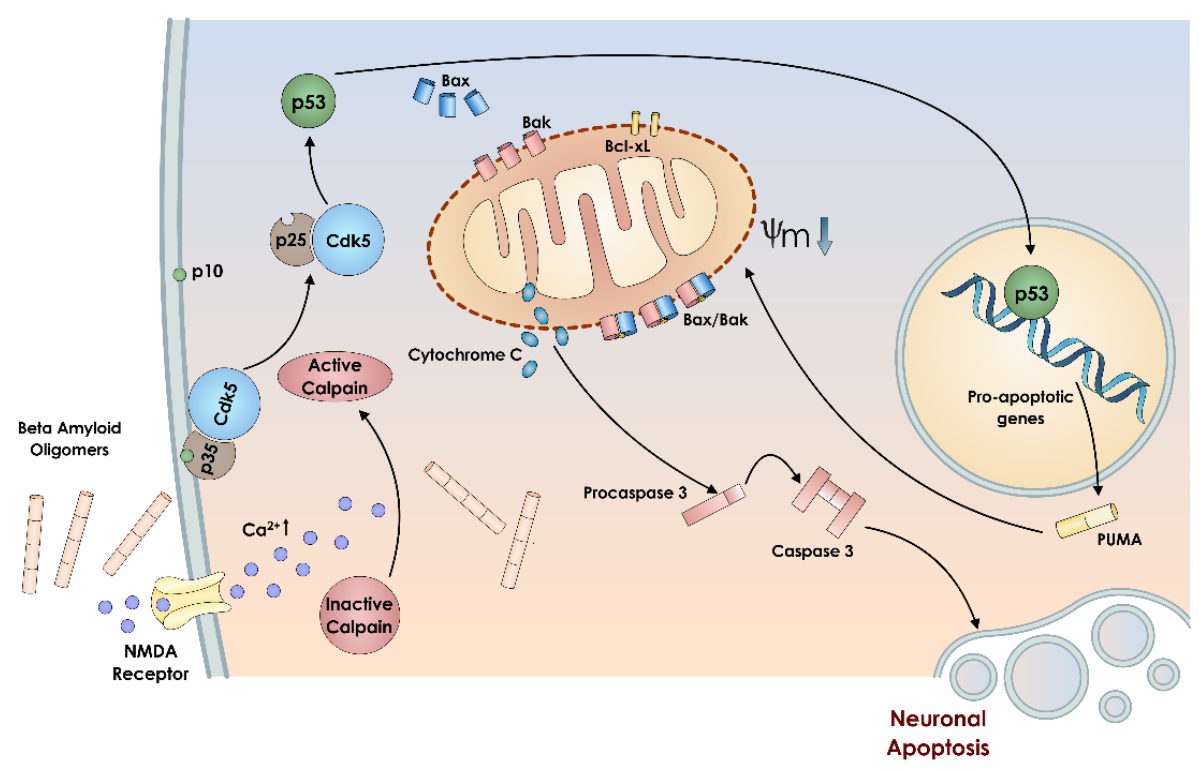

Esquema 1. La estabilización de p53 mediada por el $\beta A$ es responsable de la disfunción neuronal. El $\beta A$ estimula receptores NMDA, lo cual activa las calpaínas por entrada de $\mathrm{Ca}^{2+}$ al interior celular. Esto induce la conversión del cofactor de CDK5, p35, en p25. La hiperactivación de CDK5 por la conversión de p35 en p25 media la estabilización de p53, la cual induce la expresión de proteínas proapoptóticas como PUMA, provoca la despolarización mitocondrial. Esto libera citocromo c al citosol y conlleva la activación de la caspasa 3, dando como resultado la muerte neuronal por apoptosis.

\section{2.- CDK5 media la estabilización de p53, lo cual desencadena el daño mitocondrial y la muerte apoptótica.}

Una vez confirmado el papel fundamental que desempeña p53 en el daño neuronal causado por el BA, quisimos ahondar en el mecanismo responsable de la estabilización de p53. Como hemos descrito anteriormente, la acumulación de p53 causada por el BA no está relacionada con cambios en 
la expresión de su mRNA (Figura 4) lo que sugiere que es debido a cambios posttraducionales de la proteína. Resultados previos han descrito que la estimulación excitotóxica de los receptores NMDA en neuronas provoca la entrada de calcio en el interior de la célula, lo que induce la activación de las calpaínas que rompen p35 formando p25 y, en consecuencia, activa CDK5 (Lee et al. 2000; Kusakawa et al. 2000; Nath et al. 2000; Maestre et al. 2008). Además, la fosforilación de p53 en la Ser15, ya sea por acción directa de CDK5 (J. Zhang et al. 2002) o indirecta a través de ATM (Tian et al. 2009), induce la estabilización de la proteína. Estos antecedentes, nos hicieron pensar en CDK5 como la quinasa responsable de la estabilización de p53 causada por el BA en las neuronas.

Con este fin, en primer lugar, analizamos el efecto del BA sobre la actividad de CDK5 mediante la expresión de sus activadores p35 y p25. Como se observa en la Figura 8, el BA indujo la expresión de p25, lo que es compatible con la hiperactivación de Cdk5 (Lee et al. 2000; Kusakawa et al. 2000; Nath et al. 2000; Maestre et al. 2008), tanto en ausencia como en presencia de p53 (Figura 8).

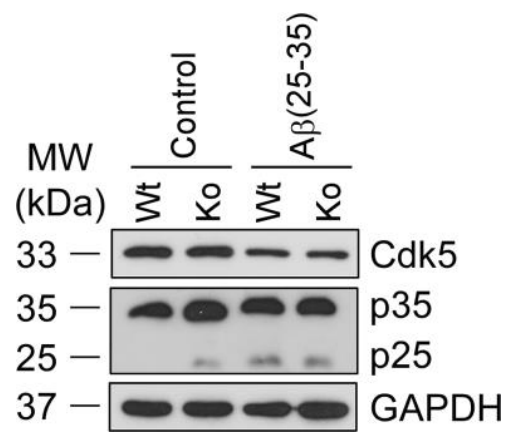

Figura 8. El $\beta$ A induce la conversión del cofactor de CDK5, p35, en su forma truncada p25. Se realizaron cultivos de neuronas procedentes de ratones silvestres (Wt) y knockout (KO) de p53 y se trataron o no (Control) con $10 \mu \mathrm{M}$ de $\beta A 25-35$ durante 24 horas. Se realizaron análisis de transferencia tipo Western de los niveles de expresión de CDK5, p35 y p25. La expresión de GAPDH se utilizó como control de carga.

El silenciamiento de Cak5 se confirmó mediante RT-qPCR (Figura 9a) y la detección de los niveles de la proteína (Figura 9b). El silenciamiento de Cdk5 en las neuronas previno la despolarización mitocondrial (Figura 10a) y la muerte neuronal por apoptosis (Figura 10b) provocadas por el BA. Asimismo, mediante transferencia tipo Western se evidenció que el silenciamento de Cdk5 era 
capaz de prevenir el incremento en los niveles de las dianas transcripcionales pro-apoptóticas de p53, Bax y PUMA, así como la activación de la caspasa 3, tras el tratamiento de las neuronas con BA (Figura 10c). Estos resultados sugieren que Cak5 está implicada en la estabilización de p53. Es más, demostramos que la acumulación de p53 causada por el BA en las neuronas era posterior a la generación de p25 (Figura 11) tras la estimulación con BA.

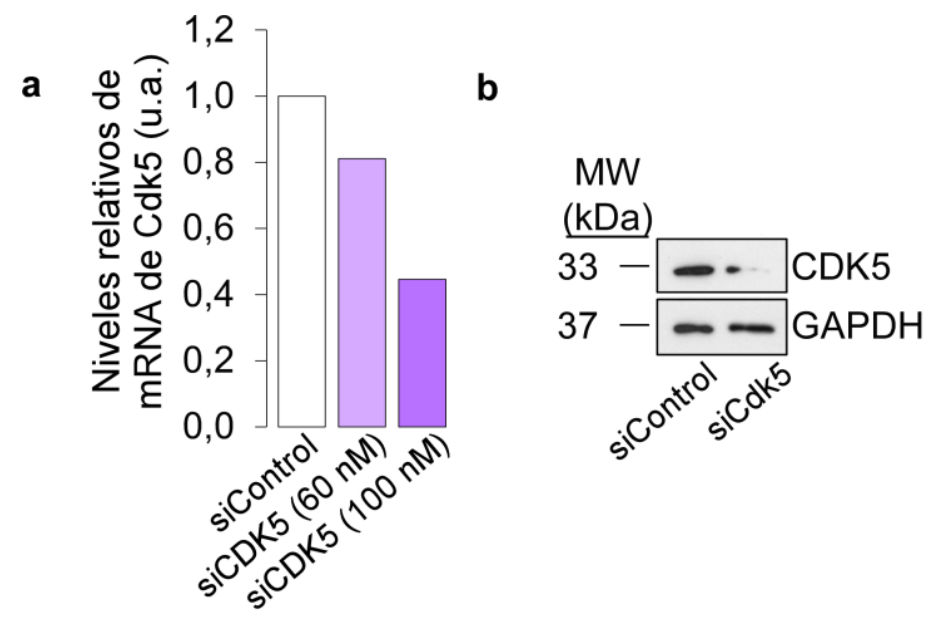

Figura 9. Análisis del silenciamiento de Cdk5. Las neuronas se transfectaron con siRNA contra la luciferasa (siControl; 100 nM) o Cdk5 (siCdk5; 100 nM). Tras 72 horas de la transfección, el silenciamiento de Cdk5 se valoró mediante (a) RTpPCR, normalizándose la expresión frente al mRNA control Gapdh y mediante (b) de transferencia tipo Western de los niveles de expresión de Cdk5. La expresión de GAPDH se utilizó como control de carga. Se utilizó como siControl (100 nM) un RNA de interferencia frente al gen de la luciferasa. Se utilizó como siControl un RNA de interferencia frente al gen de la luciferasa. 
a

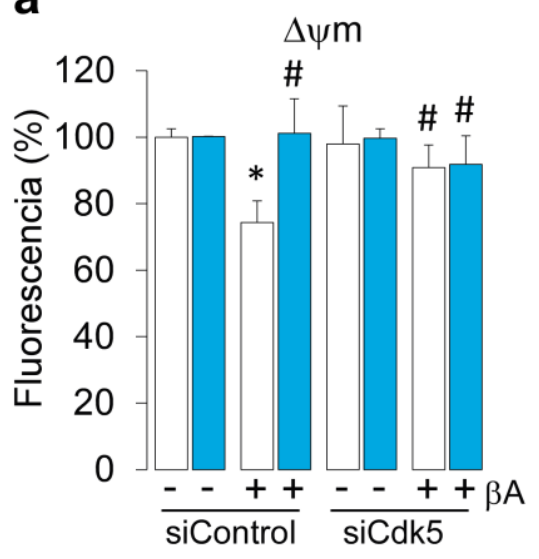

b

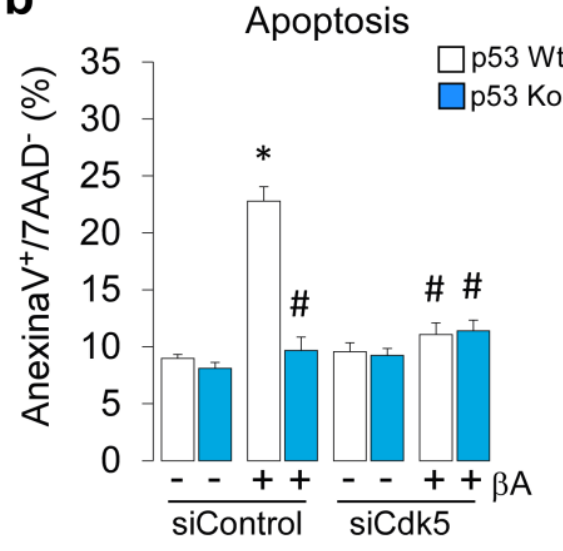

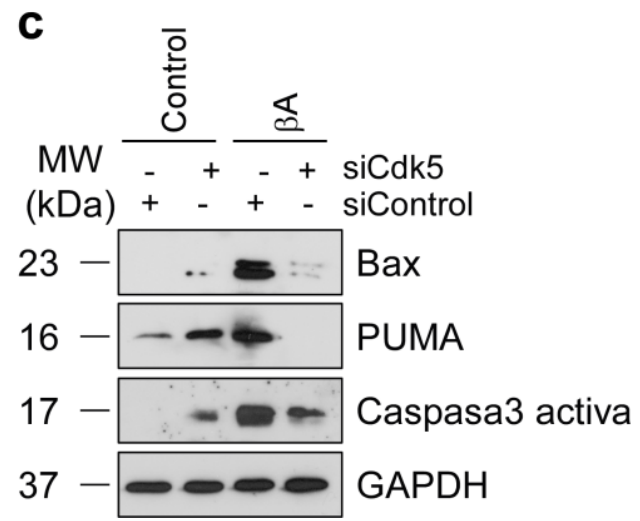

Figura 10. El silenciamiento de Cdk5 es suficiente para evitar la activación de la vía intrínseca o mitocondrial de la apoptosis en neuronas Wt. Las neuronas se trataron o no (Control) con $10 \mu M$ de $\beta A 25-35$ durante 24 horas. Se analizó Las neuronas se transfectaron con siRNA contra la luciferasa (siControl; $100 \mathrm{nM}$ ) o Cdk5 (siCdk5; $100 \mathrm{nM}$ ). Tras 72 horas de la transfección, las neuronas se trataron o no (Control) con $10 \mu \mathrm{M}$ de $\beta$ A25-35 durante 24 horas. El potencial de membrana mitocondrial (a) y apoptosis (b) se analizaron mediante citometría de flujo, tal y como se describe en Material y Métodos. (c) Se realizaron análisis de transferencia tipo Western de los niveles de expresión de Bax, PUMA y Caspasa 3 activa. La expresión de GAPDH se utilizó como control de carga. Los datos son medias \pm S.E.M, ${ }^{*} p<0,05$ vs control siControl, $\# p<0,05$ vs tratamiento con $\beta$ A25-35 siControl; (ANOVA post-hoc Bonferroni; $\mathrm{n}=3$ cultivos diferentes) 


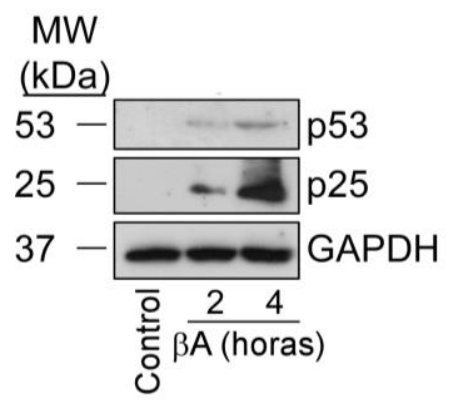

Figura 11. La formación de p25 es anterior a la estabilización de p53 en neuronas tratadas con BA. Las neuronas se trataron o no (Control) con $10 \mu \mathrm{M}$ de $\beta \mathrm{A} 25-35$ durante 24 horas. Se analizaron los niveles de expresión de p53 y p25 mediante transferencia tipo Western. La expresión de GAPDH se utilizó como control de carga.

Por tanto, hasta el momento nuestros resultados demuestran que el BA induce la activación de Cak5, que fosforila y estabiliza p53, lo que se traduce en la disfunción mitocondrial y la subsecuente muerte neuronal por apoptosis.

\section{3.- IMPLICACIÓN DEL POLIMORFISMO TP53 Arg72ProEN LA MUERTE NEURONAL ASOCIADA AL $\beta$ - AMILOIDE.}

La relevancia de la genética en la EA está muy establecida en la literatura. Los factores genéticos responsables de la forma temprana de la EA están ampliamente caracterizados. Por el contrario, existe la necesidad de encontrar herramientas genéticas robustas para un mejor manejo de los pacientes de EA esporádica (Gatz et al. 2006; Tanzi 2012; Lambert et al. 2013; Bettens et al. 2013; Cacace et al. 2016; Goldman et al. 2011; Van Cauwenberghe et al. 2016). Recientemente, hemos descrito que el SNP humano Arg72Pro de p53 regula la susceptibilidad de las neuronas a la apoptosis causada por la isquemia y, en consecuencia, determina el pronóstico funcional de pacientes de ictus (Gomez-Sanchez et al. 2011). Por ello, una vez establecido el papel decisivo de p53 en la neurotoxicidad del BA, quisimos analizar la posible función del SNP en la susceptibilidad de las neuronas al BA. 


\section{1.- La variante polimórfica Arg incrementa la susceptibilidad de las neuronas al BA.}

Como una primera aproximación experimental, se realizaron cultivos primarios de neuronas procedentes de ratones knockin "humanizados" que expresan las variantes polimórficas humanas p5372-Arg (que denominamos grupo Arg) o p5372-Pro (que denominamos grupo Pro).

Como se observa en la Figura 12, la despolarización mitocondrial causada por el BA es significativamente mayor en las neuronas Arg respecto a las neuronas Pro (Figura 12b). De manera consecuente, la apoptosis provocada por el BA en las neuronas Arg resultó ser mayor a la producida en las neuronas Pro (Figura 12b). Es más, el análisis mediante transferencia tipo Western reveló que, a pesar de tener similares niveles de p53, la expresión de caspasa 3 activa fue superior en las neuronas portadoras de la variante Arg de p53, que en aquellas que expresaban Pro (Figura 12c). 
a

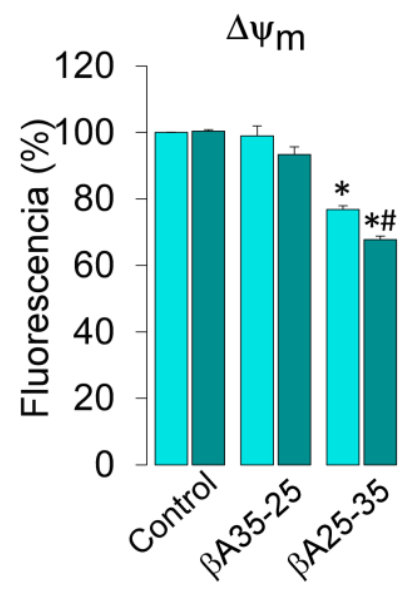

b

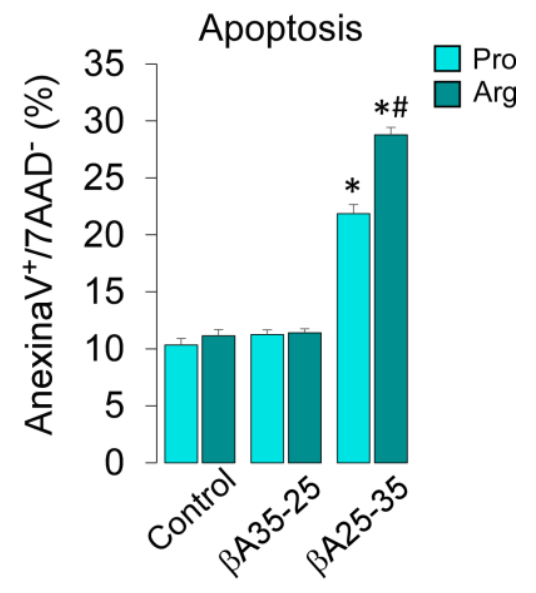

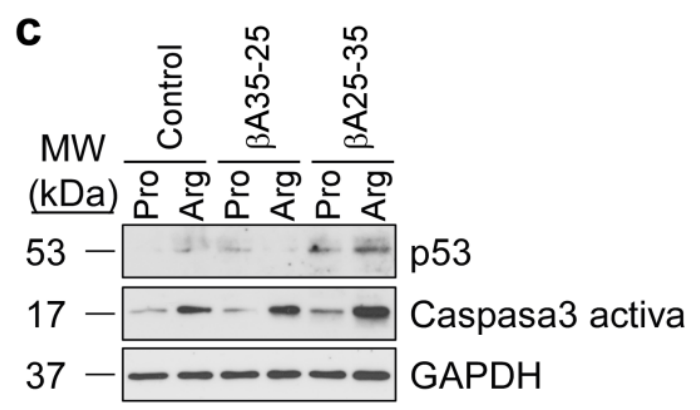

Figura 12. El polimorfismo Arg72Pro de Tp53 condiciona la susceptibilidad de las neuronas al $\beta$ A. Se realizaron cultivos de neuronas procedentes de ratones knockin de las variantes polimórficas de p53 arginina (Arg) y prolina (Pro) y se trataron o no (Control) con $10 \mu \mathrm{M}$ de $\beta \mathrm{A} 25-35$ durante 24 horas. El potencial de membrana mitocondrial (a) y apoptosis (b) se analizaron mediante citometría de flujo, tal y como se describe en Material y Métodos. El $\beta A 35-25$ se empleó como control adicional (10 $\mu \mathrm{M}, 24$ horas). (c) Se realizaron análisis de transferencia tipo Western de los niveles de expresión de p53 y caspasa 3 activa. La expresión de GAPDH se utilizó como control de carga. Los datos son medias \pm S.E.M, ${ }^{*} p<0,05$ vs control, $\# p<0,05$ vs neuronas Pro tratadas con $\beta$ A25-35; (ANOVA post-hoc Bonferroni; $\mathrm{n}=3$ cultivos diferentes)

Posteriormente, decidimos analizar el efecto del SNP sobre la susceptibilidad de las neuronas al BA en función del tiempo. Así, tanto el estudio de la determinación de la apoptosis por citometría de flujo (Figura 13a), como la detección de caspasa 3 activa por análisis de transferencia tipo Western (Figura 13b), revelaron que la neurotoxicidad del BA se produjo de manera más temprana en las neuronas Arg que en las Pro. De manera complementaria 
tratamos neuronas de ambos genotipos con BA25-35 biotilinado (10 $\mu \mathrm{M})$ para analizar mediante inmunofluorescencia la presencia de caspasa 3 activa, así como la morfología neuronal. En la Figura 13c se observa, una mayor expresión de la caspasa 3 activa en neuronas con genotipo Arg. Además, mientras que en las neuronas Pro la caspasa 3 activa aparece tanto en núcleo como en prolongaciones de neuronas que aún preservan su morfología, en las neuronas Arg la caspasa 3 activa aparece fundamentalmente en corpúsculos procedentes de neuronas que han iniciado un proceso apoptótico.

a

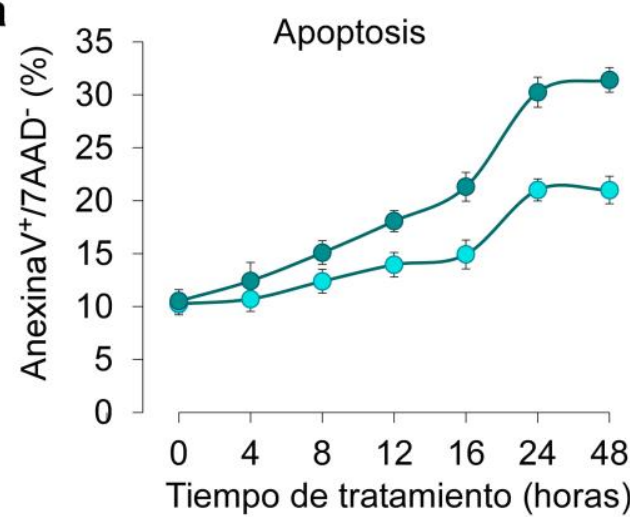

b

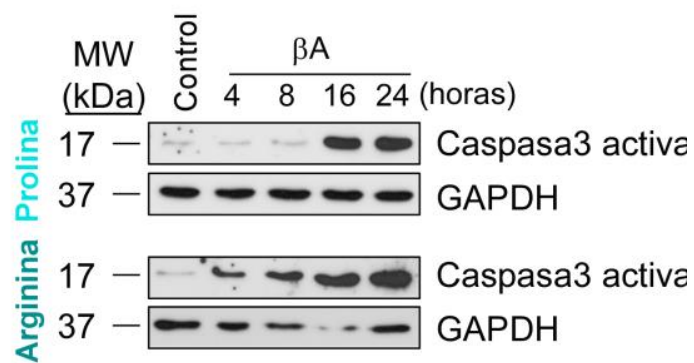

C
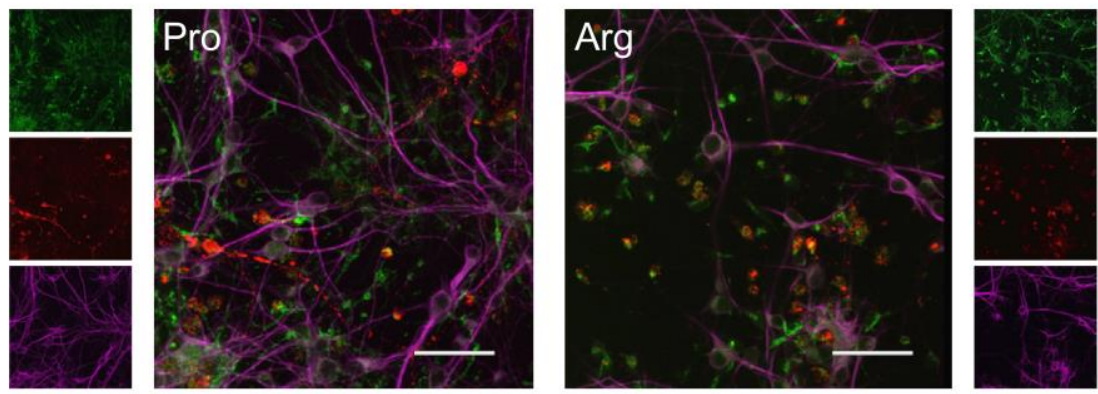

Figura 13. Las neuronas Arg son más vulnerables al $\beta A 25-35$ y comienzan a morir desde tiempos de tratamiento más tempranos. Se realizaron cultivos de neuronas procedentes de ratones knockin de las variantes polimórficas de p53 arginina (Arg) y prolina (Pro) y se trataron o no (Control) con $10 \mu \mathrm{M}$ de $\beta$ A25-35 durante diferentes tiempos. (a) Se analizó la apoptosis mediante citometría de flujo, tal y como se describe en Material y Métodos. Los datos son medias \pm S.E.M, ${ }^{*} p<0,05$ vs control, $\# p<0,05$ vs neuronas Pro tratadas con $\beta A 25$ 35; (ANOVA post-hoc Bonferroni; $n=3$ experimentos) (b) Se realizaron análisis de transferencia tipo Western de los niveles de expresión de caspasa 3 activa. La expresión de GAPDH se utilizó como control de carga. (c) Se realizaron inmunocitoquímicas de neuronas tratadas con $\beta$ A25-35 biotinilado ( $10 \mu \mathrm{M}$, verde) durante 16 horas, para detectar caspasa 3 activa (rojo). Se utilizó Map-2 como marcador neuronal (violeta). Barra $=50 \mu \mathrm{M}$ 
Todos estos resultados revelan que la variante polimórfica Arg incrementa la susceptibilidad de las neuronas al BA. Dado que en ambos genotipos el BA induce la estabilización de p53, el mecanismo parece ser independiente de la modulación de los niveles de la proteína.

\section{2.- El polimorfismo Arg72Pro de Tp53 no afecta a la ruta de activación de Cok5 en neuronas tratadas con el BA.}

Una vez conocida la vulnerabilidad diferencial entre ambas variantes polimórficas de p53, nos propusimos descartar el efecto del SNP sobre la existencia de vías de señalización adicionales capaces de promover la estabilización de p53 y la consiguiente muerte por apoptosis tras el tratamiento con BA.

Como ya hemos indicado, la estimulación excitotóxica de los receptores NMDA en neuronas provoca la entrada de calcio en el interior de la célula, lo que induce la activación de las calpaínas que rompen p35 formando p25 y, en consecuencia, activa CDK5 (Lee et al. 2000; Kusakawa et al. 2000; Nath et al. 2000; Maestre et al. 2008). Por ello, decidimos investigar la posible interferencia del SNP en esta ruta de señalización que pudiera explicar la diferente susceptibilidad que confiere frente al BA.

Con tal propósito, primeramente estudiamos la implicación de los receptores NMDA en la neurotoxicidad del BA. Como se observa en la Figura 14, la inhibición de los receptores NMDA previno la activación de la caspasa 3 en ambos genotipos. 


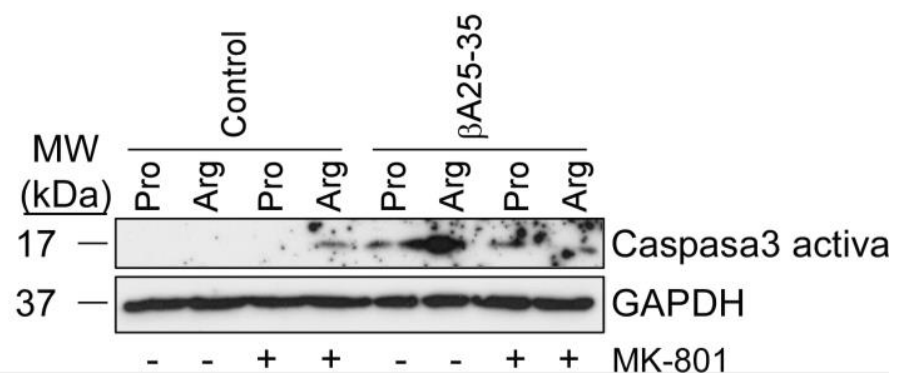

Figura 14. La neurotoxicidad del BA está mediada por la activación de los receptores NMDA. Se realizaron cultivos de neuronas procedentes de ratones knockin de las variantes polimórficas de p53 arginina (Arg) y prolina (Pro) y se trataron o no (Control) con $10 \mu \mathrm{M}$ de $\beta$ A25-35 durante 24 horas, en presencia del inhibidor de los receptores NMDA, el MK-801 (10 $\mu \mathrm{M})$. Se realizaron análisis de transferencia tipo Western de los niveles de expresión de caspasa 3 activa. La expresión de GAPDH se utilizó como control de carga.

Se sabe que la activación de los receptores NMDA conlleva a un incremento intracelular de $\mathrm{Ca}^{2+}$, que es el responsable de la mayoría de los efectos excitotóxicos del glutamato (Szydlowska \& Tymianski 2010; Arundine \& Tymianski 2003). Por ello, analizamos el efecto del BA sobre los niveles de $\mathrm{Ca}^{2+}$ en neuronas que expresan las variantes polimórficas Arg y Pro. Como control positivo, incubamos las neuronas con NMDA, un agonista selectivo del receptor ionotrópico de glutamato NMDA, a una concentración establecida como excitotóxica (100 MM) (Almeida \& Bolaños 2001; Maestre et al. 2008; JimenezBlasco et al. 2015). Como se observa en la Figura 15, la concentración de $\mathrm{Ca}^{2+}$ intracelular incrementó en presencia de NMDA, y, de forma más discreta en presencia de BA, de manera similar en neuronas de ambos genotipos. 


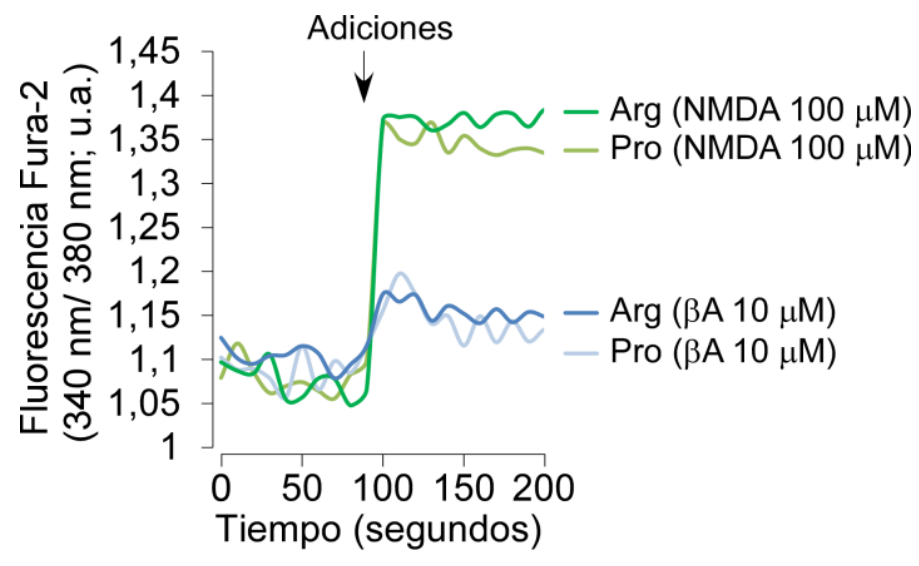

Figura 15. El polimorfismo Arg72Pro de Tp53 no afecta a la concentración de $\mathrm{Ca}^{2+}$ citosólico libre en neuronas. Se realizaron cultivos de neuronas procedentes de ratones knockin de las variantes polimórficas de $\mathrm{p} 53$ arginina (Arg) y prolina (Pro) y se trataron o no (Control) con $10 \mu \mathrm{M}$ de $\beta A 25-35$ o con $100 \mu \mathrm{M}$ de NMDA. Los registros de las concentraciones de $\mathrm{Ca}^{2+}$ citosólico libre se realizaron mediante fluorescencia, utilizando la sonda fluorescente Fura-2, tal y como se describe en Material y Métodos.

Estos resultados demuestran que el SNP Arg72Pro de p53 no parece interferir en la ruta de activación de los receptores NMDA y, en consecuencia, en la subsecuente entrada de $\mathrm{Ca}^{2+}$ en las neuronas.

Nuestro siguiente paso fue analizar el efecto del SNP sobre la activación de Cak5 mediante análisis por transferencia tipo western de la abundancia proteica p35/25 y Cdk5 en ambos genotipos. Así, como se observa en la Figura 16a, los niveles de expresión de Cdk5, así como el grado de conversión de p35 en p25 provocada por la incubación con BA durante 24 horas, fueron similares en las neuronas Arg y Pro. Es más, el incremento en los niveles de p25 se produjo ya desde las 2 horas de tratamiento con el BA de manera similar en ambos genotipos (Figura 16b), lo que descarta diferencias en la activación de la quinasa. 
a

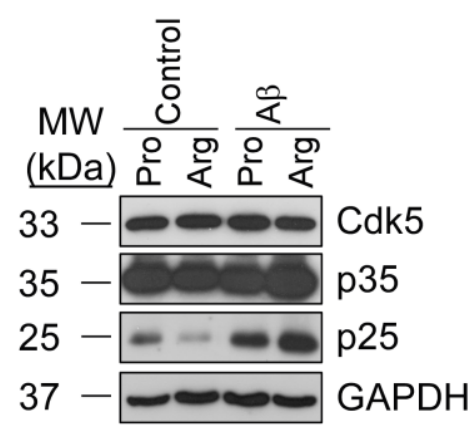

b

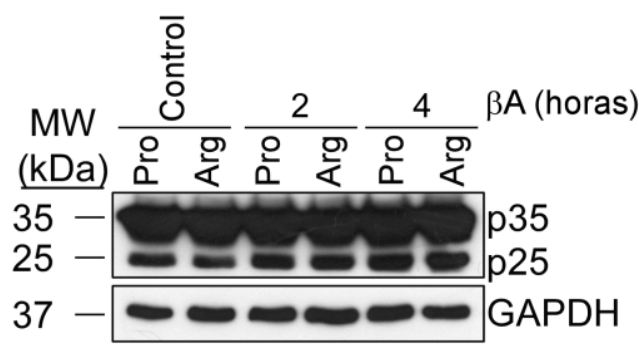

Figura 16. El polimorfismo Arg72Pro de p53 no afectó a la formación de p25 causada por el $B A$ en neuronas. Se realizaron cultivos de neuronas procedentes de ratones knockin de las variantes polimórficas de p53 arginina (Arg) y prolina (Pro) y se trataron o no (Control) con $10 \mu \mathrm{M}$ de $\beta A 25-35$ durante (a) 24 horas o (b) 2 y 4 horas. Se realizaron análisis de transferencia tipo Western de los niveles de expresión de Cdk5, p35 y p25. Se utilizó GAPDH como control de carga.

Seguidamente, decidimos bloquear la vía de estabilización de p53 mediante interferencia en la expresión de Cak5 en ambas variantes del SNP Arg72Pro de p53. Para ello, recurrimos de nuevo a la transfección de las neuronas con el RNA de interferencia contra Cdk5 (100 nM, 72 horas). Como se observa en la Figura 17, el silenciamiento de Cdk5 (siCdk5) en las neuronas previno la despolarización mitocondrial (Figura 17a) y la subsecuente muerte por apoptosis (Figura 17b) causada por el BA en ambas variantes polimórficas. Asimismo, observamos que la ausencia de Cdk5 fue capaz de prevenir tanto la estabilización de p53 como el incremento en los niveles de las dianas transcripcionales pro-apoptóticas de la misma, Bax y PUMA, y la activación de la caspasa 3, causados por el BA en neuronas, independientemente del genotipo (Figura 17c). 
a

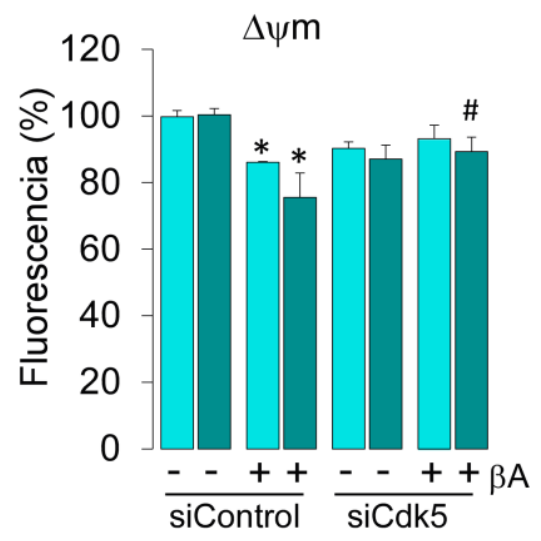

b

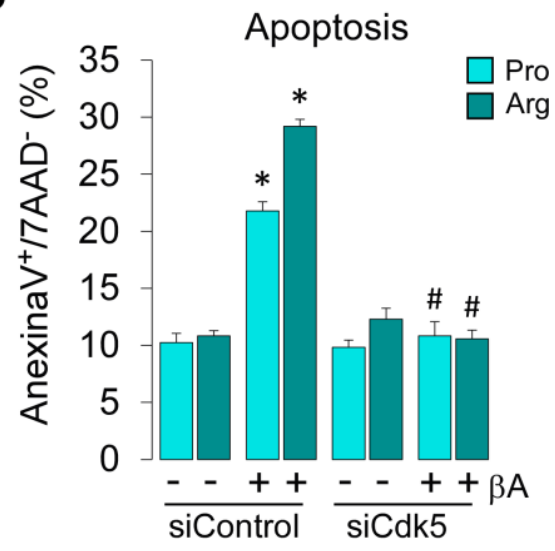

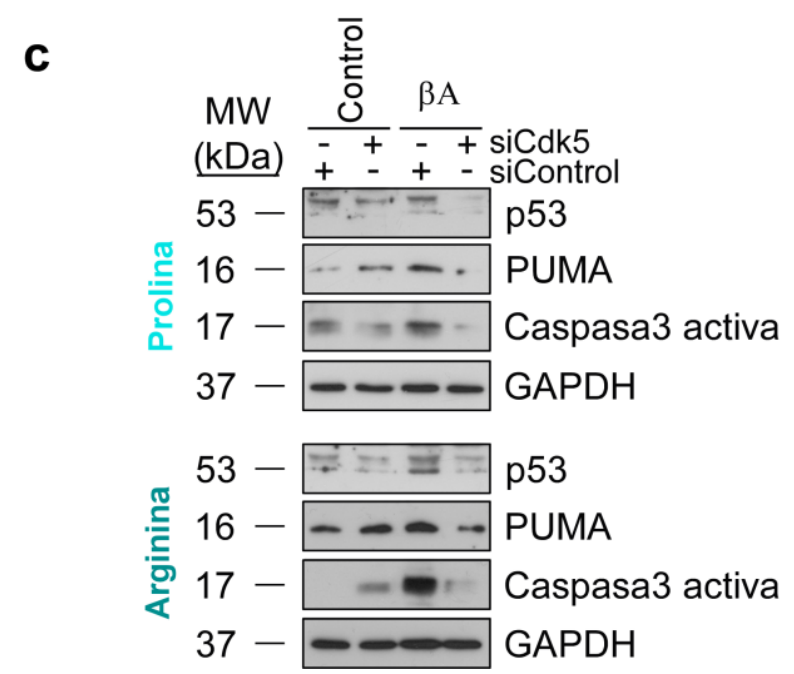

Figura 17. El silenciamiento de Cdk5 es suficiente para evitar la activación de la vía intrínseca o mitocondrial de la apoptosis tanto en neuronas Arg como Pro. Se realizaron cultivos de neuronas procedentes de ratones knockin de las variantes polimórficas de p53 arginina (Arg) y prolina (Pro) y se transfectaron con siRNA contra la luciferasa (siControl; $100 \mathrm{nM}$ ) o Cdk5 (siCdk5; 100 nM). Tras 72 horas de la transfección, las neuronas se trataron o no (Control) con $10 \mu \mathrm{M}$ de $\beta$ A25-35 durante 24 horas. El potencial de membrana mitocondrial (a) y apoptosis (b) se analizaron mediante citometría de flujo, tal y como se describe en Material y Métodos. (c) Se realizaron análisis de transferencia tipo Western de los niveles de expresión de p53, PUMA y caspasa 3 activa. La expresión de GAPDH se utilizó como control de carga. Los datos son medias \pm S.E.M, ${ }^{*} p<0,05$ vs control siControl, $\# p<0,05$ vs tratamiento con $\beta A 25-35$ siControl; (ANOVA post-hoc Bonferroni; $n=3$ cultivos diferentes) 
Por tanto, estos resultados confirman la ruta de señalización descrita en apartados anteriores que implican a la activación de Cak5 y la subsecuente estabilización de p53 como mecanismo responsable de la disfunción mitocondrial y apoptosis neuronal causada por el BA. Es más, esta cascada de señalización es la misma en neuronas que expresan una $u$ otra variante del polimorfismo Arg72Pro de Tp53, de manera que, en ambas, Cdk5 induce la estabilización de p53, lo que descarta que esta vía esté implicada en la diferente susceptibilidad que confiere el SNP frente a la neurotoxicidad del BA.

\section{3.- La actividad transcripcional de p53 no es responsable de la diferente susceptibilidad que confiere el polimorfismo Arg72Pro de Tp53 a las neuronas frente al BA.}

Una vez descartada la vía de estabilización de p53 como la responsable del efecto del SNP sobre la susceptibilidad neuronal al BA, decidimos centrarnos en mecanismos posteriores, como es la posible diferencia en la actividad trasncripcional de ambas variantes polimórficas, Arg y Pro.

Realizamos un estudio de la apoptosis en neuronas tratadas con BA en presencia del conocido inhibidor de la actividad transcripcional de p53, PFT $\alpha$ (Pifithrin $\alpha, 10 \mu \mathrm{M}$ ). Como se muestra en la Figura 18, la inhibición de la actividad transcripcional de p53 previno totalmente la neurotoxicidad del BA en las neuronas Pro, sin embargo dicho efecto no se observó en las neuronas Arg. Por tanto, estos resultados descartan que el incremento en la susceptibilidad de las neuronas al BA que confiere la variante Arg se deba a una mayor actividad transcripcional, respecto a la variante Pro. De acuerdo con estos resultados, previamente hemos descrito que ambas variantes polimórficas poseen la misma actividad transcripcional, al menos en los que se refiere a dianas involucradas en la ruta apoptótica, como son Bax, y PUMA, entre otras (GomezSanchez et al. 2011). 


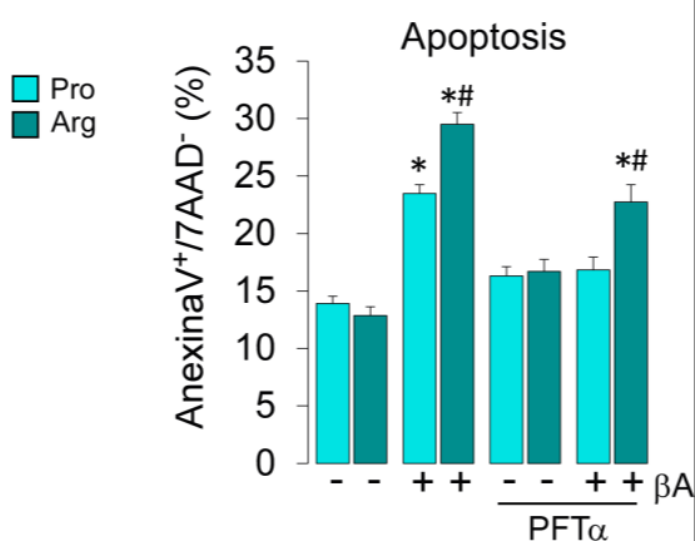

Figura 18. La inhibición de la actividad transcripcional de p53 previene la apoptosis causada por el BA en las neuronas que expresan la variante Pro, pero no en aquellas con la variante Arg. Se realizaron cultivos de neuronas procedentes de ratones knockin de las variantes polimórficas de p53 arginina (Arg) y prolina (Pro) y se trataron o no (Control) con $10 \mu \mathrm{M}$ de $\beta$ A25-35 en presencia de Pifithrin $\alpha$ (PFT $\alpha ; 10$ $\mu \mathrm{M})$, durante 24 horas. La apoptosis neuronal se analizó mediante citometría de flujo, tal y como se describe en Material y Métodos. Los datos son medias \pm S.E.M, ${ }^{*} p<0,05$ vs control; (ANOVA post-hoc Bonferroni; $\mathrm{n}=3$ cultivos independientes).

\subsection{La variante polimórfica Arg de p53 se transloca a la mitocondria, mientras que la variante Pro se sifúa en el núcleo.}

Una vez descartadas la cascada de señalización responsable de la estabilización de p53 y su actividad transcripcional como mecanismos responsables de la diferente susceptibilidad de las neuronas Arg a la neurotoxicidad del BA, nuestro siguiente objetivo fue investigar la posible diferente localización subcelular de las variantes polimórficas. En este sentido, se ha descrito que p53 tiene una función directa en la apoptosis mitocondrial, de manera que una fracción de p53 estabilizado por un estrés se transloca rápidamente a la membrana externa mitocondrial (Marchenko et al. 2000; Gomez-Sanchez et al. 2011). Es más, nuestro grupo ha demostrado que la variante Arg de p53 interacciona con Bcl-xL, lo que provoca un daño mitocondrial en neuronas tras un insulto isquémico (Gomez-Sanchez et al. 2011). Por ello, finalmente decidimos analizar la localización subcelular de las variantes Arg y Pro en neuronas ras el tratamiento con el BA. Como primera aproximación experimental, mediante centrifugación diferencial obtuvimos la fracción 
mitocondrial y analizamos la acumulación de p53 mediante transferencia tipo Western. Como se muestra en la Figura 19a, el tratamiento con BA provocó la acumulación de p53 en las neuronas que expresan la variante Arg, pero no en aquellas con la variante Pro. Estos resultados se corroboraron mediante inmunocitoquímica. Para ello, las neuronas tratadas con BA25-35 (10 $\mu \mathrm{M})$ se incubaron con una sonda que detecta específicamente las mitocondrias (Cytopainter mitocondrial staining kit Green) y se realizaron inmunocitoquímicas para detectar p53. Como se observa en la Figura 19b, mientras que en las neuronas Pro p53 se encuentra fundamentalmente en el núcleo, en las neuronas Arg se observa que una fracción importante de p53 se sitúa en las mitocondrias. 
a

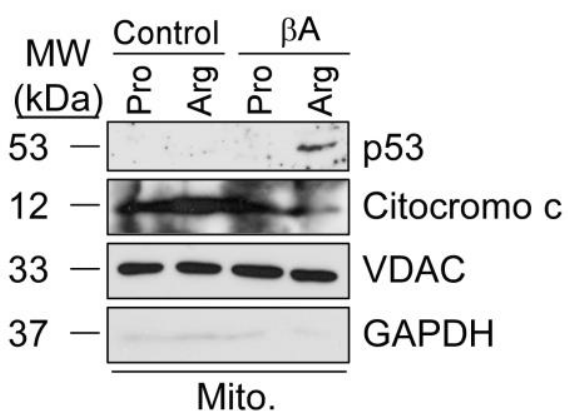

b

Control
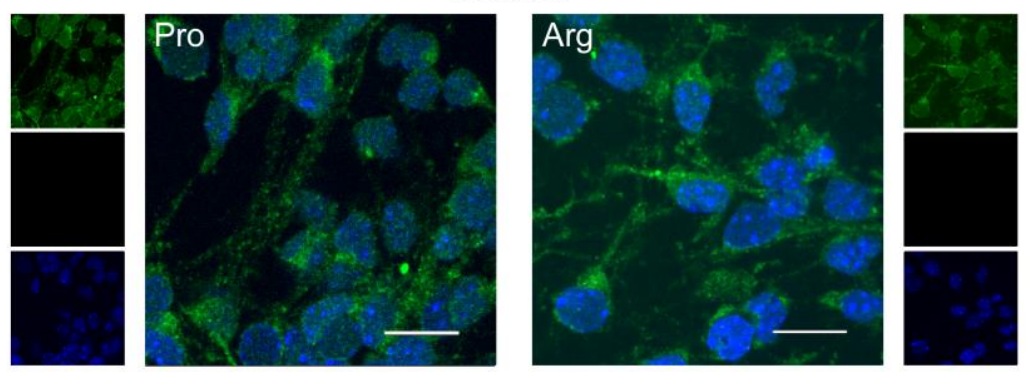

Tratamiento
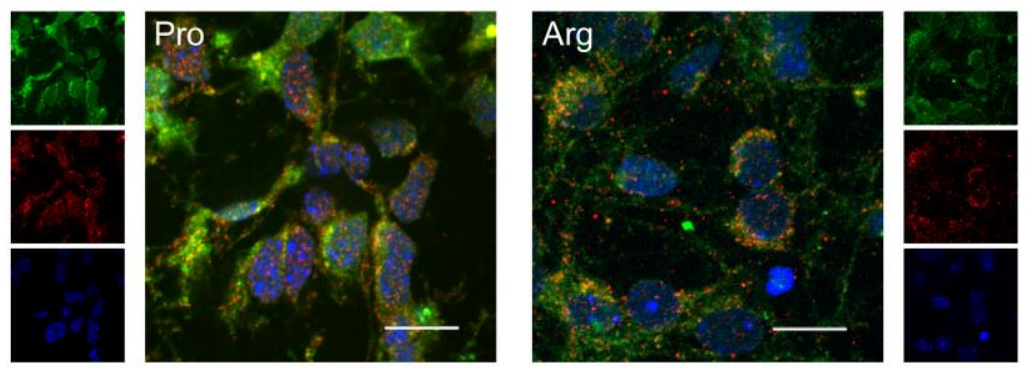

Figura 19. La variante Arg de p53 se acumula en la mitocondria tras el tratamiento de las neuronas con $\beta A$. Se realizaron cultivos de neuronas procedentes de ratones knockin de las variantes polimórficas de p53 arginina (Arg) y prolina (Pro) y se trataron o no (Control) con $10 \mu \mathrm{M}$ de $\beta A 25-35$. (a) Mediante fraccionamiento subcelular, se aislaron las fracciones mitocondriales y se analizaró la acumulación de p53 mediante transferencia tipo Western. Se utilizó VDAC como marcador de carga mitocondrial y GAPDH como marcador de contaminación citosólica. (b) Mediante inmunofluorescencia se detectó la localización de p53 (rojo) en las neuronas. Se empleó la sonda mitocondrial Cytopainter (verde) y Dapi como marcador nuclear (azul). Barra $=20 \mu \mathrm{M}$.

Estos resultados demuestran que la localización mitocondrial de la variante polimórfica Arg puede ser la responsable de la mayor susceptibilidad 
que confiere frente al BA. Así, la interacción de la variante Arg de p53 con la mitocondria, a través de BCl-XL (Gomez-Sanchez et al. 2011), induce la rápida despolarización mitocondrial,, hecho que es responsable de la alta susceptibilidad de las neuronas a la apoptosis inducida por el BA (Esquema 2).

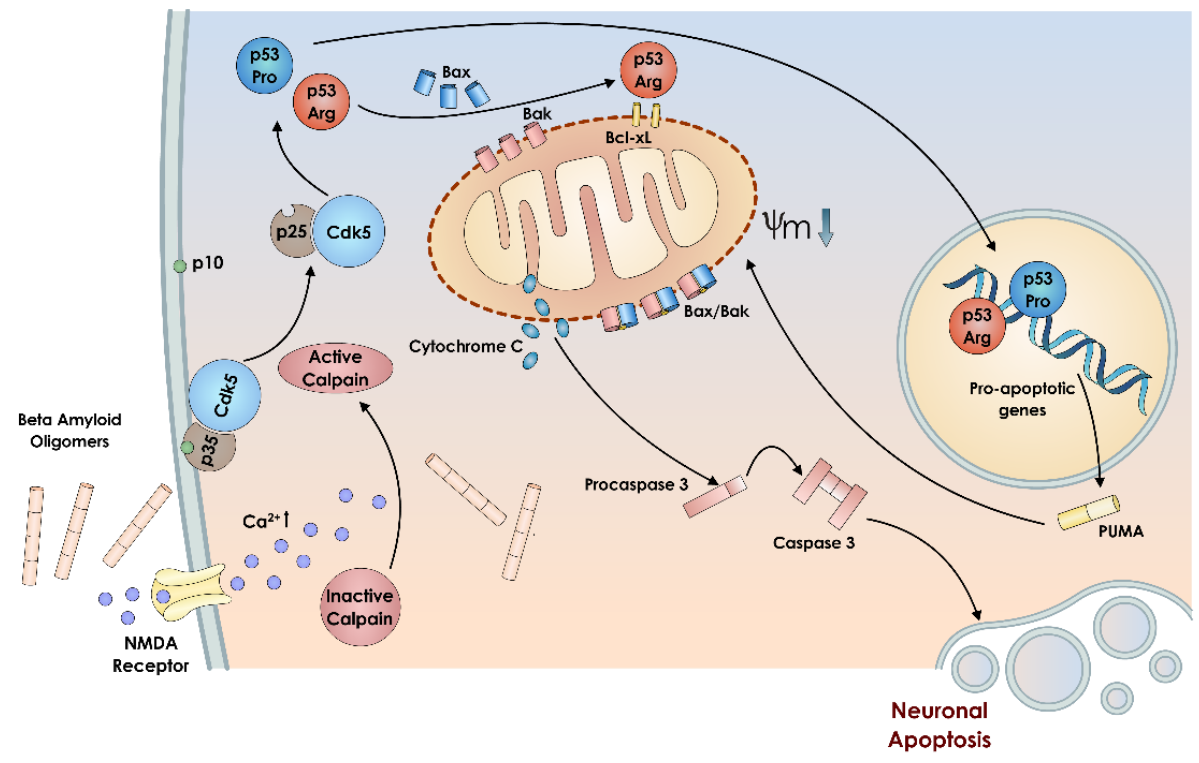

Esquema 2. La variante polimórfica p53Arg incrementa la susceptibilidad neuronal a la toxicidad del $\beta A$, fundamentalmente, por su acumulación en la mitocondria. En ambas variantes del polimorfismo Arg72Pro de Tp53, el $\beta A$ estimula receptores NMDA, lo que conlleva entrada de $\mathrm{Ca}^{2+}$ en la neurona. La hiperactivación de CDK5 por conversión de p35 en p25 media la estabilización de p53. Sin embargo, la variante p53Arg se acumula rápidamente en la mitocondria, de manera que aumenta la susceptibilidad neuronal al daño mitocondrial y la muerte por apoptosis provocada por el $\beta$ A.

\section{4.- INFLUENCIA DE LOS DISTINTOS ALELOS DE LA APOLIPOPROTEINA E (ApoE) SOBRE EL POLIMORFISMO Tp53 Arg72Pro.}

Los distintos alelos de la Apolipoproteína E (ApoE), E2, E3 y E4, influyen altamente en el riesgo de padecer EA. De hecho, la variabilidad genética del polimorfismo de ApoE constituye el factor más importante asociado a la predisposición de la EA Así, mientras que a la isoforma E2 se le atribuye un papel protector, la presencia de la isoforma E4 incrementa potentemente el riesgo de 
sufrir EA, a la vez que disminuye la edad de comienzo de la enfermedad (Corder et al. 1993; C.-C. Liv et al. 2013).

Para analizar el efecto del polimorfismo de ApoE4 sobre las diferencias observadas en la susceptibilidad al BA entre las variantes polimórficas Arg y Pro, procedimos a co-transfectar neuronas corticales primarias de ambas variantes polimórficas de p53 con cada una de las tres isoformas de la ApoE junto con GFP, de manera que nos permitiera seleccionar la población de neuronas transfectadas $\left(\mathrm{GFP}^{+}\right)$con éxito. Mediante citometría de flujo analizamos el potencial de membrana mitocondrial y la apoptosis neuronal tras el tratamiento con BA. Como se observa en la Figura 20a, el BA reduce el potencial de membrana mitocondrial en las neuronas que expresan las isoformas ApoE3 y ApoE4, pero no en las ApoE2. De la misma manera, el BA indujo la apoptosis en neuronas de todos los genotipos, si bien la función neurotóxica del péptido resultó ser menor en las neuronas que expresaron la isoforma E2, lo que es compatible con el efecto neuroprotector de la misma (C.-C. Liu et al. 2013).

Cabe destacar que mientras que en las neuronas que expresan ApoE3 se mantuvo el efecto del polimorfismo de Arg72Pro de Tp53 sobre la despolarización mitocondrial (Figura 20a) y la apoptosis (Figura 20b) causados por el BA, dicho efecto no se observó en las neuronas que expresaban la isoforma ApoE4. Así, la expresión de la ApoE4 en las neuronas previno la diferente susceptibilidad de las neuronas al BA que confiere la variante polimórfica Arg (Figura 20). 
a

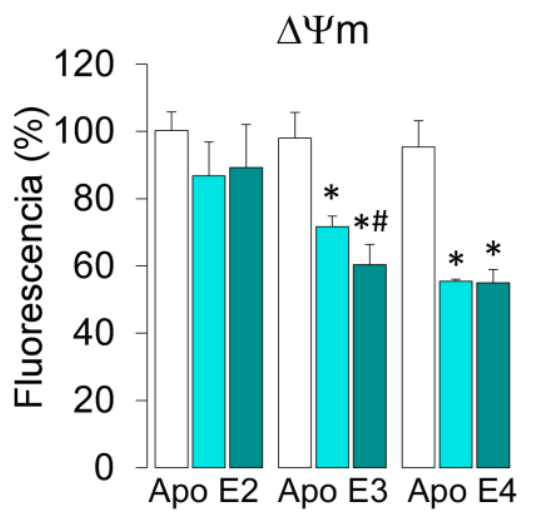

b

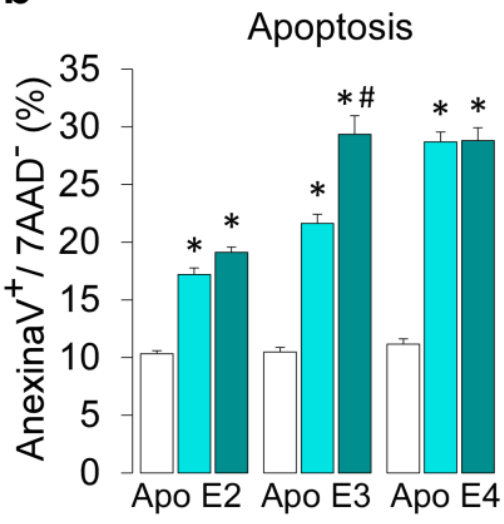

$\square$ Control $\square$ Pro $+\beta A \square$ Arg $+\beta A$

Figura 20. La presencia del alelo $\varepsilon 4$ de la ApoE anula el efecto del polimorfismo Arg72 Pro de Tp53 sobre la neurotoxicidad del BA. Se realizaron cultivos de neuronas procedentes de ratones knockin de las variantes polimórficas de p53 arginina (Arg) y prolina (Pro) y se co-transfectaron con plásmidos que expresan las variantes polimórficas de $\operatorname{ApoE}(\varepsilon 2, \varepsilon 3$ y $\varepsilon 4)$ y el plásmido que expresa GFP, durante 48 horas. El potencial de membrana mitocondrial (a) y apoptosis (b) se analizaron mediante citometría de flujo en las neuronas transfectadas (GFP+), tal y como se describe en Material y Métodos. Los datos son medias \pm S.E.M, ${ }^{*} p<0,05$ vs control; (ANOVA post-hoc Bonferroni; $\mathrm{n}=3$ cultivos independientes).

Nuestros resultados demuestran que la presencia del alelo 2 de la ApoE ejerce un efecto neuroprotector frente a la toxicidad del BA con independencia del genotipo de p53 que se posea. Sin embargo, la presencia del alelo 4 de la ApoE elimina las diferencias entre las variantes polimórficas Arg y Pro, de manera que la vulnerabilidad al daño inducido por el BA en neuronas Pro alcanza los mismos niveles que en neuronas Arg. 


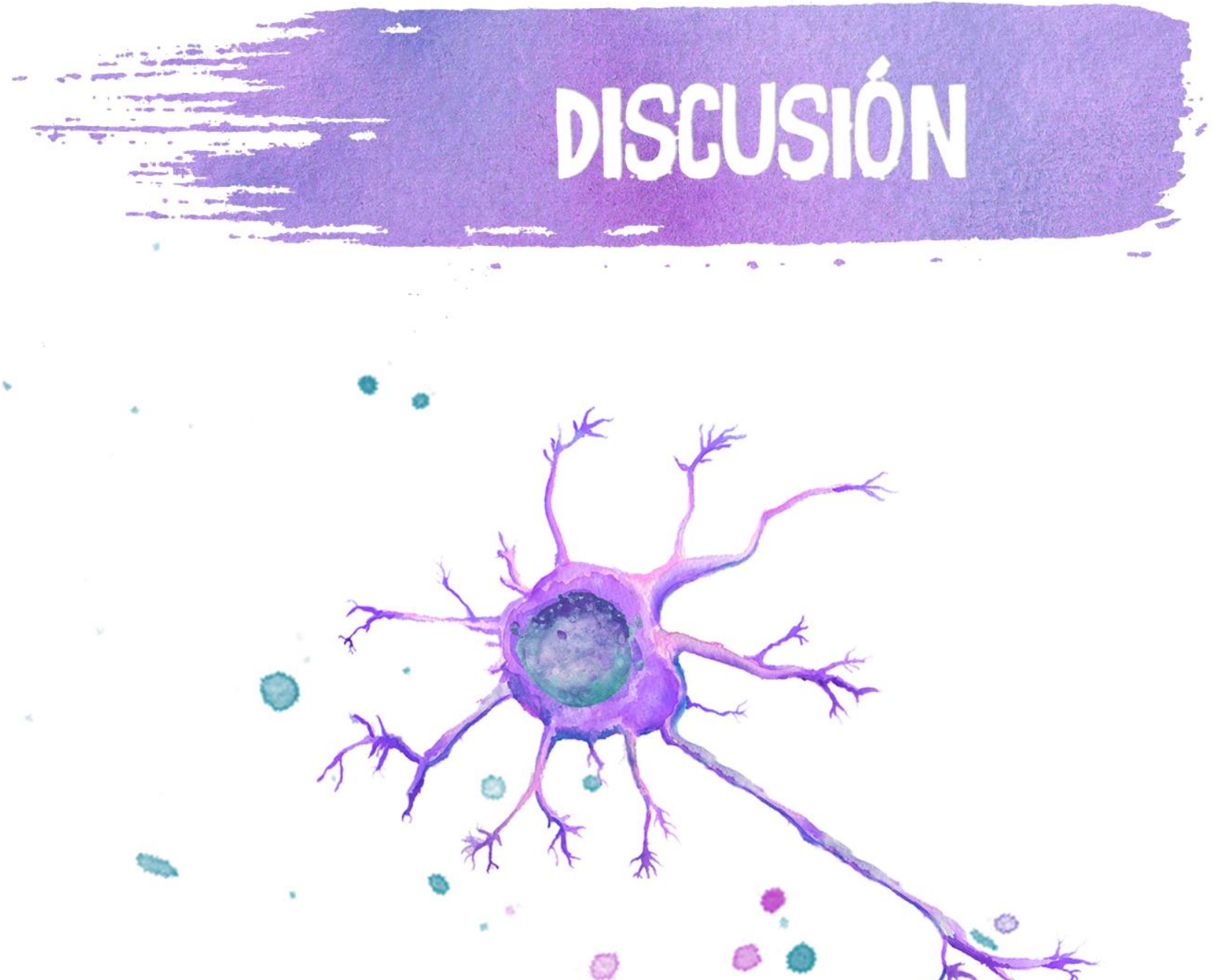

La EA es una enfermedad compleja y multifactorial en la que los eventos fundamentales asociados a la misma se han relacionado, entre otros, con los depósitos de BA (Serrano-Pozo et al. 2011; Ittner \& Götz 2011). Así, los oligómeros de BA desencadenan cascadas de señalización que implican, entre otros, la alteración de la homeostasis del calcio, producción de especies reactivas de oxígeno, procesos inflamatorios y disfunción mitocondrial, culminando todo ello en la apoptosis neuronal (Haass \& Selkoe 2007; Sakono \& Zako 2010; Kayed \& Lasagna-Reeves 2012). El conocimiento de los mecanismos moleculares que median la neurodegeneración asociada a esta enfermedad es esencial para establecer nuevas vías de actuación terapéutica que permitan paliar la pérdida neuronal y, por tanto, el deterioro cognitivo en la EA (Tarawneh \& Galvin 2010; Huang \& Mucke 2013; Hong-Qi et al. 2012). A la hora de estudiar los mecanismos moleculares implicados en la enfermedad, existen diversos modelos in vitro que persiguen mimetizar los efectos del BA y de Tau en esta patología (Calissano et al. 2009). Pese a que existen diversas teorías que pretenden explicar los mecanismos fisiopatológicos responsables de la EA, la hipótesis más aceptada actualmente es la Hipótesis de la cascada amiloide (Hardy \& Higgins 1992; Hardy \& Selkoe 2002; Selkoe \& Hardy 2016). De acuerdo con esta hipótesis, la presencia de BA es un factor desencadenante de los eventos moleculares responsables de la EA, que afecta posteriormente al metabolismo de Tau (Hardy \& Selkoe 2002; Choi et al. 2014). Para estudiar los mecanismos moleculares que median la neurotoxicidad del BA, aún por establecer, hemos utilizado un sistema in vitro de estimulación de neuronas corticales en cultivo primario con el fragmento 25-35 del BA, considerado el dominio biológicamente activo del péptido amiloide completo (Stepanichev et al. 2006; Stepanichev et al. 2003; Stepanichev MYu et al. 1998; Stepanichev et al. 2005; Limón et al. 2009). Este sistema nos ha permitido establecer que el BA induce la activación de la quinasa Cdk5, lo que provoca la estabilización de p53 y, en consecuencia, la despolarización mitochondrial y la subsecuente muerte neuronal por apoptosis.

Está descrito que el daño mitocondrial es un evento temprano en la EA que, además, está estrechamente relacionado con la neurodegeneración (Schmitt et al. 2012; Moreira et al. 2010; Eckert, Keil, et al. 2003). De hecho, el BA es una potente toxina mitocondrial que afecta de forma dramática al pool mitocondrial sináptico (Mungarro-Menchaca et al. 2002), de manera que es 
capaz de alterar la mayoría de funciones mitocondriales (Mungarro-Menchaca et al. 2002; Chen \& Yan 2007; Bolaños et al. 2009). Resultados previos del grupo han puesto de manifiesto que el mantenimiento del potencial de membrana mitocondrial es esencial para la supervivencia neuronal (García et al. 2005; Veas-Pérez de Tudela et al. 2015; Delgado-Esteban et al. 2000; Almeida \& Bolaños 2001). En este sentido, hemos observado que el daño mitocondrial precede a la apoptosis neuronal causada por el BA, de manera que la despolarización mitocondrial es causa, y no consecuencia, del proceso apoptótico.

Una de las vías mejor caracterizadas que desencadenan la muerte neuronal como consecuencia de la disfunción mitocondrial es la apoptosis dependiente de p53. En condiciones de estrés celular, p53 ejerce sus funciones neurotóxicas actuando tanto como factor de transcripción, induciendo o reprimiendo la transcripción de mediadores pro- o anti-apoptóticos (Bieging \& Attardi 2012; Riley et al. 2008), como de forma directa mediante su interacción con la mitocondria (Vaseva \& Moll 2009; Green \& Kroemer 2009; GomezSanchez et al. 2011). De hecho, trabajos anteriores de nuestro grupo han demostrado que p53 interacciona con la proteína anti-apoptótica Bcl-xL, secuestrándola e provocando la apoptosis neuronal tras un insulto isquémico (Gomez-Sanchez et al. 2011). En el presente trabajo demostramos que la neurotoxicidad del BA está mediada por p53, de manera que la estabilización de p53 induce la despolarización mitocondrial y, en consecuencia, la muerte neuronal por apoptosis. Esto concuerda con estudios previos en los que se ha observado una relación entre los niveles de p53 y la muerte neuronal tanto en cerebros de pacientes con EA (Sajan et al. 2007; Morrison \& Kinoshita 2000) como en modelos animales (Morrison \& Kinoshita 2000) y en neuronas primarias humanas (Y. Zhang et al. 2002). Sin embargo, Blasko et al han descrito en un modelo de neurotoxicidad en queratinocitos humanos que la toxicidad del BA es independiente de p53, por lo que parece que la relación entre p53 y la apoptosis podría ser dependiente del tipo celular.

De todas las modificaciones post-traduccionales implicadas en la estabilización de la proteína p53, la fosforilación en la Ser-15 (Ser-18 en el ratón) es la mejor caracterizada. Dicha fosforilación se lleva a cabo por la quinasa Cdk5, bien de manera directa (Lee et al. 2007) o indirecta a través de ATM (Saito 
et al. 2002). Además, se ha establecido una relación entre CDK5 y la apoptosis neuronal en la EA (Liu et al. 2015). Así, se han observado acumulaciones de p25, cofactor activador de CDK5, en zonas cerebrales dañadas de pacientes con EA, lo que ha permitido relacionar la activación de CDK5 con la neurodegeneración en estos pacientes (Tseng et al. 2002; Lee et al. 2007). Nuestros resultados demuestran que Cdk5 es la responsable de la estabilización de p53, de manera que la ausencia de la quinasa previene el daño mitocondrial y la neurodegeneración causadas por el BA. Trabajos previos del grupo han demostrado que la activación de receptores de NMDA implica una hiperactivación de la quinasa CDK5 por conversión de su cofactor p35 en la forma truncada p25 (Maestre et al. 2008). Bajo nuestras condiciones experimentales, el BA induce la entrada de $\mathrm{Ca}^{2+}$ a través de los receptores NMDA, que es suficiente para activar a las calpaínas responsables de la proteólisis de p35 a p25 (Maestre et al. 2008). Nuestros datos muestran, además, que esta conversión de p35 a p25 es anterior a la estabilización de p53. Estos datos, junto con el hecho de que la ausencia de Cak5 previene la estabilización de p53, demuestran que esta está mediada por el complejo CDK5-p25. Sin embargo, nuestros datos no arrojan luz a la manera en que CDK5 estabiliza p53, ya que puede hacerlo por fosforilación directa o bien a través de ATM (Lee et al. 2007; Tian et al. 2009). En cualquier caso, la ausencia de Cdk5 previene el daño mitocondrial y la apoptosis neuronal causada por el BA mediante un mecanismo que implica la acumulación de p53 en las neuronas. Por tanto, nuestros resultados posicionan a la quinasa Cdk5 y la proteína p53 como elementos clave en la patogénesis de la EA y, por tanto, como potenciales dianas moleculares para el establecimiento de nuevas vías de actuación terapéutica en la EA.

El polimorfismo Arg72Pro en el codón 72 de Tp53 consiste en la sustitución de una guanina (CGC, que codifica prolina) por una citosina (CCC, que codifica arginina). Este cambio condiciona que se sintetice la variante polimórfica que contiene prolina (p53-Pro) o bien la que contiene arginina (p53Arg), dentro del dominio rico en prolina que es esencial para la actividad apoptótica de la proteína (Thomas et al. 1999; Dumont et al. 2003; Bonafé et al. 2004; Gomez-Sanchez et al. 2011). Así, se ha descrito que la variante Arg de p53 tiene una capacidad de inducir apoptosis en superior a la variante p53-Pro (Gomez-Sanchez et al. 2011; Bonafé et al. 2004), lo que relaciona al 
polimorfismo Arg72Pro con la resistencia al desarrollo neoplásico. Además, el polimorfismo regula la susceptibilidad de las neuronas a la muerte excitotóxica. En el presente trabajo, demostramos que el SNP Arg72Pro de Tp53 determina la neurotoxicidad del BA, siendo la variante Arg más susceptible a la misma. El trabajo de Jeong et al. atribuye a la variante Arg una mayor capacidad para transcribir, entre otros, genes pro-apoptóticos como PUMA (Jeong et al. 2010). Sin embargo, otros grupos han descrito que dicho efecto es independiente de la actividad transcripcional de la proteína (Bonafé et al. 2004; Gomez-Sanchez et al. 2011). Nuestros datos están de acuerdo con esta última tendencia y demuestran que la modulación de la actividad apoptótica que ejerce el SNP no está relacionada con diferencias en la actividad transcripcional entre las variantes polimórficas. De hecho, la neurotoxicidad del BA se previene totalmente al inhibir la actividad transcripcional de p53 con PFT en neuronas que expresan la variante Pro, pero no en aquellas con la variante Arg. Existen trabajos que describen que la mayor capacidad pro-apoptótica característica de la variante arginina (Thomas et al. 1999) se debe a la interacción de p53 con la mitocondria (Dumont et al. 2003; Gomez-Sanchez et al. 2011). En este sentido, la mayor vulnerabilidad al BA que describimos en la variante Arg se debe, al menos en parte, a su mayor capacidad para acumular p53 en la mitocondria, respecto de la variante Pro que se acumula fundamentalmente en el núcleo. Estos resultados refuerzan nuestra idea de que la alteración de la homeostasis mitocondrial por interferencia con p53 tras su estabilización, es la responsable de la neurodegeneración asociada al BA.

La diferente susceptibilidad de las neuronas a la apoptosis que confiere el SNP tiene relevancia en pacientes de distintas patologías, como son el ictus (Gomez-Sanchez et al. 2011) y el glaucoma primario de ángulo abierto (Neamatzadeh et al. 2015). Si bien nuestros resultados en neuronas in vitro parecen sugerir que el SNP Arg72Pro podría condicionar el riesgo y/o la progresión de la EA, los escasos estudios que hay en la literatura difieren en sus conclusiones. Hasta el momento, se han descrito dos trabajos que demuestran una débil asociación entre el polimorfismo Arg72Pro de Tp53 y el riesgo de padecer EA en una cohorte de judíos (Rosenmann et al. 2003) y de italianos (Scacchi et al. 2009). Sin embargo, es necesario que se realicen nuevos trabajos para establecer el posible efecto del SNP en pacientes de la EA, especialmente en relación a la progresión del deterioro cognitivo, que es un proceso ligado a 
la neurodegeneración (Masliah et al. 1989; Masliah et al. 1991; Terry et al. 1991; Serrano-Pozo et al. 2011; Koffie et al. 2011).

Finalmente, en el presente trabajo investigamos la influencia de los distintos alelos de la ApoE sobre el SNP Arg72Pro de Tp53. La ApoE, principal apolipoproteína en el tejido cerebral (Bu 2009), existe como tres isoformas proteicas distintas: ApoE2, ApoE3 y ApoE4 (Mahley et al. 2006). Hasta el momento, la única variante génica considerada como un factor de riesgo establecido para LOAD es el alelo 4 del gen de la apolipoproteina E (APOE) (Strittmatter et al., 1990). Nuestros datos demuestran que la variante ApoE4 neutraliza las diferencias observadas entre las variantes polimórficas Arg y Pro de p53 en cuanto a la susceptibilidad a la neurotoxicidad del BA, mientras que la mayor susceptibilidad de la variante Arg se mantiene en presencia de los alelos 2 y 3 de la ApoE. Este resultado es muy interesante, dado que la mayoría de la población carece del alelo 4 de la ApoE (Robert W. Mahley \& Huang 2012). Por ello, cobra importancia el análisis del SNP Arg72Pro de Tp53 entre los pacientes con EA que son ApoE4 negativos. De esta manera, el SNP humano Arg72Pro de Tp53 se posiciona como un posible biomarcador de riesgo y/o pronóstico de la EA, al menos en los pacientes que no portan el alelo ApoE4. Es más, nuestros datos deben tenerse en cuenta para establecer posibles nuevos biomarcadores de riesgo y/o pronótico en la EA, complementando el efecto de los polimorfismos de ApoE ya descritos. 


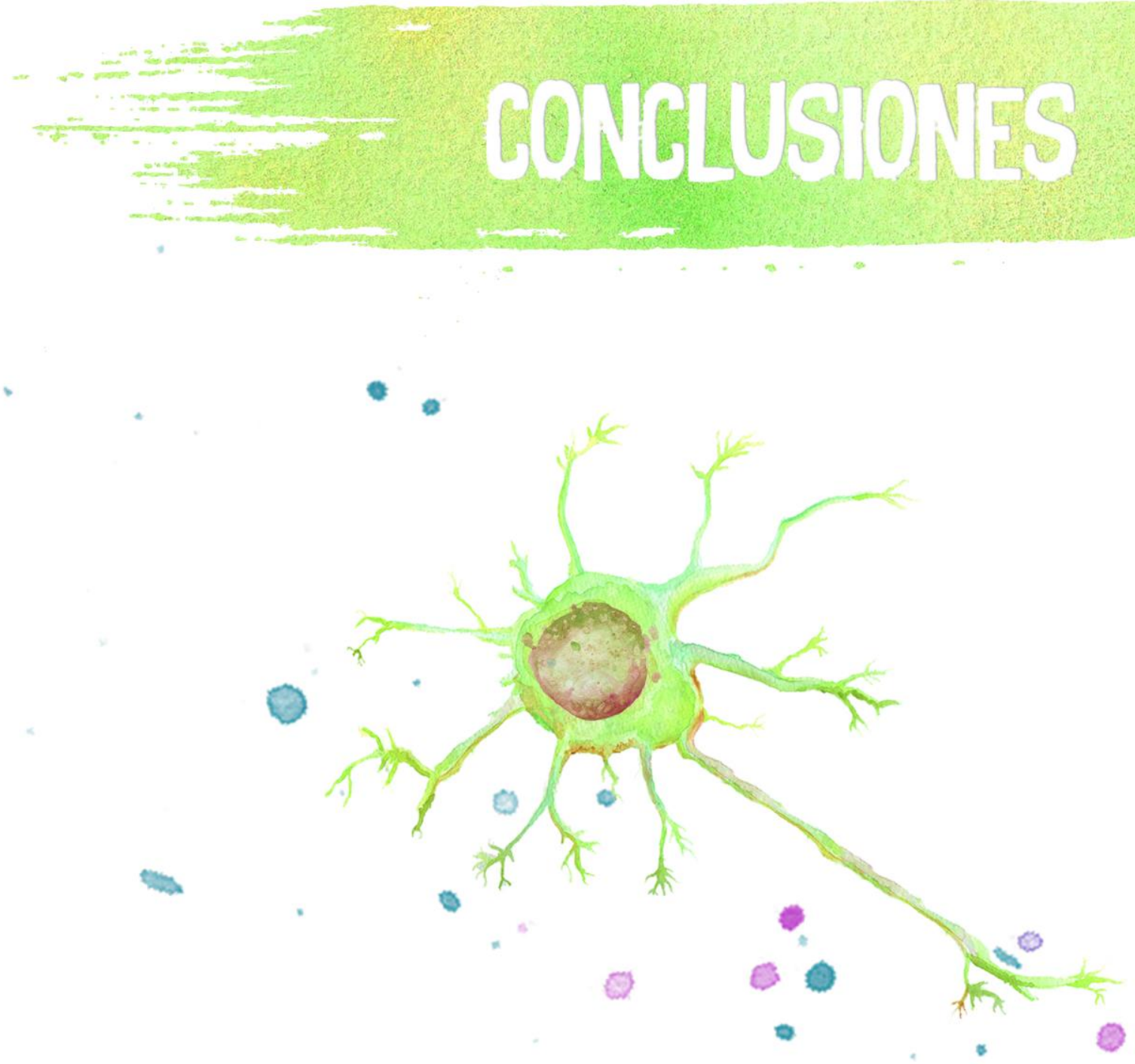

A la luz de los resultados obtenidos en esta Tesis Doctoral, hemos obtenido las siguientes conclusiones:

1.- El B-amiloide induce la estabilización de p53 en las neuronas, que, por interacción con la mitocondria, provoca la despolarización de la membrana interna mitocondrial, y, posteriormente, desencadena la apoptosis neuronal. Por tanto, p53 está implicada en la neurotoxicidad del B-amiloide.

2.- La quinasa responsable de la fosforilación y estabilización de p53, en respuesta al tratamiento con $\mathrm{BA}$, es la proteína quinasa dependiente de ciclina5 (Cdk5). Así, el $\beta$-amiloide, a través de la activación de los receptores NMDA y la subsiguiente entrada de $\mathrm{Ca}^{2+}$ en la neurona, provoca la la hiperactivación de Cdk5 por conversión del complejo Cdk5-p35 en Cdk5-p25, lo que culmina en la estabilización de p53, el daño mitocondrial y la apoptosis neuronal.

3.- El polimorfismo humano en el exón 4, codón 72 del gen Tp53 condiciona la susceptibilidad de las neuronas a la neurotoxicidad del Bamiloide. Así, la variante polimórfica Arg de p53 promueve su localización en la mitocondria, lo que desencadena un daño mitocondrial en la neurona, incrementando la susceptibilidad a la neurotoxicidad causada por el Bamiloide.

4.- La presencia del alelo E4 de la apoplipoproteína E abroga las diferencias entre las dos variantes prolimórficas Arg72Pro de Tp53, Prolina y Arginina en cuanto a la susceptibilidad a la neurotoxicidad del B-amiloide, mientras que la mayor vulnerabilidad de la variante Arg se mantiene en presencia de los alelos 2 y 3 de la ApoE. 


\section{Conclusión final}

Los resultados de la presente Memoria demuestran que el B-amiloide activa la quinasa dependiente de ciclina-5 lo que promueve la estabilización de p53 y, en consecuencia, la disfunción mitocondrial y la apoptosis neuronal. Así, hemos identificado a la quinasa Cdk5 y la proteína p53 como elementos clave en la patogénesis de la EA y, por tanto, como potenciales dianas moleculares para el establecimiento de nuevas vías de actuación terapéutica en la enfermedad de Alzheimer. Es más, el polimorfismo Arg72Pro de Tp53 modula la susceptibilidad de las neuronas a la neurotoxicidad del B-amiloide, convirtiéndolo en un posible biomarcador genético de riesgo y/o pronóstico de la enfermedad de Alzheimer, al menos en los pacientes que portan el alelo E2 y E3 de la apoplipoproteína E. 

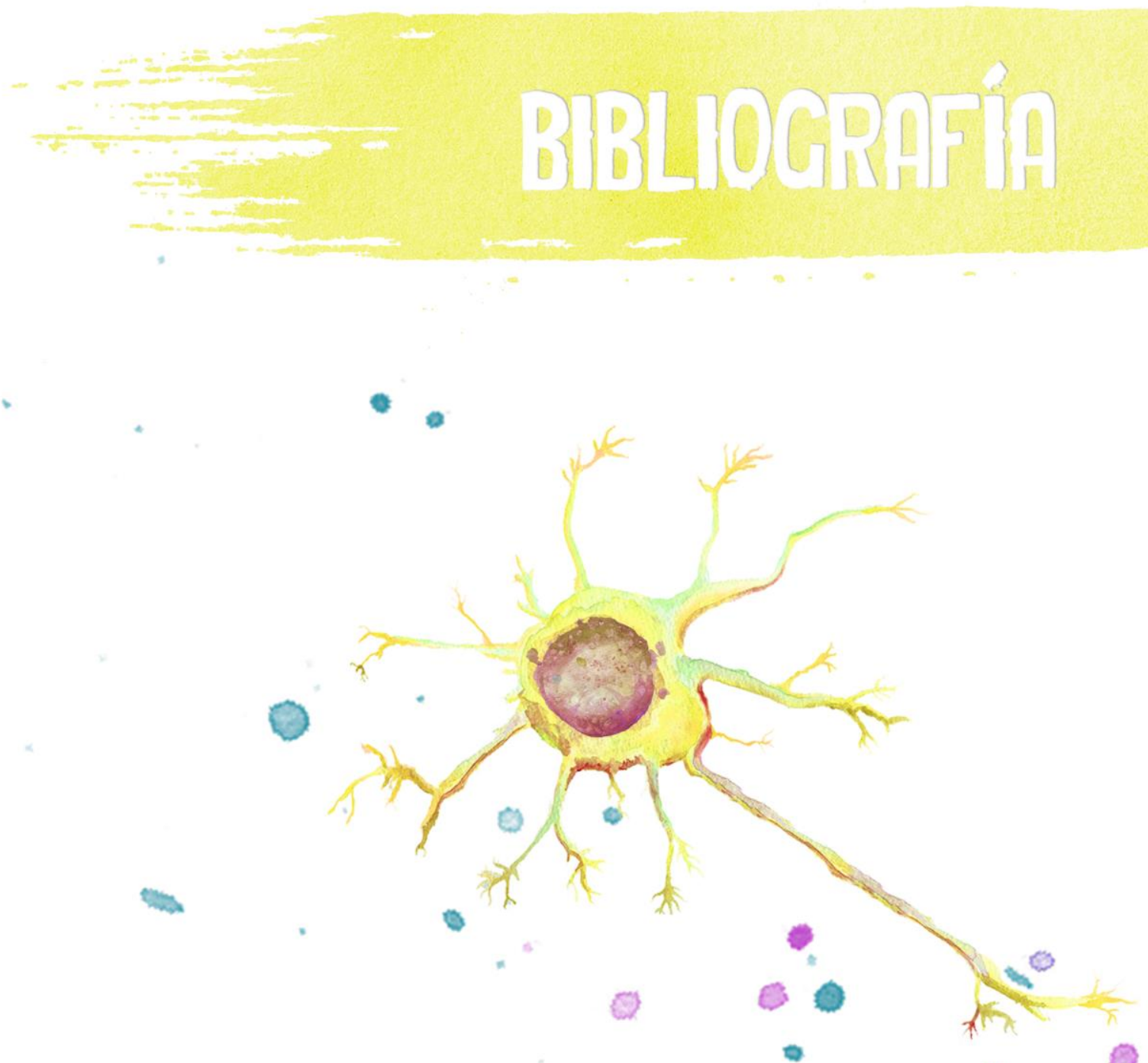

Allinson, T.M.J. et al., 2003. ADAMs family members as amyloid precursor protein alphasecretases. Journal of neuroscience research, 74(3), pp.342-352.

Almeida, A., 2013. Genetic determinants of neuronal vulnerability to apoptosis. Cellular and Molecular Life Sciences, 70(1), pp.71-88.

Almeida, A., Bolaños, J.P. \& Moreno, S., 2005. Cdh1/Hct1-APC is essential for the survival of postmitotic neurons. The Journal of neuroscience : the official journal of the Society for Neuroscience, 25(36), pp.8115-8121.

Almeida, A. \& Medina, J.M., 1998. A rapid method for the isolation of metabolically active mitochondria from rat neurons and astrocytes in primary culture. Brain research. Brain research protocols, 2(3), pp.209-14.

Almeida, A., Moncada, S. \& Bolaños, J.P., 2004. Nitric oxide switches on glycolysis through the AMP protein kinase and 6-phosphofructo-2-kinase pathway. Nature cell biology, 6(1), pp.45-51.

Almeida, a \& Bolaños, J.P., 2001. A transient inhibition of mitochondrial ATP synthesis by nitric oxide synthase activation triggered apoptosis in primary cortical neurons. Journal of neurochemistry, 77(2), pp.676-90.

Alves da Costa, C. et al., 2006. Presenilin-dependent gamma-secretase-mediated control of p53-associated cell death in Alzheimer's disease. J Neurosci, 26(23), pp.63776385.

Alzheimer, A., 1907. Uber eine eigenartige Erkrankung der Hirninde. Allg Zeits Psychiatry Psychisch Y Gerichtlich Med, 64, pp.146-8.

Amin, N.D., Albers, W. \& Pant, H.C., 2002. Cyclin-dependent kinase 5 (cdk5) activation requires interaction with three domains of p35. Journal of Neuroscience Research, 67(3), pp.354-362.

Anand, R., Gill, K.D. \& Mahdi, A.A., 2014. Therapeutics of Alzheimer's disease: Past, present and future. Neuropharmacology, 76(PART A), pp.27-50.

Appella, E. \& Anderson, C.W., 2001. Post-translational modifications and activation of p53 by genotoxic stresses. European Journal of Biochemistry, 268(10), pp.2764-2772.

Arima, Y. et al., 2005. Transcriptional blockade induces p53-dependent apoptosis associated with translocation of p53 to mitochondria. Journal of Biological Chemistry, 280(19), pp.19166-19176.

Arispe, N., 2004. Architecture of the Alzheimer's A beta P ion channel pore. The Journal of membrane biology, 197(1), pp.33-48.

Armstrong, R.A., 1998. ??-amyloid plaques: Stages in life history or independent origin? Dementia and Geriatric Cognitive Disorders, 9(4), pp.227-238.

Armstrong, R. a., 2006. Plaques and tangles and the pathogenesis of Alzheimer's disease. Folia Neuropathologica, 44(1), pp.1-11.

Arundine, M. \& Tymianski, M., 2003. Molecular mechanisms of calcium-dependent neurodegeneration in excitotoxicity. Cell Calcium, 34(4-5), pp.325-337.

Asada, A. et al., 2008. Myristoylation of p39 and p35 is a determinant of cytoplasmic or 
nuclear localization of active cycline-dependent kinase 5 complexes. Journal of Neurochemistry, 106(3), pp.1325-1336.

Atwood, C.S. et al., 2002. Senile plaque composition and posttranslational modification of amyloid-?? peptide and associated proteins. Peptides, 23(7), pp.1343-1350.

Bayer, T.A. \& Wirths, O., 2010. Intracellular accumulation of amyloid-Beta-a predictor for synaptic dysfunction and neuron loss in Alzheimer's disease. Frontiers in aging neuroscience, 2(March), p.8.

Bayer, T. a et al., 1999. It all sticks together--the APP-related family of proteins and Alzheimer's disease. Molecular psychiatry, 4(6), pp.524-528.

Beckman, G. et al., 1994. Is p53 polymorphism maintained by natural selection? Hum Hered, 44(5), pp.266-270.

Bekris, L.M. et al., 2010. Review Article: Genetics of Alzheimer Disease. Journal of Geriatric Psychiatry and Neurology, 23(4), pp.213-227.

Berridge, M.J., 1998. Neuronal calcium signaling. Neuron, 21 (1), pp.13-26.

Bettens, K., Sleegers, K. \& Van Broeckhoven, C., 2013. Genetic insights in Alzheimer's disease. The Lancet Neurology, 12(1), pp.92-104.

Beyreuther, K. \& Masters, C.L., 1991. Amyloid precursor protein (APP) and beta A4 amyloid in the etiology of Alzheimer's disease: precursor-product relationships in the derangement of neuronal function. Brain Pathology, 1 (4), pp.241-251.

Bieging, K.T. \& Attardi, L.D., 2012. Deconstructing p53 transcriptional networks in tumor suppression. Trends in Cell Biology, 22(2), pp.97-106.

Billnitzer, A.J. et al., 2013. APP independent and dependent effects on neurite outgrowth are modulated by the receptor associated protein (RAP). Journal of Neurochemistry, 124(1), pp.123-132.

Bitan, G. et al., 2003. Amyloid $\beta$-protein (A $\beta$ ) assembly: $A \beta 40$ and $A \beta 42$ oligomerize through distinct pathways. Proceedings of the National Academy of Sciences of the United States of America, 100(1), pp.330-335.

Blasko, I. et al., 2000. The amyloid beta peptide abeta (25-35) induces apoptosis independent of p53. FEBS letters, 470(2), pp.221-5.

Bode, A.M. \& Dong, Z., 2004. Post-translational modification of p53 in tumorigenesis. Nature reviews. Cancer, 4(10), pp.793-805.

Bojarski, L., Herms, J. \& Kuznicki, J., 2008. Calcium dysregulation in Alzheimer's disease. Neurochemistry International, 52(4-5), pp.621-633.

Bolaños, J.P., 2016. Bioenergetics and redox adaptations of astrocytes to neuronal activity. Journal of Neurochemistry.

Bolaños, J.P. et al., 2009. Mitochondria and reactive oxygen and nitrogen species in neurological disorders and stroke: Therapeutic implications. Advanced Drug Delivery Reviews, 61 (14), pp.1299-1315.

Bonafé, M. et al., 2004. The different apoptotic potential of the p53 codon 72 alleles increases with age and modulates in vivo ischaemia-induced cell death. Cell death 
and differentiation, 11 (9), pp.962-73.

Bozner, P. et al., 1997. The amyloid beta protein induces oxidative damage of mitochondrial DNA. Journal of neuropathology and experimental neurology, 56(12), pp.1356-1362.

Brun, A. \& Englund, E., 1981. Regional pattern of degeneration in Alzheimer's disease: neuronal loss and histopathological grading. Histopathology, 5(5), pp.549-64.

Bu, G., 2009. Apolipoprotein E and its receptors in Alzheimer's disease: pathways, pathogenesis and therapy. Nature reviews. Neuroscience, 10(5), pp.333-44.

Cacace, R., Sleegers, K. \& Van Broeckhoven, C., 2016. Molecular genetics of early-onset Alzheimer disease revisited. Alzheimer's and Dementia, pp.1-16.

Calissano, P., Matrone, C. \& Amadoro, G., 2009. Apoptosis and in vitro Alzheimer disease neuronal models. Communicative and Integrative Biology, 2(2), pp.163-169.

Canale, C. et al., 2013. Different effects of Alzheimer's peptide A?? (1-40) oligomers and fibrils on supported lipid membranes. Biophysical Chemistry, 182, pp.23-29.

Casley, C.S. et al., 2002. Beta-amyloid fragment 25-35 causes mitochondrial dysfunction in primary cortical neurons. Neurobiology of disease, 10(3), pp.258-67.

Caspersen, C., 2005. Mitochondrial A : a potential focal point for neuronal metabolic dysfunction in Alzheimer's disease. The FASEB Journal, 19(14), pp.2040-1.

Van Cauwenberghe, C., Van Broeckhoven, C. \& Sleegers, K., 2016. The genetic landscape of Alzheimer disease: clinical implications and perspectives. Genetics in medicine: official journal of the American College of Medical Genetics, 18(5), pp.421-430.

Cescon, D.W. et al., 2009. p53 Arg72Pro and MDM2 T309G polymorphisms, histology, and esophageal cancer prognosis. Clinical Cancer Research, 15(9), pp.3103-3109.

Chan, D. et al., 2001. Patterns of temporal lobe atrophy in semantic dementia and Alzheimer's disease. Annals of Neurology, 49(4), pp.433-442.

Chan, W.M. et al., 2004. How many mutant p53 molecules are needed to inactivate a tetramer? Mol Cell Biol, 24(8), pp.3536-3551.

Chang, J.R. et al., 2012. Role of p53 in neurodegenerative diseases. Neurodegenerative Diseases, 9(2), pp.68-80.

Chasseigneaux, S. \& Allinquant, B., 2012. Functions of A $\beta$, SAPPa and SAPP $\beta$ : Similarities and differences. Journal of Neurochemistry, 120(SUPPL. 1), pp.99-108.

Chen, J.X. \& Yan, S. Du, 2007. Amyloid-beta-induced mitochondrial dysfunction. Journal of Alzheimer's disease: JAD, 12(2), pp.177-84.

Chesneau, V. et al., 2000. Purified recombinant insulin-degrading enzyme degrades amyloid beta-protein but does not promote its oligomerization. The Biochemical journal, 351 P† 2, pp.509-16.

Chipuk, J.E. et al., 2004. Direct activation of Bax by p53 mediates mitochondrial membrane permeabilization and apoptosis. Science, 303(5660), pp.1010-4.

Choi, S.H. et al., 2014. A three-dimensional human neural cell culture model of Alzheimer's 
disease. Nature, 515(7526), pp.274-278.

Cole, S.L. \& Vassar, R., 2007. The Basic Biology of BACE1: A Key Therapeutic Target for Alzheimer's Disease. Curr Genomics, 8, pp.509-530.

Corder, E.H. et al., 1993. Gene dose of apolipoprotein E type 4 allele and the risk of Alzheimer's disease in late onset families. Science (New York, N.Y.), 261(5123), pp.921-923.

Crews, L. et al., 2011. Modulation of aberrant CDK5 signaling rescues impaired neurogenesis in models of Alzheimer's disease. Cell death \& disease, 2(2), p.e120.

Crumrine, R.C., Thomas, a L. \& Morgan, P.F., 1994. Attenuation of p53 expression protects against focal ischemic damage in transgenic mice. Journal of cerebral blood flow and metabolism: official journal of the International Society of Cerebral Blood Flow and Metabolism, 14(6), pp.887-891.

Cruz, J.C. et al., 2003. Aberrant Cdk5 activation by p25 triggers pathological events leading to neurodegeneration and neurofibrillary tangles. Neuron, 40(3), pp.471483.

Cruz, J.C. \& Tsai, L.H., 2004a. A Jekyll and Hyde kinase: Roles for Cdk5 in brain development and disease. Current Opinion in Neurobiology, 14(3), pp.390-394.

Cruz, J.C. \& Tsai, L.H., 2004b. Cdk5 deregulation in the pathogenesis of Alzheimer's disease. Trends in Molecular Medicine, 10(9), pp.452-458.

Cuende, J. et al., 2008. Retinoic acid downregulates Rael leading to APC(Cdh1) activation and neuroblastoma SH-SY5Y differentiation. Oncogene, 27(23), pp.33393344.

Culmsee, C. et al., 2001. A synthetic inhibitor of p53 protects neurons against death induced by ischemic and excitotoxic insults, and amyloid??-peptide. Journal of Neurochemistry, 77(1), pp.220-228.

Culmsee, C. \& Mattson, M.P., 2005. p53 in neuronal apoptosis. Biochemical and Biophysical Research Communications, 331 (3), pp.761-777.

Cummings, J.L. et al., 1994. The Neuropsychiatric Inventory: comprehensive assessment of psychopathology in dementia. Neurology, 44(12), pp.2308-14.

D'Andrea, M.R. et al., 2002. Consistent immunohistochemical detection of intracellular beta-amyloid42 in pyramidal neurons of Alzheimer's disease entorhinal cortex. Neuroscience letters, 333(3), pp.163-166.

DeKosky, S.T. \& Scheff, S.W., 1990. Synapse loss in frontal cortex biopsies in Alzheimer's disease: Correlation with cognitive severity. Annals of Neurology, 27(5), pp.457-464.

Delgado-Esteban, M., Almeida, A. \& Bolaños, J.P., 2000. D-glucose prevents glutathione oxidation and mitochondrial damage after glutamate receptor stimulation in rat cortical primary neurons. Journal of Neurochemistry, 75(4), pp.1618-1624.

Dickerson, B.C. et al., 2001. MRl-derived entorhinal and hippocampal atrophy in incipient and very mild Alzheimer's disease. Neurobiology of Aging, 22(5), pp.747-754.

Dickson, D.W., 1997. The pathogenesis of senile plaques. Journal of neuropathology and 
experimental neurology, 56(4), pp.321-39.

Du, H. et al., 2008. Cyclophilin D deficiency attenuates mitochondrial and neuronal perturbation and ameliorates learning and memory in Alzheimer's disease. Nature medicine, 14(10), pp.1097-105.

Duan, W. et al., 2002. p53 inhibitors preserve dopamine neurons and motor function in experimental parkinsonism. Annals of Neurology, 52(5), pp.597-606.

Dubois, B. et al., 2010. Revising the definition of Alzheimer's disease: A new lexicon. The Lancet Neurology, 9(11), pp.1118-1127.

Dumont, P. et al., 2003. The codon 72 polymorphic variants of p53 have markedly different apoptotic potential. Nature genetics, 33(3), pp.357-365.

Eckert, A., Marques, C.A., et al., 2003. Increased Apoptotic Cell Death in Sporadic and Genetic Alzheimer's Disease. In Annals of the New York Academy of Sciences. pp. 604-609.

Eckert, A., Keil, U., et al., 2003. Mitochondrial dysfunction, apoptotic cell death, and Alzheimer's disease. Biochemical Pharmacology, 66(8), pp.1627-1634.

Eckman, E.A. et al., 2003. Alzheimer's disease ??-amyloid peptide is increased in mice deficient in endothelin-converting enzyme. Journal of Biological Chemistry, 278(4), pp.2081-2084.

Farrer, L.A. et al., 1997. Effects of Age, Sex, and Ethnicity on the Association Between Apolipoprotein E Genotype and Alzheimer Disease: A Meta-analysis. JAMA: The Journal of the American Medical Association, 278(16), pp.1349-1356.

Farris, W. et al., 2007. Loss of neprilysin function promotes amyloid plaque formation and causes cerebral amyloid angiopathy. The American journal of pathology, 171(1), pp.241-51.

De Felice, F.G. et al., 2007. A?? oligomers induce neuronal oxidative stress through an Nmethyl-D-aspartate receptor-dependent mechanism that is blocked by the Alzheimer drug memantine. Journal of Biological Chemistry, 282(15), pp.1159011601.

Feng, L. et al., 2005. Functional Analysis of the Roles of Posttranslational Modifications at the p53 C Terminus in Regulating p53 Stability and Activity Functional Analysis of the Roles of Posttranslational Modifications at the p53 C Terminus in Regulating p53 Stability and Ac. Society, 25(13), pp.5389-5395.

Fernandez-Fernandez, M.R. \& Sot, B., 2011. The relevance of protein-protein interactions for p53 function: The CPE contribution. Protein Engineering, Design and Selection, 24(12), pp.41-51.

Fu, R. et al., 2014. Phagocytosis of microglia in the central nervous system diseases. Molecular Neurobiology, 49(3), pp.1422-1434.

García, O. et al., 2005. Increased mitochondrial respiration maintains the mitochondrial membrane potential and promotes survival of cerebellar neurons in an endogenous model of glutamate receptor activation. Journal of Neurochemistry, 92(1), pp.183190. 
Gatz, M. et al., 2006. Role of genes and environments for explaining Alzheimer disease. Archives of general psychiatry, 63(2), pp.168-174.

Gatz, S. a \& Wiesmüller, L., 2006. P53 in Recombination and Repair. Cell death and differentiation, 13(6), pp.1003-1016.

Ghavami, S. et al., 2014. Autophagy and apoptosis dysfunction in neurodegenerative disorders. Progress in Neurobiology, 112, pp.24-49.

Goldman, J.S. et al., 2011. Genetic counseling and testing for Alzheimer disease: joint practice guidelines of the American College of Medical Genetics and the National Society of Genetic Counselors. Genetics in medicine: official journal of the American College of Medical Genetics, 13(6), pp.597-605.

Gomez-Sanchez, J.C. et al., 2011. The human Tp53 Arg72Pro polymorphism explains different functional prognosis in stroke. The Journal of experimental medicine, 208(3), pp.429-37.

Gonçalves, M. et al., 2014. Association of the TP53 codon 72 polymorphism and breast cancer risk: a meta-analysis. SpringerPlus, 3(1), p.749.

Gong, Y. et al., 2003. Alzheimer's disease-affected brain: presence of oligomeric A beta ligands (ADDLs) suggests a molecular basis for reversible memory loss. Proceedings of the National Academy of Sciences of the United States of America, 100(18), pp.10417-10422.

Gouras, G.K. et al., 2000. Intraneuronal Aß42 Accumulation in Human Brain. The American journal of pathology, 156(1), pp.15-20.

Green, D.R. \& Kroemer, G., 2009. Cytoplasmic functions of the tumour suppressor p53. Nature, 458(7242), pp.1127-30.

Green, K.N. \& LaFerla, F.M., 2008. Linking calcium to Abeta and Alzheimer's disease. Neuron, 59(2), pp.190-194.

GU, B. \& Zhu, W.G., 2012. Surf the Post-translational Modification Network of p53 Regulation. International Journal of Biological Sciences, 8(5), pp.672-684.

Gu, Y. et al., 2001. Distinct intramembrane cleavage of the beta-amyloid precursor protein family resembling gamma-secretase-like cleavage of Notch. The Journal of biological chemistry, 276(38), pp.35235-8.

Haaspasalo, A. \& Kovacs, D., 2012. The many substrates of Presenilin/g-Secretase. J Alzheimers Disease, 25(1), pp.3-28.

Haass, C. et al., 2012. Trafficking and proteolytic processing of APP. Cold Spring Harbor Perspectives in Medicine, 2(5).

Haass, C. \& Selkoe, D.J., 2007. Soluble protein oligomers in neurodegeneration: lessons from the Alzheimer's amyloid beta-peptide. Nature reviews. Molecular cell biology, 8(2), pp.101-112.

Hama, E. \& Saido, T.C., 2005. Etiology of sporadic Alzheimer's disease: somatostatin, neprilysin, and amyloid beta peptide. Medical hypotheses, 65(3), pp.498-500.

Hardy, J.A. \& Higgins, G.A., 1992. Alzheimer's disease: the amyloid cascade hypothesis. 
Science (New York, N.Y.), 256(5054), pp.184-185.

Hardy, J. \& Allsop, D., 1991. Amyloid deposition as the central event in the aetiology of Alzheimer's disease. Trends in Pharmacological Sciences, 12(C), pp.383-388.

Hardy, J. \& Selkoe, D.J., 2002. The amyloid hypothesis of Alzheimer's disease: progress and problems on the road to therapeutics. Science (New York, N.Y.), 297(5580), pp.353356.

Harms, K.L. et al., 2005. The C terminus of p53 family proteins is a cell fate determinant. Molecular and cellular biology, 25(5), pp.2014-30.

Harper, J.D. et al., 1997. Observation of metastable Abeta amyloid protofibrils by atomic force microscopy. Chemistry \& Biology, 4(2), pp.119-125.

Hasegawa, K. \& Yoshikawa, K., 2008. Necdin regulates p53 acetylation via Sirtuin1 to modulate DNA damage response in cortical neurons. Journal of Neuroscience, 28(35), pp.8772-8784.

Haupt, Y. et al., 1995. Induction of apoptosis in HeLa cells by trans-activation-deficient p53. Genes and Development, 9(17), pp.2170-2183.

Hemming, M.L. \& Selkoe, D.J., 2005. Amyloid beta-protein is degraded by cellular angiotensin-converting enzyme (ACE) and elevated by an ACE inhibitor. The Journal of biological chemistry, 280(45), pp.37644-50.

Hensley, K. et al., 1994. A model for beta-amyloid aggregation and neurotoxicity based on free radical generation by the peptide: relevance to Alzheimer disease. Proceedings of the National Academy of Sciences of the United States of America, 91 (8), pp.3270-4.

Hernandez-Zimbron, L.F. et al., 2012. Amyloid-?? peptide binds to cytochrome C oxidase subunit 1. PLOS ONE, 7(8).

Hisanaga, S. \& Endo, R., 2010. Regulation and role of cyclin-dependent kinase activity in neuronal survival and death. J Neurochem, 115(6), pp.1309-1321.

Hong-Qi, Y., Zhi-Kun, S. \& Sheng-Di, C., 2012. Current Advances in the treatment of Alzheimer's disease: focused on considerations targeting Alphabeta and tau. Translational Neurodegeneration, 1 (1), p.21.

Hooper, C. et al., 2007. p53 is upregulated in Alzheimer's disease and induces tau phosphorylation in HEK293a cells. Neuroscience Letters, 418(1), pp.34-37.

Huang, Y. \& Mucke, L., 2013. Alzheimer Mechanisms and Therapeutic Strategies. , 148(6), pp.1204-1222.

Ikonomovic, M.D. et al., 1999. Distribution of glutamate receptor subunit NMDAR1 in the hippocampus of normal elderly and patients with Alzheimer's disease. Experimental neurology, 160(1), pp.194-204.

Iqbal, K. \& Grundke-lqbal, I., 2008. Alzheimer neurofibrillary degeneration: Significance, etiopathogenesis, therapeutics and prevention: Alzheimer Review Series. Journal of Cellular and Molecular Medicine, 12(1), pp.38-55.

Ittner, L.M. \& Götz, J., 2011 . Amyloid- $\beta$ and tau--a toxic pas de deux in Alzheimer's disease. 
Nature reviews. Neuroscience, 12(2), pp.65-72.

Iwata, N. et al., 2000. Identification of the major Abeta 1-42-degrading catabolic pathway in brain parenchyma: suppression leads to biochemical and pathological deposition. Nature medicine, 6(2), pp.143-50.

Iwata, N. et al., 2001. Metabolic regulation of brain Abeta by neprilysin. Science (New York, N.Y.), 292(5521), pp.1550-2.

J Gotz et al., 2001. Formation of neurofibrillary tangles in P301 L tau transgenic mice induced by Ab42 fibrils. Science, 293(August), pp.1491-1495.

Jeong, B.-S. et al., 2010. Differential levels of transcription of p53-regulated genes by the arginine/proline polymorphism: p53 with arginine at codon 72 favors apoptosis. The FASEB journal: official publication of the Federation of American Societies for Experimental Biology, 24(5), pp.1347-1353.

Jimenez-Blasco, D. et al., 2015. Astrocyte NMDA receptors' activity sustains neuronal survival through a Cak5-Nrf2 pathway. Cell Death and Differentiation, pp.1-13.

Joerger, A.C. \& Fersht, A.R., 2010. The tumor suppressor p53: from structures to drug discovery. Cold Spring Harbor perspectives in biology, 2(6).

Kayed, R. \& Lasagna-Reeves, C.A., 2012. Molecular mechanisms of amyloid oligomers toxicity. Advances in Alzheimer's Disease, 3, pp.67-78.

Khachaturian, Z.S. et al., 1985. Diagnosis of Alzheimer's Disease. Archives of Neurology, 42(11), pp.1097-1105.

Killiany, R.J. et al., 2002. MRI measures of entorhinal cortex vs hippocampus in preclinical AD. Neurology, 58(8), pp.1188-1196.

Kinoshita, A. et al., 2003. Demonstration by FRET of BACE interaction with the amyloid precursor protein at the cell surface and in early endosomes. Journal of cell science, 116 (Pt 16), pp.3339-3346.

Kitamura, Y. et al., 1998. Alteration of proteins regulating apoptosis, BCl-2, BCl-x, Bax, Bak, Bad, ICH-1 and CPP32, in Alzheimer's disease. Brain Research, 780(2), pp.260-269.

Kitamura, Y. et al., 1997. Changes of p53 in the brains of patients with Alzheimer's disease. Biochemical and biophysical research communications, 232(2), pp.418-21.

Klionsky, D.J. et al., 2011. A comprehensive glossary of autophagy-related molecules and processes (2 nd edition). Autophagy, 7(11), pp.1273-1294.

Koffie, R.M., Hyman, B.T. \& Spires-Jones, T.L., 2011 . Alzheimer's disease: synapses gone cold. Molecular neurodegeneration, 6(1), p.63.

Kruse, J.P. \& Gu, W., 2008. SnapShot: p53 Posttranslational Modifications. Cell, 133(5), pp.56.

Kruse, J.-P. \& Gu, W., 2009. Modes of p53 regulation. Cell, 137(4), pp.609-22.

Kubo, T. et al., 2003. Beta-amyloid racemized at the Ser26 residue in the brains of patients with Alzheimer disease: implications in the pathogenesis of Alzheimer disease. Journal of neuropathology and experimental neurology, 62(3), pp.248-59. 
Kubo, T. et al., 2002. In vivo conversion of racemized ?-amyloid ([D-Ser26]A? 1-40) to truncated and toxic fragments ([D-Ser26]A?25-35/40) and fragment presence in the brains of Alzheimer's patients. Journal of Neuroscience Research, 70(3), pp.474-483.

Kuhn, P.-H. et al., 2010. ADAM10 is the physiologically relevant, constitutive alphasecretase of the amyloid precursor protein in primary neurons. The EMBO journal, 29(17), pp.3020-32.

Kumar, A., Singh, A. \& Ekavali, 2015. A review on Alzheimer's disease pathophysiology and its management: An update. Pharmacological Reports, 67(2), pp.195-203.

Kurochkin, I. V. \& Goto, S., 1994. Alzheimer's ??-amyloid peptide specifically interacts with and is degraded by insulin degrading enzyme. FEBS Letters, 345(1), pp.33-37.

Kusakawa, G.I. et al., 2000. Calpain-dependent proteolytic cleavage of the p35 cyclindependent kinase 5 activator to p25. Journal of Biological Chemistry, 275(22), pp.17166-17172.

Kuwana, T. et al., 2005. BH3 domains of BH3-only proteins differentially regulate Baxmediated mitochondrial membrane permeabilization both directly and indirectly. Molecular Cell, 17(4), pp.525-535.

de la Monte, S.M., 1999. Molecular abnormalities of the brain in Down syndrome: relevance to Alzheimer's neurodegeneration. J Neural Transm Suppl, 57, pp.1-19.

De La Monte, S.M., Sohn, Y.K. \& Wands, J.R., 1997. Correlates of p53- and Fas (CD95)mediated apoptosis in Alzheimer's disease. Journal of the Neurological Sciences, 152(1), pp.73-83.

Lacor, P.N. et al., 2007. Abeta oligomer-induced aberrations in synapse composition, shape, and density provide a molecular basis for loss of connectivity in Alzheimer's disease. Journal of Neuroscience, 27(4), pp.796-807.

LaFerla, F. et al., 1996. Extracellular deposition of beta-amyloid upon p53-dependent neuronal cell death in transgenic mice. Journal of Clinical Investigation, 98(7), pp.1626-1632.

LaFerla, F.M., Green, K.N. \& Oddo, S., 2007. Intracellular amyloid- $\beta$ in Alzheimer's disease. Nature Reviews Neuroscience, 8(7), pp.499-509.

Lai, A.Y. \& McLauring, J., 2012. Clearance of amyloid-b peptides by microblia and macrophages:the issue of what, when and where. Future Nerology, 7(2), pp.165176.

Lambert, J.C. et al., 2013. Meta-analysis of 74,046 individuals identifies 11 new susceptibility loci for Alzheimer's disease. Nature genetics, 45(12), pp.1452-8.

Lambert, M.P. et al., 1998. Diffusible, nonfibrillar ligands derived from Abeta $1-42$ are potent central nervous system neurotoxins. Proceedings of the National Academy of Sciences of the United States of America, 95(1 1), pp.6448-53.

Lanara, Z. et al., 2013. Comparative study and meta-analysis of meta-analysis studies for the correlation of genomic markers with early cancer detection. Cancer, 7(1), p.14.

Lansdall, C.J., 2014. An effective treatment for Alzheimer's disease must consider both amyloid and tau. Bioscience Horizons, 7. 
Lashuel, H.A. et al., 2002. Neurodegenerative disease: Amyloid pores from pathogenic mutations. Nature, 418(6895), pp.291-291.

Lau, K.-F. et al., 2002. Cyclin-dependent kinase-5/p35 phosphorylates Presenilin 1 to regulate carboxy-terminal fragment stability. Molecular and cellular neurosciences, 20(1), pp.13-20.

Lau, T.L. et al., 2003. Magnetic resonance studies of beta-amyloid peptides. Australian Journal of Chemistry, 56(5), pp.349-356.

Lavin, M.F. \& Gueven, N., 2006. The complexity of p53 stabilization and activation. Cell death and differentiation, 13(6), pp.941-950.

Lee, C.Y.D. \& Landreth, G.E., 2010. The role of microglia in amyloid clearance from the AD brain. Journal of Neural Transmission, 117(8), pp.949-960.

Lee, J. et al., 2014. Role of the fast kinetics of pyroglutamate-modified amyloid- $\beta$ oligomers in membrane binding and membrane permeability. Biochemistry, 53(28), pp.470414.

Lee, J.-H. et al., 2007. Stabilization and activation of p53 induced by Cdk5 contributes to neuronal cell death. Journal of cell science, 120(Pt 13), pp.2259-71.

Lee, K.Y. et al., 1999. Elevated neuronal Cdc2-like kinase activity in the Alzheimer disease brain. Neuroscience Research, 34(1), pp.21-29.

Lee, K.Y. et al., 1996. Interaction of cyclin-dependent kinase 5 (Cdk5) and neuronal Cdk5 activator in bovine brain. Journal of Biological Chemistry, 271 (3), pp.1538-1543.

Lee, M.S. et al., 2000. Neurotoxicity induces cleavage of p35 to p25 by calpain. Nature, 405(6784), pp.360-4.

Lee, V.M., Goedert, M. \& Trojanowski, J.Q., 2001. Neurodegenerative tauopathies. Annual review of neuroscience, 24, pp.1121-59.

Lehericy, S. et al., 1994. Amygdalohippocampal MR volume measurements in the early stages of Alzheimer disease. American Journal of Neuroradiology, 15(5), pp.929-937.

Lesné, S. et al., 2006. A specific amyloid-beta protein assembly in the brain impairs memory. Nature, 440(7082), pp.352-357.

Letai, A. et al., 2002. Distinct BH3 domains either sensitize or activate mitochondrial apoptosis, serving as prototype cancer therapeutics. Cancer Cell, 2(3), pp.183-192.

Levine, B. \& Kroemer, G., 2008. Autophagy in the Pathogenesis of Disease. Cell, 132(1), pp. $27-42$.

Levy-Lahad, E. et al., 1995. Candidate gene for the chromosome 1 familial Alzheimer's disease locus. Science, 269(5226), pp.973-977.

Lewis, J. et al., 2001. Enhanced neurofibrillary degeneration in transgenic mice expressing mutant tau and APP. Science (New York, N.Y.), 293(5534), pp.1487-91.

Li, T. et al., 2016. The neuritic plaque facilitates pathological conversion of tau in an Alzheimer's disease mouse model. Nature Communications, 7(May), p.12082.

Liang, J.H. \& Jia, J.P., 2014. Dysfunctional autophagy in Alzheimer's disease: Pathogenic 
roles and therapeutic implications. Neuroscience Bulletin, 30(2), pp.308-316.

Limón, I.D. et al., 2009. Amyloid-beta(25-35) impairs memory and increases NO in the temporal cortex of rats. Neuroscience research, 63(2), pp.129-37.

Liu, C.-C. et al., 2013. Apolipoprotein E and Alzheimer disease: risk, mechanisms and therapy. Nature reviews. Neurology, 9(2), pp.106-18.

Liu, F. et al., 2003. Regulation of amyloid precursor protein (APP) phosphorylation and processing by p35/Cdk5 and p25/Cdk5. FEBS Letters, 547(1-3), pp.193-196.

Liu, S.-L. et al., 2015. The Role of Cdk5 in Alzheimer's Disease. Molecular neurobiology, (February).

Liv, T. et al., 2013. Cooperative role of RanBP9 and P73 in mitochondria-mediated apoptosis. Cell death \& disease, 4, p.e476.

Lopes, J.P. \& Agostinho, P., 2011. Cdk5: Multitasking between physiological and pathological conditions. Progress in Neurobiology, 94(1), pp.49-63.

Lopes, J.P., Oliveira, C.R. \& Agostinho, P., 2009. Cdk5 acts as a mediator of neuronal cell cycle re-entry triggered by amyloid-?? and prion peptides. Cell Cycle, 8(1), pp.97104.

Lopes, J.P., Oliveira, C.R. \& Agostinho, P., 2010. Neurodegeneration in an Abeta-induced model of Alzheimer's disease: the role of Cdk5. Aging cell, 9(1), pp.64-77.

Louneva, N. et al., 2008. Caspase-3 is enriched in postsynaptic densities and increased in Alzheimer's disease. The American journal of pathology, 173(5), pp.1488-95.

Lue, L.F. et al., 1999. Soluble amyloid beta peptide concentration as a predictor of synaptic change in Alzheimer's disease. The American journal of pathology, 155(3), pp.85362.

Lüscher, C. \& Malenka, R.C., 2012. NMDA receptor-dependent long-term potentiation and long-term depression (LTP/LTD). Cold Spring Harbor Perspectives in Biology, 4(6), pp.1-15.

Lustbader, J.W. et al., 2004. ABAD directly links Abeta to mitochondrial toxicity in Alzheimer's disease. Science (New York, N.Y.), 304(2004), pp.448-452.

Maccioni, R.B. et al., 2001. The protein kinase cdk5: Structural aspects, roles in neurogenesis and involvement in Alzheimer's pathology. European Journal of Biochemistry, 268(6), pp.1518-1527.

Maestre, C. et al., 2008. Cdk5 phosphorylates Cdh1 and modulates cyclin B1 stability in excitotoxicity. The EMBO journal, 27(20), pp.2736-45.

Mahley, R.W. \& Huang, Y., 2012. Apolipoprotein E Sets the Stage: Response to Injury Triggers Neuropathology. Neuron, 76(5), pp.871-885.

Mahley, R.W. \& Huang, Y., 2012. Small-molecule Structure Correctors Target Abnormal Protein Structure and Function: The Structure Corrector Rescue of Apolipoprotein E4 - associated Neuropathology Small-molecule Structure Correctors Target Abnormal Protein Structure and Function: Glads. Journal of Medicinal Chemistry.

Mahley, R.W., Weisgraber, K.H. \& Huang, Y., 2006. Apolipoprotein E4: a causative factor 
and therapeutic target in neuropathology, including Alzheimer's disease. Proceedings of the National Academy of Sciences of the United States of America, 103(15), pp.5644-51.

Marchenko, N.D., Zaika, A. \& Moll, U.M., 2000. Death signal-induced localization of p53 protein to mitochondria: A potential role in apoptotic signaling. Journal of Biological Chemistry, 275(21), pp.16202-16212.

Marchetti, C. \& Marie, H., 2011. Hippocampal synaptic plasticity in Alzheimer's disease: what have we learned so far from transgenic models? Reviews in the neurosciences, 22(4), pp.373-402.

Marcus, C., Mena, E. \& Subramaniam, R.M., 2014. Brain PET in the diagnosis of Alzheimer's disease. Clinical nuclear medicine, 39(10), pp.e413-22-6.

Masliah, E. et al., 1991. Cortical and subcortical patterns of synaptophysinlike immunoreactivity in Alzheimer's disease. The American journal of pathology, 138(1), pp.235-246.

Masliah, E. et al., 1989. Immunohistochemical quantification of the synapse-related protein synaptophysin in Alzheimer disease. Neuroscience Letters, 103(2), pp.234-239.

Matlashewski, G.J. et al., 1987. Primary structure polymorphism at amino acid residue 72 of human p53. Molecular and Cellular Biology, 7(2), pp.961-3.

Mattson, M.P. et al., 1997. Abeta25-35 induces rapid lysis of red blood cells: contrast with Abetal-42 and examination of underlying mechanisms. Brain research, 771(1), pp.147-53.

Mattson, M.P., 2000. Apoptosis in Neurodegenerative Disorders. , 1 (October), pp.120-129.

Mattson, M.P. et al., 1993. Evidence for excitoprotective and intraneuronal calciumregulating roles for secreted forms of the beta-amyloid precursor protein. Neuron, 10(2), pp.243-54.

McKeith, I.G., 2006. Consensus guidelines for the clinical and pathologic diagnosis of dementia with Lewy bodies (DLB): report of the Consortium on DLB International Workshop. Journal of Alzheimer's disease: JAD, 9(3 Suppl), pp.417-23.

Merlo, P. et al., 2014. P53 Prevents Neurodegeneration By Regulating Synaptic Genes. Proceedings of the National Academy of Sciences of the United States of America, 111 (50), pp.18055-60.

Miguel-Hidalgo, J.J. et al., 2002. Neuroprotection by memantine against neurodegeneration induced by??-amyloid(1-40). Brain Research, 958(1), pp.210221.

Mihara, M. et al., 2003. P53 Has a Direct Apoptogenic Role At the Mitochondria. Molecular Cell, 11 (3), pp.577-590.

Millucci, L. et al., 2010. Conformations and biological activities of amyloid beta peptide 25-35. Current protein \& peptide science, 11 (1), pp.54-67.

Mirza, A. et al., 2003. Global transcriptional program of p53 target genes during the process of apoptosis and cell cycle progression. Oncogene, 22(23), pp.3645-3654. 
Miyashita T, Krajewski S, Krajewska M, Wang HG, Lin HK, Liebermann DA, Hoffman B, R.J., 1994. Tumor suppressor p53 is a regulator of bcl-2 and bax gene expression in vitro and in vivo. Oncogene, 9(6), pp.1799-1805.

Mizuguchi, M., Ikeda, K. \& Kim, S.U., 1992. Differential distribution of cellular forms of betaamyloid precursor protein in murine glial cell cultures. Brain research, 584(1-2), pp.219-225.

Mondragón-Rodríguez, S. et al., 2012. Amyloid beta and tau proteins as therapeutic targets for Alzheimer's disease treatment: Rethinking the current strategy. International Journal of Alzheimer's Disease.

Moreira, P.I. et al., 2010. Mitochondrial dysfunction is a trigger of Alzheimer's disease pathophysiology. Biochimica et Biophysica Acta - Molecular Basis of Disease, 1802(1), pp.2-10.

Morrison, R.S. \& Kinoshita, Y., 2000. The role of p53 in neuronal cell death. Cell death and differentiation, 7(10), pp.868-79.

Mungarro-Menchaca, X., Morán, P.F.J. \& Clorinda, A., 2002. $\beta$-amyloid peptide induces ultrastructural changes in synaptosomes and potentiates mitochondrial dysfunction in the presence of ryanodine. Journal of Neuroscience Research, 68(1), pp.89-96.

Nakamura, Y., 2004. Isolation of p53-target genes and their functional analysis. Cancer Science, 95(1), pp.7-11.

Napieralski, J.A., Raghupathi, R. \& McIntosh, T.K., 1999. The tumor-suppressor gene, p53, is induced in injured brain regions following experimental traumatic brain injury. Molecular Brain Research, 71 (1), pp.78-86.

Nath, R. et al., 2000. Processing of cdk5 activator p35 to its truncated form (p25) by calpain in acutely injured neuronal cells. Biochemical and biophysical research communications, 274(1), pp.16-21.

Neamatzadeh, H. et al., 2015. Association between p53 codon 72 (Arg72pro) polymorphism and primary open-angle glaucoma in Iranian patients. Iranian Biomedical Journal, 19(1), pp.51-56.

Nickerson, D.A. et al., 2000. Sequence diversity and large-scale typing of SNPs in the human apolipoprotein E gene. Genome Research, 10(10), pp.1532-1545.

Nisbet, R.M. et al., 2015. Tau aggregation and its interplay with amyloid- $\beta$. Acta neuropathologica, 129(2), pp.207-20.

Nixon, R.A. et al., 2005. Extensive Involvement of Autophagy in Alzheimer Disease: An Immuno-Electron Microscopy Study. Journal of Neuropathology \& Experimental Neurology, 64(2), pp.113-122.

Oddo, S. et al., 2006. A Dynamic Relationship between Intracellular and Extracellular Pools of A $\beta$. The American journal of pathology, 168(1), pp.184-194.

Oddo, S. et al., 2007. Genetically augmenting tau levels does not modulate the onset or progression of A? pathology in transgenic mice. Journal of Neurochemistry, 102(4), pp.1053-1063.

Ohyagi, Y. et al., 2005. Intracellular Abeta42 activates p53 promoter: a pathway to 
neurodegeneration in Alzheimer's disease. FASEB journal : official publication of the Federation of American Societies for Experimental Biology, 19(2), pp.255-7.

Olney, J.W., Wozniak, D.F. \& Farber, N.B., 1998. Glumate receptor dysfunction and Alzheimer's disease. Restorative neurology and neuroscience, 13(1-2), pp.75-83.

Palop, J.J., Chin, J. \& Mucke, L., 2006. A network dysfunction perspective on neurodegenerative diseases. Nature, 443(7113), pp.768-773.

Palop, J.J. \& Mucke, L., 2010. Amyloid-[beta]-induced neuronal dysfunction in Alzheimer's disease: from synapses toward neural networks. Nature neuroscience, 13(7), pp.812818.

Paradis, E. et al., 1996. Amyloid beta peptide of Alzheimer's disease downregulates BCl-2 and upregulates bax expression in human neurons. Journal of Neuroscience, 16(23), pp.7533-7539.

Patrick, G.N. et al., 1999. Conversion of p35 to p25 deregulates Cdk5 activity and promotes neurodegeneration. Nature, 402(6762), pp.615-622.

Patrick, G.N. et al., 1998. p35, the neuronal-specific activator of cyclin-dependent kinase 5 (Cdk5) is degraded by the ubiquitin-proteasome pathway. Journal of Biological Chemistry, 273(37), pp.24057-24064.

Perl, D.P., 2010. Neuropathology of Alzheimer 's Disease. Mt Sinai J Med, 77(1), pp.32-42.

Perry, R.T. et al., 2001. The role of TNF and its receptors in Alzheimer's disease. Neurobiology of aging, 22(6), pp.873-83.

Pike, C.J. et al., 1995. Structure-activity analyses of beta-amyloid peptides: contributions of the beta 25-35 region to aggregation and neurotoxicity. Journal of neurochemistry, 64(1), pp.253-65.

Pinto, G.R. et al., 2008. Prognostic value of TP53 Pro47Ser and Arg72Pro single nucleotide polymorphisms and the susceptibility to gliomas in individuals from Southeast Brazil. Genetics and Molecular Research, 7(1), pp.207-216.

Prince, M. et al., 2013. The global prevalence of dementia: a systematic review and metaanalysis. Alzheimer's \& Dementia, 9, pp.63-75.

Qiao, Q. \& Hu, W., 2013. The association between TP53 Arg72Pro polymorphism and lung cancer susceptibility: Evidence from 30,038 subjects. Lung, 191 (4), pp.369-377.

Querfurth, H.W. \& Laferla, F.M., 2010. Alzheimer's Disease. N End J Med, pp.329-344.

Rabins, P. V. et al., 2007. American Psychiatric Association practice guideline for the treatment of patients with Alzheimer's disease and other dementias. Second edition. The American journal of psychiatry, 164(12 Suppl), pp.5-56.

Raff, M.C. et al., 1993. Programmed cell death and the control of cell survival: lessons from the nervous system. Science, 262(5134), p.695-700.

Rego, A.C. \& Oliveira, C.R., 2003. Mitochondrial dysfunction and reactive oxygen species in excitotoxicity and apoptosis: Implications for the pathogenesis of neurodegenerative diseases. Neurochemical Research, 28(10), pp.1563-1574.

Ren, D. et al., 2010. BID, BIM, and PUMA are essential for activation of the BAX- and BAK- 
dependent cell death program. Science (New York, N.Y.), 330(6009), pp.1390-3.

Riley, T. et al., 2008. Transcriptional control of human p53-regulated genes. Nature reviews. Molecular cell biology, 9(5), pp.402-412.

Rogaev, E.l. et al., 1995. Familial Alzheimers-Disease in Kindreds with Missense Mutations in a Gene on Chromosome-1 Related to the Alzheimers-Disease Type-3 Gene. Nature, 376(6543), pp.775-778.

Rosenmann, H. et al., 2003. An association study of the codon 72 polymorphism in the proapoptotic gene p53 and Alzheimer's disease. Neuroscience Letters, 340(1), pp.2932.

Saido, T. \& Leissring, M.A., 2012. Proteolytic degradation of amyloid $\beta$-protein. Cold Spring Harbor Perspectives in Medicine, 2(6).

Saito, S. et al., 2002. ATM mediates phosphorylation at multiple p53 sites, including Ser46, in response to ionizing radiation. Journal of Biological Chemistry, 277(15), pp.1249112494.

Sajan, F.D. et al., 2007. Apoptotic gene expression in Alzheimer's disease hippocampal tissue. American journal of Alzheimer's disease and other dementias, 22(4), pp.31928.

Sakono, M. \& Zako, T., 2010. Amyloid oligomers: Formation and toxicity of A?? oligomers. FEBS Journal, 277(6), pp.1348-1358.

Sansome, C. et al., 2001. Hypoxia death stimulus induces translocation of p53 protein to mitochondria - Detection by immunofluorescence on whole cells. FEBS Letters, 488(3), pp.110-115.

Sastre, M. et al., 2001. Presenilin-dependent??-secretase processing of ??-amyloid precursor protein at a site corresponding to the $\$ 3$ cleavage of Notch. EMBO Reports, 2(9), pp.835-841.

Saunders, a M. et al., 1993. Association of apolipoprotein E allele epsilon 4 with late-onset familial and sporadic Alzheimer's disease. Neurology, 43(8), pp.1467-1472.

Scacchi, R. et al., 2009. Association study between P53 and P73 gene polymorphisms and the sporadic late-onset form of Alzheimer's disease. Journal of Neural Transmission, 116(9), pp.1179-1184.

Scahill, R.I. et al., 2002. Mapping the evolution of regional atrophy in Alzheimer's disease: unbiased analysis of fluid-registered serial MRI. Proceedings of the National Academy of Sciences of the United States of America, 99(7), pp.4703-7.

Scheltens, P. et al., 2016. Alzheimer's disease. The Lancet.

Schmidt, C. et al., 2008. Amyloid precursor protein and amyloid beta-peptide bind to ATP synthase and regulate its activity at the surface of neural cells. Molecular psychiatry, 13(10), pp.953-69.

Schmitt, K. et al., 2012. Insights into mitochondrial dysfunction: aging, amyloid- $\beta$, and tauA deleterious trio. Antioxidants \& redox signaling, 16(12), pp.1456-66.

Sekine-Aizawa, Y. et al., 2001. Matrix metalloproteinase (MMP) system in brain: 
Identification and characterization of brain-specific MMP highly expressed in cerebellum. European Journal of Neuroscience, 13(5), pp.935-948.

Selkoe, D.J., 2001. Alzheimer's Disease: Genes, Proteins, and Therapy. Physiological Reviews, 81 (2), pp.741-766.

Selkoe, D.J., 2008. Biochemistry and molecular biology of amyloid beta-protein and the mechanism of Alzheimer's disease. Handbook of clinical neurology, 89, pp.245-60.

Selkoe, D.J., 1991. The molecular pathology of Alzheimer's disease. Neuron, 6(4), pp.487498.

Selkoe, D.J. \& Hardy, J., 2016. The amyloid hypothesis of Alzheimer's disease at 25 years. EMBO molecular medicine, pp.1-14.

Serrano-Pozo, A. et al., 2011. Neuropathological alterations in Alzheimer disease. Cold Spring Harbor perspectives in medicine, 1(1), pp.1-23.

Seubert, P. et al., 1993. Secretion of beta-amyloid precursor protein cleaved at the amino terminus of the beta-amyloid peptide. Nature, 361 (6409), pp.260-3.

Shankar, G.M. \& Walsh, D.M., 2009. Alzheimer's Disease: Synaptic Dysfunction and Aß. Molecular neurodegeneration, 4, p.48.

Sherrington, R. et al., 1995. Cloning of a gene bearing missense mutations in early-onset familial Alzheimer's disease. Nature, 375(6534), pp.754-760.

Sirk, D. et al., 2007. Chronic exposure to sub-lethal beta-amyloid (Abeta) inhibits the import of nuclear-encoded proteins to mitochondria in differentiated PC12 cells. Journal of neurochemistry, 103(5), pp.1989-2003.

Sivanesan, S., Tan, A. \& Rajadas, J., 2013. Pathogenesis of Abeta oligomers in synaptic failure. Current Alzheimer research, 10(3), pp.316-23.

Sjalander, A. et al., 1996. p53 polymorphisms and haplotypes show distinct differences between major ethnic groups. Human Heredity, 46, pp.41-48.

Spuch, C., Ortolano, S. \& Navarro, C., 2012. New insights in the amyloid-beta interaction with mitochondria. Journal of Aging Research, 2012.

Stahl, R. et al., 2014. Shedding of APP limits its synaptogenic activity and cell adhesion properties. Frontiers in cellular neuroscience, 8(December), p.410.

Stefanis, L., Burke, R.E. \& Greene, L. a, 1997. Apoptosis in neurodegenerative disorders. Current opinion in neurology, 10(4), pp.299-305.

Stelzmann, R.A., Schnitzlein, H.N. \& Murtagh, F.R., 1995. An English translation of Alzheimer's 1907 paper, "uber eine eigenartige erkankung der hirnrinde." Clinical Anatomy, 8(6), pp.429-431.

Stepanichev, M.Y. et al., 2003. Single intracerebroventricular administration of amyloidbeta (25-35) peptide induces impairment in short-term rather than long-term memory in rats. Brain Research Bulletin, 61 (2), pp.197-205.

Stepanichev, M.Y. et al., 2006. Studies of the effects of central administration of betaamyloid peptide (25-35): pathomorphological changes in the Hippocampus and impairment of spatial memory. Neuroscience and behavioral physiology, 36(1), 
pp.101-6.

Stepanichev, M.Y. et al., 2005. Studies of the effects of fragment (25-35) of beta-amyloid peptide on the behavior of rats in a radial maze. Neuroscience and behavioral physiology, 35(5), pp.511-8.

Stepanichev MYu et al., 1998. Effects of doses of fragment (25-35) of beta-amyloid peptide on behavior in rats. Neuroscience and behavioral physiology, 28(5), pp.564-6.

Streit, W.J. et al., 2009. Dystrophic (senescent) rather than activated microglial cells are associated with tau pathology and likely precede neurodegeneration in Alzheimer's disease. Acta Neuropathologica, 118(4), pp.475-485.

Strittmatter, W.J. et al., 1993. Apolipoprotein E: high-avidity binding to beta-amyloid and increased frequency of type 4 allele in late-onset familial Alzheimer disease. Proceedings of the National Academy of Sciences of the United States of America, 90(5), pp.1977-81.

Sugars, K.L. et al., 2001. A minimal Bcl-x promoter is activated by Brn-3a and repressed by p53. Nucleic acids research, 29(22), pp.4530-40.

Sun, X. et al., 2011. Regulator of calcineurin 1 (RCAN1) facilitates neuronal apoptosis through caspase-3 activation. Journal of Biological Chemistry, 286(11), pp.90499062.

Szydlowska, K. \& Tymianski, M., 2010. Calcium, ischemia and excitotoxicity. Cell Calcium, 47(2), pp.122-129.

Tanzi, R.E., 2012. The genetics of Alzheimer disease (7). Cold Spring Harbor perspectives in medicine, 2(10), p.a006296-.

Tarawneh, R. \& Galvin, J.E., 2010. Potential Future Neuroprotective Therapies for Neurodegenerative Disorders and Stroke. Clinics in Geriatric Medicine, 26(1), pp.125-147.

Taylor, R.C., Cullen, S.P. \& Martin, S.J., 2008. Apoptosis: controlled demolition at the cellular level. Nature reviews. Molecular cell biology, 9(3), pp.231-241.

Tecza, K. et al., 2015. Genetic polymorphisms and gene-dosage effect in ovarian cancer risk and response to paclitaxel/cisplatin chemotherapy. Journal of experimental \& clinical cancer research : CR, 34, p.2.

Tellechea, P. et al., 2015. Early- and late-onset Alzheimer disease: Are they the same entity? Neurologia.

Terry, R.D. et al., 1991. Physical basis of cognitive alterations in Alzheimer's disease: synapse loss is the major correlate of cognitive impairment. Annals of neurology, 30(4), pp.572-80.

Thomas, M. et al., 1999. Two polymorphic variants of wild-type p53 differ biochemically and biologically. Molecular and cellular biology, 19(2), pp.1092-1100.

Tian, B., Yang, Q. \& Mao, Z., 2009. Phosphorylation of ATM by Cdk5 mediates DNA damage signalling and regulates neuronal death. Nature cell biology, 11 (2), pp.211-8.

Tickler, A.K., Wade, J.D. \& Separovic, F., 2005. The role of Abeta peptides in Alzheimer's 
disease. Protein and peptide letters, 12(6), pp.513-9.

Tseng, H.C. et al., 2002. A survey of Cdk5 activator p35 and p25 levels in Alzheimer's disease brains. FEBS Letters, 523(1-3), pp.58-62.

Vaseva, A. V. \& Moll, U.M., 2009. The mitochondrial p53 pathway. Biochimica et Biophysica Acta-Bioenergetics, 1787(5), pp.414-420.

Veas-Pérez de Tudela, M. et al., 2015. Regulation of BCl-xL-ATP Synthase Interaction by Mitochondrial Cyclin B1-Cyclin-Dependent Kinase-1 Determines Neuronal Survival. The Journal of neuroscience: the official journal of the Society for Neuroscience, 35(25), pp.9287-301.

Vousden, K.H., 2005. Apoptosis. p53 and PUMA: a deadly duo. Science (New York, N.Y.), 309 (5741), pp.1685-6.

Walsh, D.M. et al., 1999. Amyloid beta-protein fibrillogenesis. Structure and biological activity of protofibrillar intermediates. The Journal of biological chemistry, 274(36), pp.25945-25952.

Walsh, D.M. et al., 2002. Naturally secreted oligomers of amyloid beta protein potently inhibit hippocampal long-term potentiation in vivo. Nature, 416(6880), pp.535-539.

Walsh, D.M. et al., 2000. The oligomerization of amyloid ??-protein begins intracellularly in cells derived from human brain. Biochemistry, 39(35), pp.10831-10839.

Wang, B. et al., 2014. Mapping the p53 transcriptome universe using p53 natural polymorphs. Cell death and differentiation, 21 (4), pp.521-532.

Wang, C. \& Youle, R.J., 2009. The role of mitochondria in apoptosis*. Annual review of genetics, 43, pp.95-118.

Wang, D.B. et al., 2014. P53 and mitochondrial function in neurons. Biochimica et Biophysica Acta - Molecular Basis of Disease, 1842(8), pp.1186-1197.

Wang, H.. Y. et al., 2000. beta-Amyloid(1-42) binds to alpha7 nicotinic acetylcholine receptor with high affinity. Implications for Alzheimer's disease pathology. The Journal of biological chemistry, 275, pp.5626-5632.

Wang, $\mathrm{X}$. et al., 2008. Amyloid-beta overproduction causes abnormal mitochondrial dynamics via differential modulation of mitochondrial fission/fusion proteins. Proceedings of the National Academy of Sciences of the United States of America, 105(49), pp.19318-23.

Wang, X. et al., 2015. Genetic determinants of disease progression in Alzheimer's disease. Journal of Alzheimer's disease: JAD, 43(2), pp.649-55.

Weggen, S. \& Beher, D., 2012. Molecular consequences of amyloid precursor protein and presenilin mutations causing autosomal-dominant Alzheimer's disease. Alzheimer's research \& therapy, 4(2), p.9.

Weidemann, A. et al., 2002. A novel epsilon-cleavage within the transmembrane domain of the Alzheimer amyloid precursor protein demonstrates homology with Notch processing. Biochemistry, 41, pp.2825-2835.

Weyer, S.W. et al., 2011. APP and APLP2 are Essential at PNS and CNS Synapses for 
Transmission, Spatial Learning and LTP. The EMBO Journal, 30(11), pp.2266-2280.

Whibley, C., Pharoah, P.D.P. \& Hollstein, M., 2009. P53 Polymorphisms: Cancer Implications. Nat Rev Cancer, 9(2), pp.95-107.

Willem, M. et al., 2015. n-Secretase processing of APP inhibits neuronal activity in the hippocampus. Nature, 526(7573), pp.443-447.

Woods, N.K. \& Padmanabhan, J., 2012. Neuronal calcium signaling and Alzheimer's disease. Adv Exp Med Biol, 740, pp.1193-1217.

Xia, Z. \& Storm, D.R., 2005. The role of calmodulin as a signal integrator for synaptic plasticity. Nature reviews. Neuroscience, 6(4), pp.267-76.

XU, H., Greengard, P. \& Gandy, S., 1995. Regulated formation of Golgi secretory vesicles containing Alzheimer ??-amyloid precursor protein. Journal of Biological Chemistry, 270(40), pp.23243-23245.

Xu, Y., 2003. Regulation of p53 responses by post-translational modifications. Cell death and differentiation, 10(4), pp.400-3.

Yan, Y. \& Wang, C., 2006. Abeta42 is more rigid than Abeta40 at the C terminus: implications for Abeta aggregation and toxicity. Journal of molecular biology, 364(5), pp.853-62.

Yates, E.A. et al., 2013. Specific domains of $A$ ?? facilitate aggregation on and association with lipid bilayers. Journal of Molecular Biology, 425(11), pp.1915-1933.

Yew, D.T., Ping Li, W. \& Liu, W.K., 2004. Fas and activated caspase 8 in normal, Alzheimer and multiple infarct brains. Neuroscience Letters, 367(1), pp.113-117.

Yiannopoulou, K.G. \& Papageorgiou, S.G., 2013. Current and future treatments for Alzheimer's disease. Therapeutic advances in neurological disorders, 6(1), pp.19-33.

Young-Pearse, T.L. et al., 2007. A Critical Function for -Amyloid Precursor Protein in Neuronal Migration Revealed by In Utero RNA Interference. Journal of Neuroscience, 27(52), pp.14459-14469.

Yu, J. et al., 1999. Identification and classification of p53-regulated genes. Proceedings of the National Academy of Sciences of the United States of America, 96(25), pp.14517-14522.

Zetterberg, H., Blennow, K. \& Hanse, E., 2010. Amyloid $\beta$ and APP as biomarkers for Alzheimer's disease. Experimental Gerontology, 45(1), pp.23-29.

Zhang, J., Krishnamurthy, P.K. \& Johnson, G.V.W., 2002. Cdk5 phosphorylates p53 and regulates its activity. Journal of Neurochemistry, 81 (2), pp.307-313.

Zhang, Y. et al., 2002. Selective cytotoxicity of intracellular amyloid?? peptide 1-42 through p53 and Bax in cultured primary human neurons. Journal of Cell Biology, 156(3), pp.519-529.

Zhao, C. et al., 2009. PKCdelta regulates cortical radial migration by stabilizing the Cak5 activator p35. Proceedings of the National Academy of Sciences of the United States of America, 106(50), pp.21353-21358.

Zhao, G. et al., 2007. The same gamma-secretase accounts for the multiple 
intramembrane cleavages of APP. Journal of neurochemistry, 100(5), pp.1234-46.

Zheng, H. \& Koo, E.H., 2006. The amyloid precursor protein: beyond amyloid. Molecular neurodegeneration, 1, p.5.

Zheng, Y.L. et al., 2007. Cak5 Modulation of mitogen-activated protein kinase signaling regulates neuronal survival. Molecular biology of the cell, 18(2), pp.404-413.

Zheng, Y.-L. et al., 2005. A Cdk5 inhibitory peptide reduces tau hyperphosphorylation and apoptosis in neurons. The EMBO journal, 24(1), pp.209-20.

Zhu, Y.S. et al., 2005. Activation of latent cyclin-dependent kinase 5 (Cdk5)-p35 complexes by membrane dissociation. Journal of Neurochemistry, 94(6), pp.1535-1545.

Zilfou, J.T. \& Lowe, S.W., 2009. Tumor suppressive functions of p53. Cold Spring Harbor perspectives in biology, 1(5). 